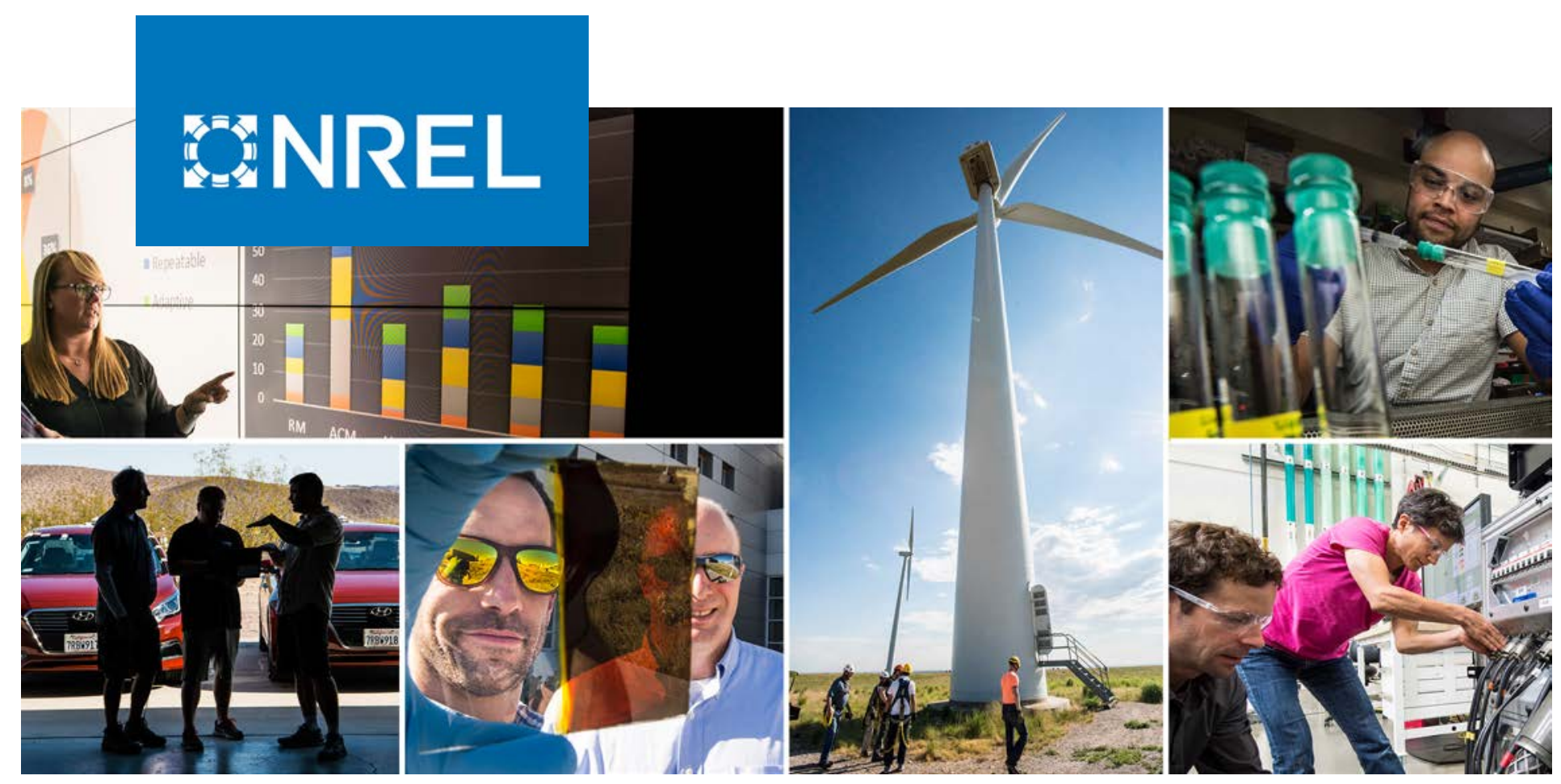

\title{
Geothermal Drilling and Completions: Petroleum Practices Technology Transfer
}

Charles F. Visser, ${ }^{1}$ Alfred W. Eustes III, ${ }^{2}$ Walt Baker, ${ }^{2}$ Jordan Tucker, ${ }^{2}$ Ralph Quick, ${ }^{2}$ Taylor Nagle, ${ }^{2}$ Jason Bell, ${ }^{2}$ Sean Bell, ${ }^{2}$ Daniel Bolton, ${ }^{2}$ and Uneshddarann Nagandran ${ }^{2}$

1 National Renewable Energy Laboratory

2 Colorado School of Mines

NREL is a national laboratory of the U.S. Department of Energy

Office of Energy Efficiency \& Renewable Energy

Operated by the Alliance for Sustainable Energy, LLC

This report is available at no cost from the National Renewable Energy Laboratory (NREL) at www.nrel.gov/publications.
Technical Report

NREL/TP-6A20-72277

December 2018 


\title{
GNREL
}

\section{Geothermal Drilling and Completions: Petroleum Practices Technology Transfer}

\section{Charles F. Visser, ${ }^{1}$ Alfred W. Eustes III, ${ }^{2}$ Walt Baker, ${ }^{2}$} Jordan Tucker, ${ }^{2}$ Ralph Quick, ${ }^{2}$ Taylor Nagle, ${ }^{2}$ Jason Bell, ${ }^{2}$ Sean Bell, ${ }^{2}$ Daniel Bolton, ${ }^{2}$ and Uneshddarann Nagandran ${ }^{2}$

\author{
1 National Renewable Energy Laboratory \\ 2 Colorado School of Mines
}

\section{Suggested Citation}

Visser, Charles F., Alfred W. Eustes III, Walt Baker, Jordan Tucker, Ralph Quick, Taylor Nagle, Jason Bell, Sean Bell, Daniel Bolton, and Uneshddarann Nagandran. 2018. Geothermal Drilling and Completions: Petroleum Practices Technology Transfer. Golden, CO: National Renewable Energy Laboratory. NREL/TP-6A20-72277.

https://www.nrel.gov/docs/fy19osti/72277.pdf.

NREL is a national laboratory of the U.S. Department of Energy Office of Energy Efficiency \& Renewable Energy Operated by the Alliance for Sustainable Energy, LLC

This report is available at no cost from the National Renewable Energy Laboratory (NREL) at www.nrel.gov/publications.

Contract No. DE-AC36-08GO28308
Technical Report NREL/TP-6A20-72277

December 2018

National Renewable Energy Laboratory 15013 Denver West Parkway Golden, CO 80401

303-275-3000 • www.nrel.gov 


\section{NOTICE}

This work was authored in part by the National Renewable Energy Laboratory, operated by Alliance for Sustainable Energy, LLC, for the U.S. Department of Energy (DOE) under Contract No. DE-AC36-08G028308. Funding provided by the U.S. Department of Energy Office of Energy Efficiency and Renewable Energy Geothermal Technologies Office. The views expressed in the article do not necessarily represent the views of the DOE or the U.S. Government.

This report is available at no cost from the National Renewable Energy Laboratory (NREL) at www.nrel.gov/publications.

U.S. Department of Energy (DOE) reports produced after 1991 and a growing number of pre-1991 documents are available free via www.OSTI.gov.

Cover Photos by Dennis Schroeder: (clockwise, left to right) NREL 51934, NREL 45897, NREL 42160, NREL 45891, NREL 48097, NREL 46526.

NREL prints on paper that contains recycled content. 


$\begin{array}{ll}\text { List of Acronyms } \\ \text { BI } & \text { bit index } \\ \text { Colorado SURGE } & \text { Colorado Collaboration for Subsurface Research in Geothermal Energy } \\ \text { CPF } & \text { cost per foot } \\ \text { CSM } & \text { Colorado School of Mines } \\ \text { DOE } & \text { U.S. Department of Energy } \\ \text { DSATS } & \text { Drilling Systems Automation Technical Section } \\ \text { EDR } & \text { Electronic Drilling Recorder } \\ \text { ERDA } & \text { Energy Research and Development Administration } \\ \text { FORGE } & \text { Frontier Observatory for Research in Geothermal Energy } \\ \text { GRC } & \text { Geothermal Resources Council } \\ \text { GTO } & \text { Geothermal Technologies Office } \\ \text { GWe } & \text { gigawatts electricity } \\ \text { HHP } & \text { hydraulic horsepower } \\ \text { HTHP } & \text { high temperature and high pressure } \\ \text { IADC } & \text { International Association of Drilling Contractors } \\ \text { IDS } & \text { Independent Data Services } \\ \text { ILT } & \text { invisible lost time } \\ \text { LCOE } & \text { levelized cost of electricity } \\ \text { MD } & \text { measured depth } \\ \text { MSE } & \text { mechanical specific energy } \\ \text { MWD } & \text { measurement while drilling } \\ \text { NOV } & \text { National Oilwell Varco } \\ \text { NPT } & \text { nonproductive time } \\ \text { NREL } & \text { National Renewable Energy Laboratory } \\ \text { PE } & \text { Petroleum Engineering } \\ \text { ROP } & \text { rate of penetration } \\ \text { SPE } & \text { Society of Petroleum Engineers } \\ \text { SubTER } & \text { Subsurface Technology and Engineering Research, Development, and } \\ & \text { Demonstration } \\ \text { WOB } & \text { weight on bit } \\ & \end{array}$




\section{Executive Summary}

In the summer of 2013, members of the National Renewable Energy Laboratory (NREL) and Colorado School of Mines (CSM) identified opportunities to improve geothermal drilling operations by transferring practices from the petroleum drilling field. The NREL/CSM group noted that significant changes in drilling efficiencies in petroleum operations have been made during the last decade. For example, five years ago, 14,000-foot wells in Wyoming took 60 days to drill. However, in September of 2015, these same wells were drilled in 7 days. This significant decrease in required drilling days resulted from analysis, goal setting, and management and technology improvements. The geothermal drilling industry can import these methods and technologies, where appropriate, with the possibility of similar improvements in drilling operations.

In Fiscal Year 2014, the first step in this research was to identify the issues contributing to differences in petroleum and geothermal drilling performance. Because time is a significant independent variable in this improvement, CSM set up a team of undergraduate students to analyze rig-time data from the International Association of Drilling Contractors (IADC) and daily drilling reports from 21 geothermal and 21 petroleum wells. The FY14 report contains the analysis of these 42 wells. For each well, the daily operations were input into a software database called IDS Datanet. This software is a web-delivered online database that formats IADC-coded daily drilling reports and then uses this daily information to generate time-analysis figures. The team looked at this process in the context of an "historical perfect well," studied all of the wells in aggregate, and then considered the best-in-class of the 21 petroleum wells and compared it to the best-in-class geothermal well. The results showed a significant difference to the same depths between geothermal and petroleum wells, with not all of the differences attributable to geologic differences.

Six major issues commonly found in geothermal drilling operations were identified and compared to similar situations in petroleum drilling operations. These issues include lost circulation, rig and equipment selection, cementing, rate of penetration (ROP), drilling program efficiency and consistency, and effective time management. Because of problems in these areas, as a whole, geothermal drilling operations analyzed in this report averaged 56.4 days longer than comparable petroleum wells. The petroleum wells reached an average depth of 12,500 feet faster than any geothermal well reached 10,000 feet.

In many instances, comparable events such as drilling the same-sized hole, tripping in/out, cementing, and running the same-sized casing took substantially less time in the petroleum operations. The comparisons identified in the FY14 report help to indicate potential improvements of geothermal drilling operations. The FY15 task was to take two of these issues and determine more specific details related to them.

The FY15 project had some challenges in starting the funding cycle, with funding not available until July 2015. This delay was fortuitous in some ways because the project obtained unprecedented access to the drilling and geological records of four geothermal wells located near each other in the western United States that summer. However, the first newly drilled well was delayed and spud occurred in the fall of 2015, which deferred the FY15 drilling research project 
into FY16. The team was granted a no-cost grant extension to allow the team to review and research drilling efforts for these four geothermal wells.

The well data included the various mud and wireline logs, the daily drilling reports, and - most useful - the electronic drilling data from the various surface sensors. In addition, one of the wells was drilled during the timeframe of the project, which allowed the team to specify specific data needs, to which the operator graciously agreed.

One major issue studied for this project is the effective management of time by the rig and crew. This management is difficult to analyze because of the disappearance of "lost time" within the reports. However, one goal of this project is to quantify the effect of time management seen in the geothermal field. With the data available for analysis in this project, it would appear that the geothermal industry could benefit from this crucial management tool. The team went into great detail in how to break out productive versus non-productive time, which provided more details of the specific non-productive time issues related to at least the four "typical" geothermal wells. The team also had access to economic data, but we are unable to share specific costs due to the operator's request. However, we can give a percentage basis and can identify, classify, and determine the time lost quantitatively.

The other major issue studied was rate of penetration. Using the daily drilling reports, logs, and especially the electronic drilling data, the team was able to review-second by second, foot by foot - the drilling energetics of the operations and compare them to the geology. This analysis allowed the team to identify the effectiveness of applying energy to ROP efficiencies. The team identified possible drilling dysfunctions and determined wear issues on the bits. 


\section{Table of Contents}

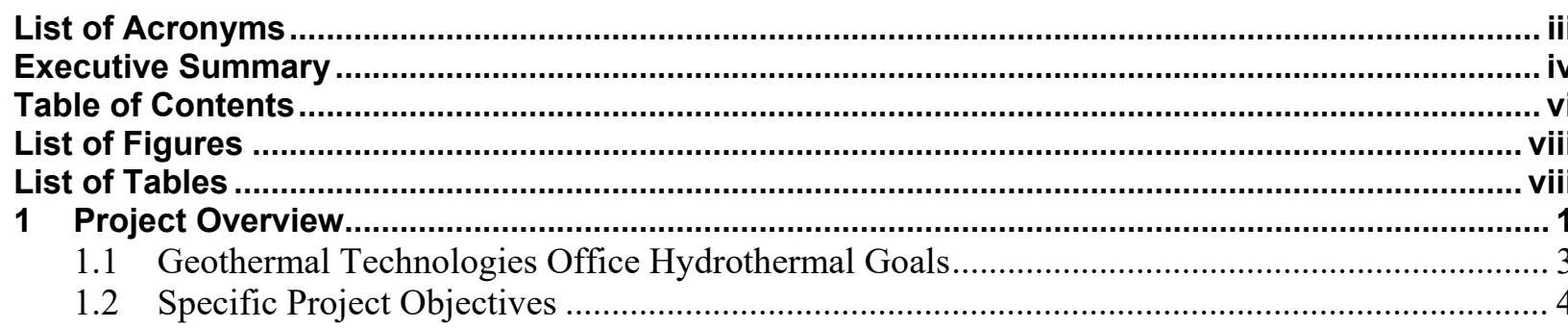

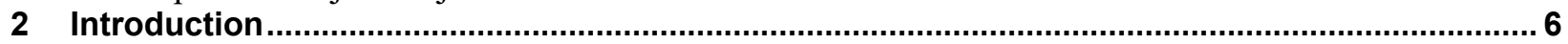

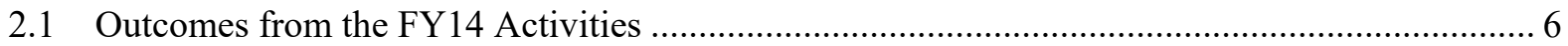

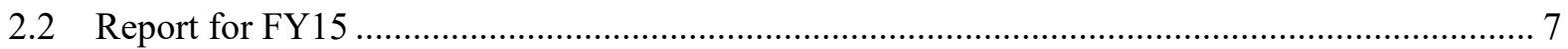

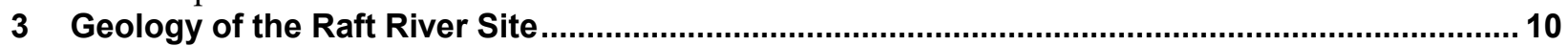

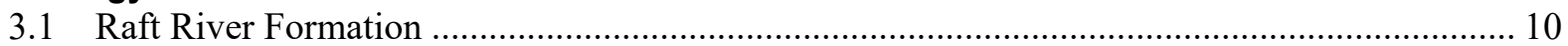

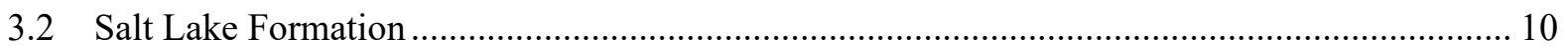

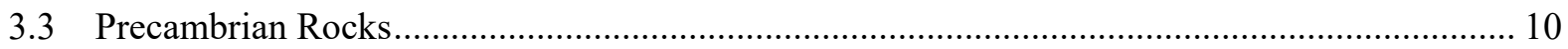

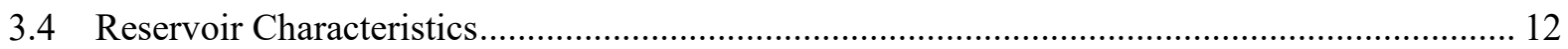

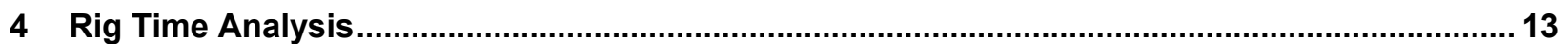

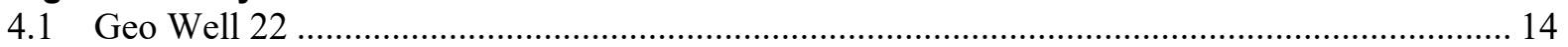

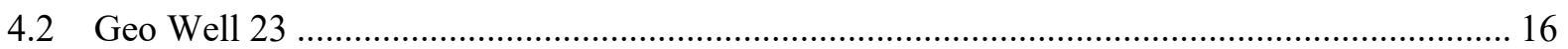

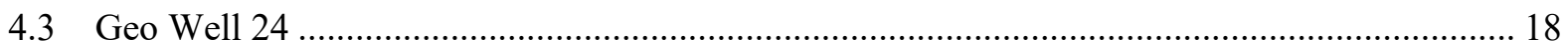

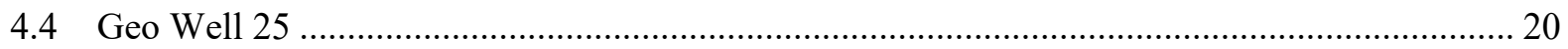

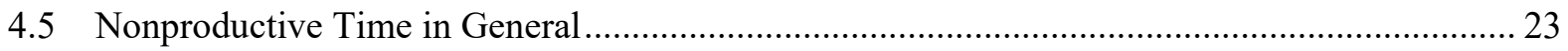

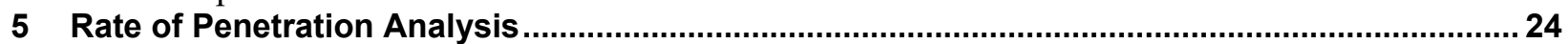

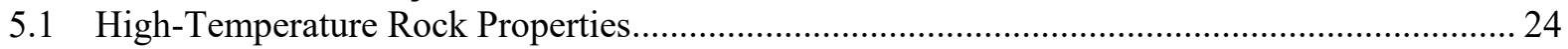

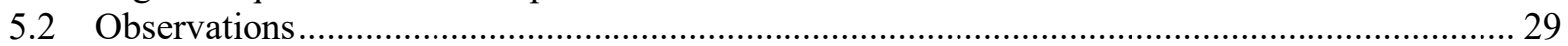

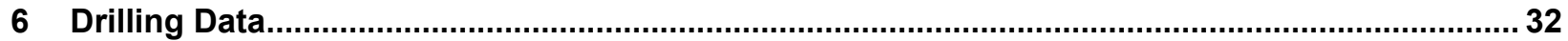

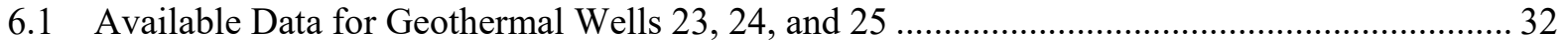

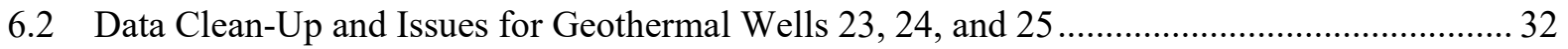

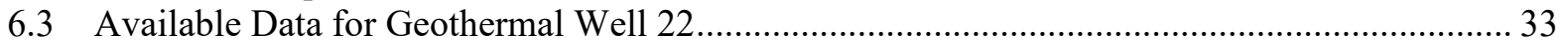

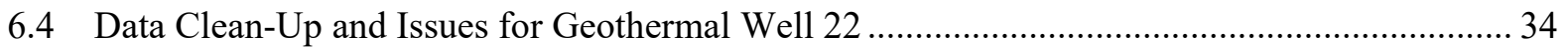

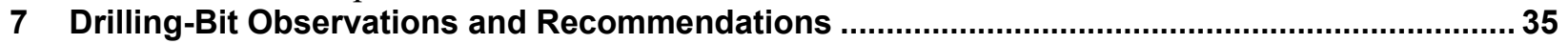

7.1 International Association of Drilling Contractors Dull Grading .............................................. 37

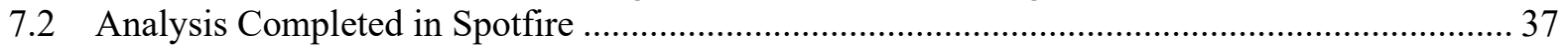

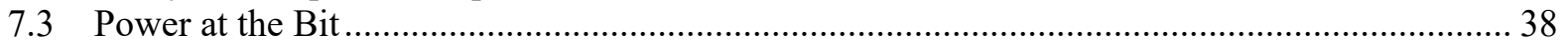

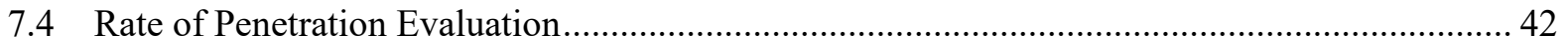

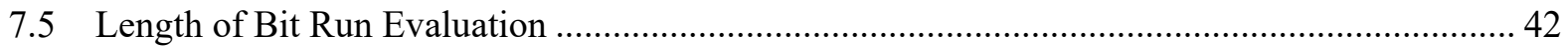

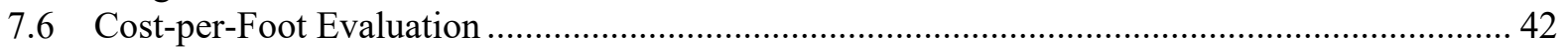

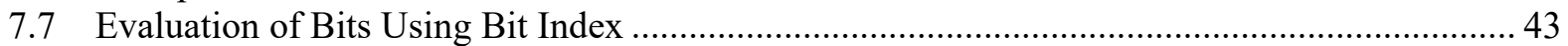

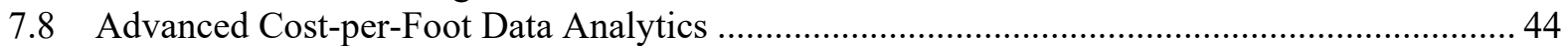

7.9 Comparison of Polycrystalline Diamond Compact and Tricone Bits ........................................ 52

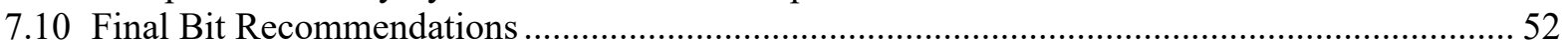

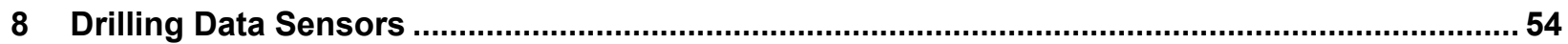

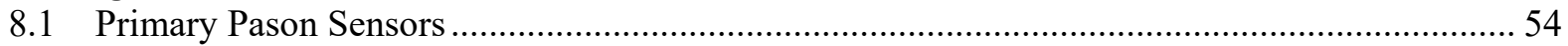

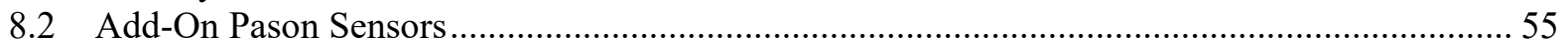

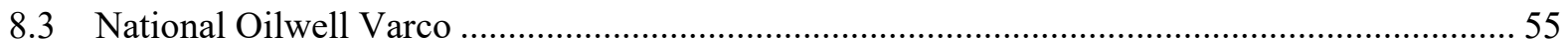

9 Recommendation for Future U.S. Department of Energy Wells ................................................. 57

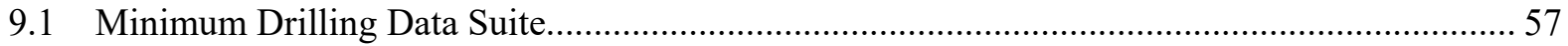

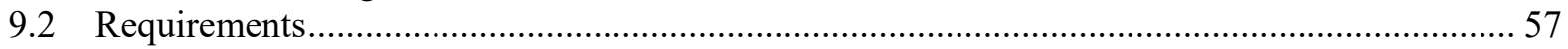

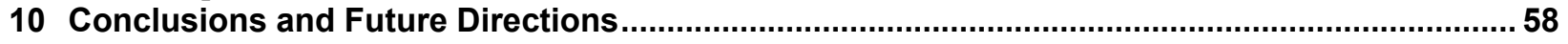

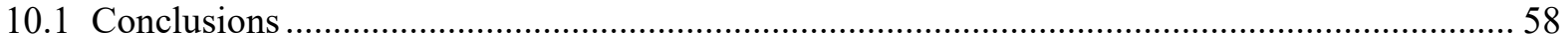




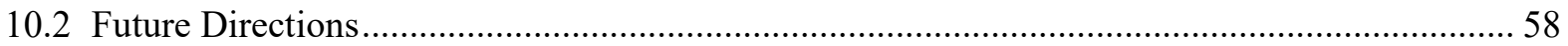

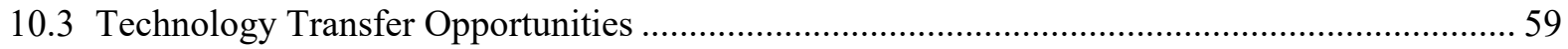

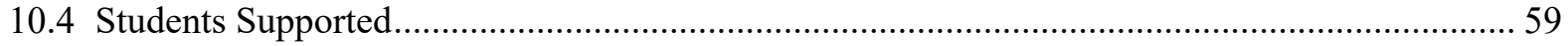

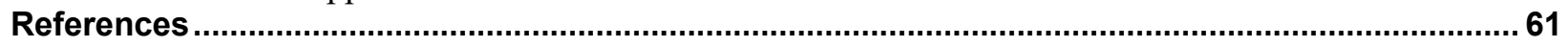




\section{List of Figures}

Figure 1. Comparing geothermal drilling time to petroleum drilling time ............................................. 2

Figure 2. Petroleum drilling operations nonproductive time (orange) ................................................. 2

Figure 3. Geothermal drilling operations nonproductive time (orange and yellow) .................................. 3

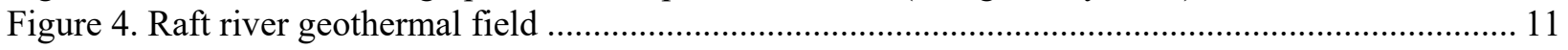

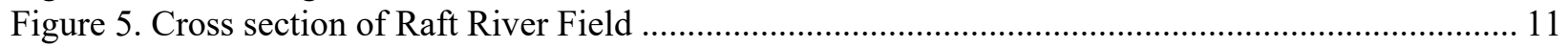

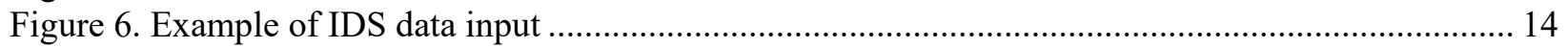

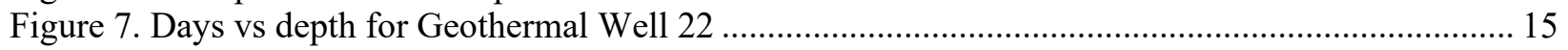

Figure 8. Root cause of NPT identified for Geothermal Well 22 ...................................................... 15

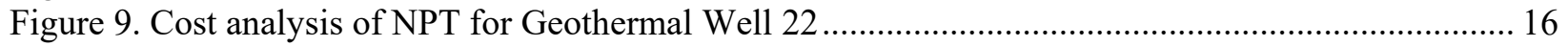

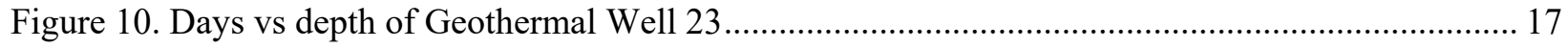

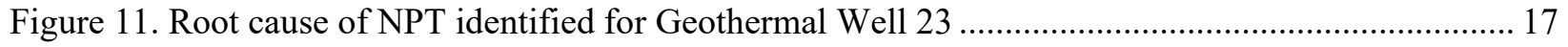

Figure 12. Mechanical-caused NPT experienced by Geothermal Well 23 .............................................. 18

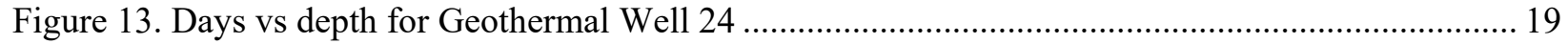

Figure 14. Root cause of NPT identified for Geothermal Well 24 ..................................................... 19

Figure 15. Human- and geological-caused NPT experienced by Geothermal Well 24 .......................... 20

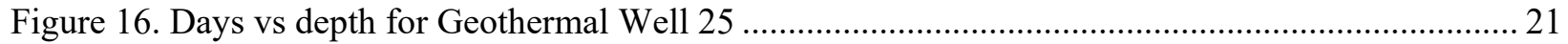

Figure 17. Root causes of NPT experienced in Geothermal Well 25 ................................................... 21

Figure 18. Geothermal causes of NPT experienced by Geothermal Well 25 ........................................... 22

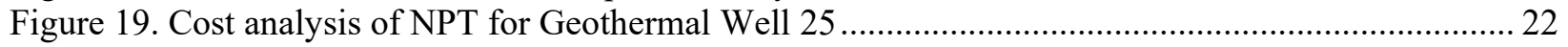

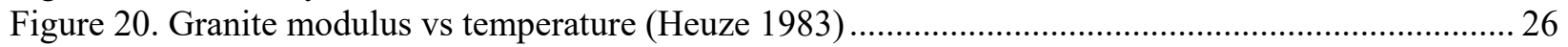

Figure 21: Granite ultimate strength vs temperature (Heuze 1983) ....................................................... 27

Figure 22: Granite normalized modulus vs temperature and pressure (Heuze 1983) ............................... 27

Figure 23. Granite ultimate strength vs temperature and pressures (Heuze 1983) ................................... 30

Figure 24. Bit horsepower in the production section of Geothermal Well 22 ....................................... 39

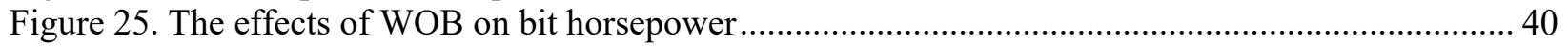

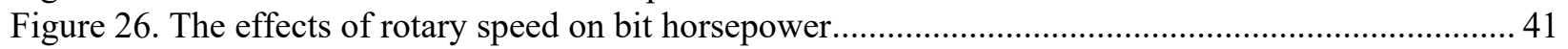

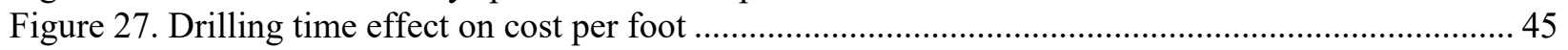

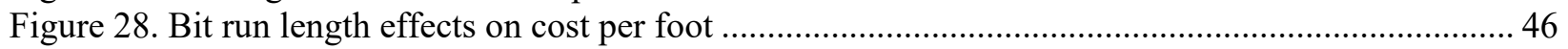

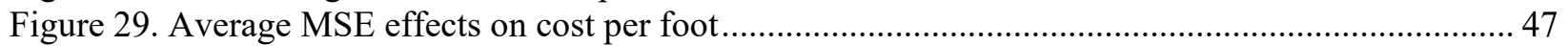

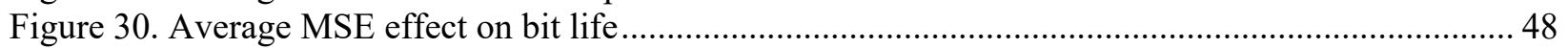

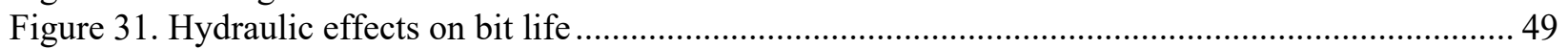

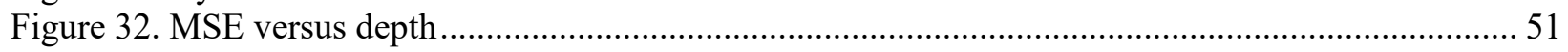

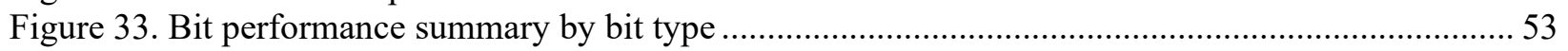

\section{List of Tables}

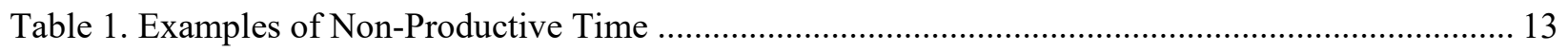

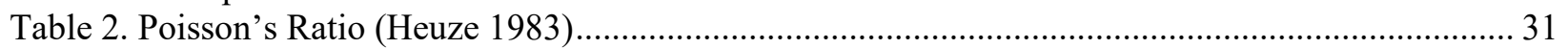

Table 3. Available Drilling and Well Data for Geothermal Wells 23, 24, and 25 ............................... 33

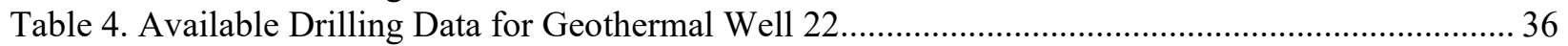

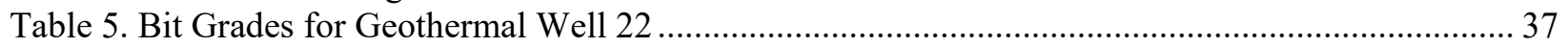

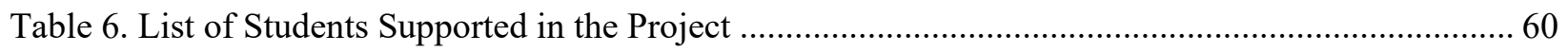




\section{Project Overview}

Wellbore construction costs continue to be one of the most significant economic barriers to geothermal development. Although there are some differences, the geothermal and petroleum wellbore construction industries generally share many of the same drilling and completion challenges. However, the petroleum industry has a huge advantage in the scale of investment, people, and wells. Using that advantage, the petroleum drilling and completion teams have made huge strides in improving efficiency and containing costs. The geothermal industry has applied petroleum drilling knowledge in the past, but the challenging economics and one-off nature of many geothermal exploration and development projects often lead to underinvesting in technology and practices. Hence, there is an opportunity for major improvements in drilling effectiveness and cost reduction. We propose to capture improved processes and technology from the petroleum industry and apply them, where appropriate, to the geothermal industry.

The National Renewable Energy Laboratory (NREL) and Colorado School of Mines (CSM) formed a team known as the Colorado Collaboration for Subsurface Research in Geothermal Energy ("Colorado SURGE"). In the ongoing project, "Geothermal Drilling and Completions: Petroleum Practices Technology Transfer," the team identified and quantified the most promising areas for technology cross-transfer. The data accessed by Colorado SURGE in FY15 pointed the team toward fruitful directions and showed the geothermal community the potential for serious improvement in drilling performance. The project has identified multiple petroleum drilling practices, methods, and technologies that can potentially provide the geothermal industry with methods that are more effective and have lower cost and lower risk.

Through 2014, the project used data from geothermal wells based on daily drilling reports with a typical granularity of 15 -minute increments. This gross sampling interval has been a barrier to precisely fine-tuning operations for efficiency, with only gross events able to be identified. Even then, as shown in Figure 1-the days vs depth chart of a sample of 21 geothermal wells and 21 petroleum wells - there is room for significant improvement in time, which is the variable that most affects costs in wellbore construction operations.

The Colorado SURGE team analyzed drilling records of geothermal and petroleum wells in FY14. The project showed that geothermal drilling suffers from much slower rates of penetration and greater nonproductive time (NPT) than that in petroleum drilling operations. This NPT is attributable to many factors identified in the final project report for FY14 (see Figure 2 and Figure 3).

The opportunities identified by the team are not technological "magic bullets" that solve drilling problems; rather, they consist of many small operational improvements, such as specific mechanical tool solutions. Identifying these opportunities begins with knowing what is actually occurring at depth, which requires a more detailed data stream — both on the rig for operations and for subsequent analysis. 


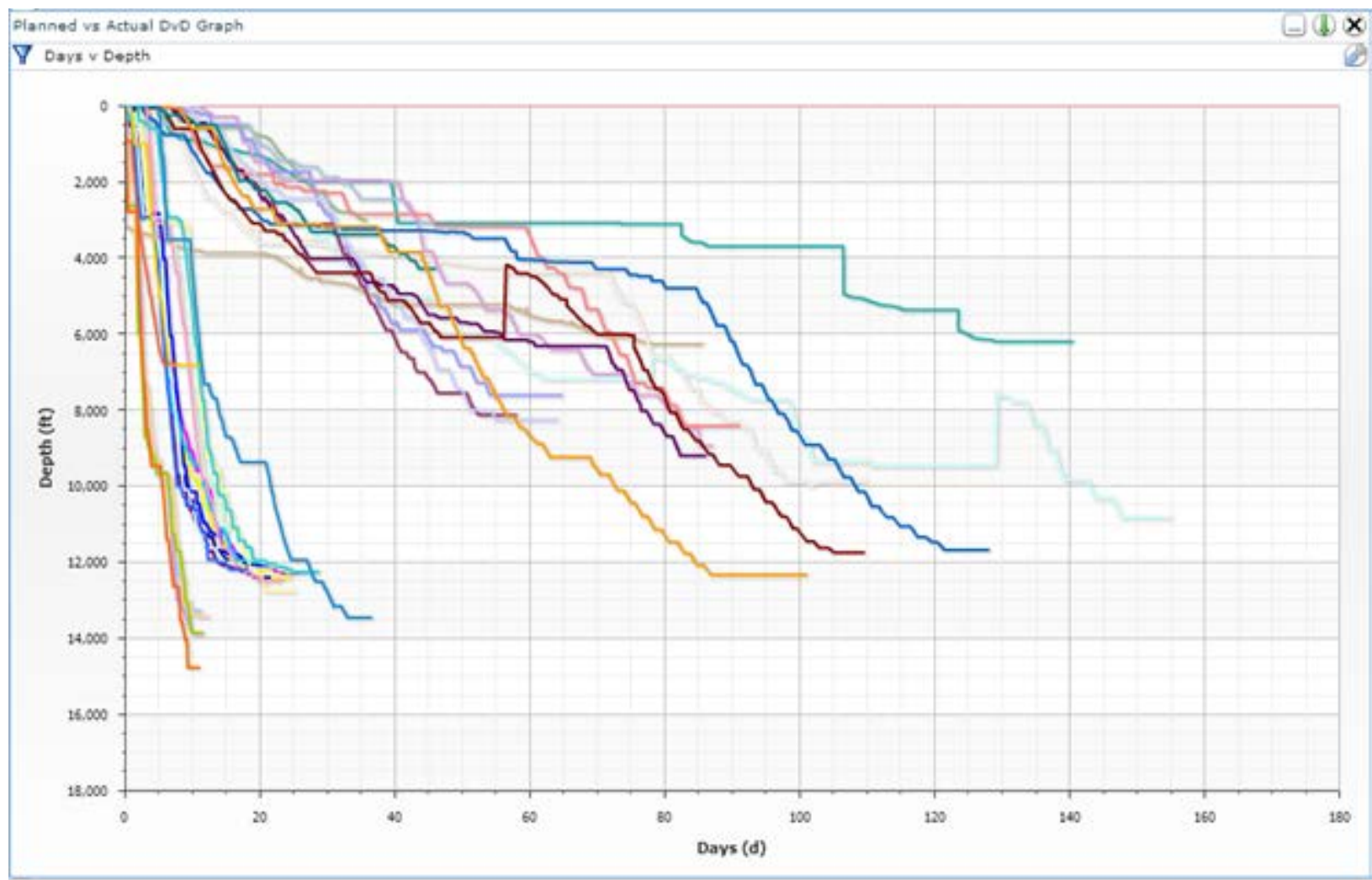

Figure 1. Comparing geothermal drilling time to petroleum drilling time

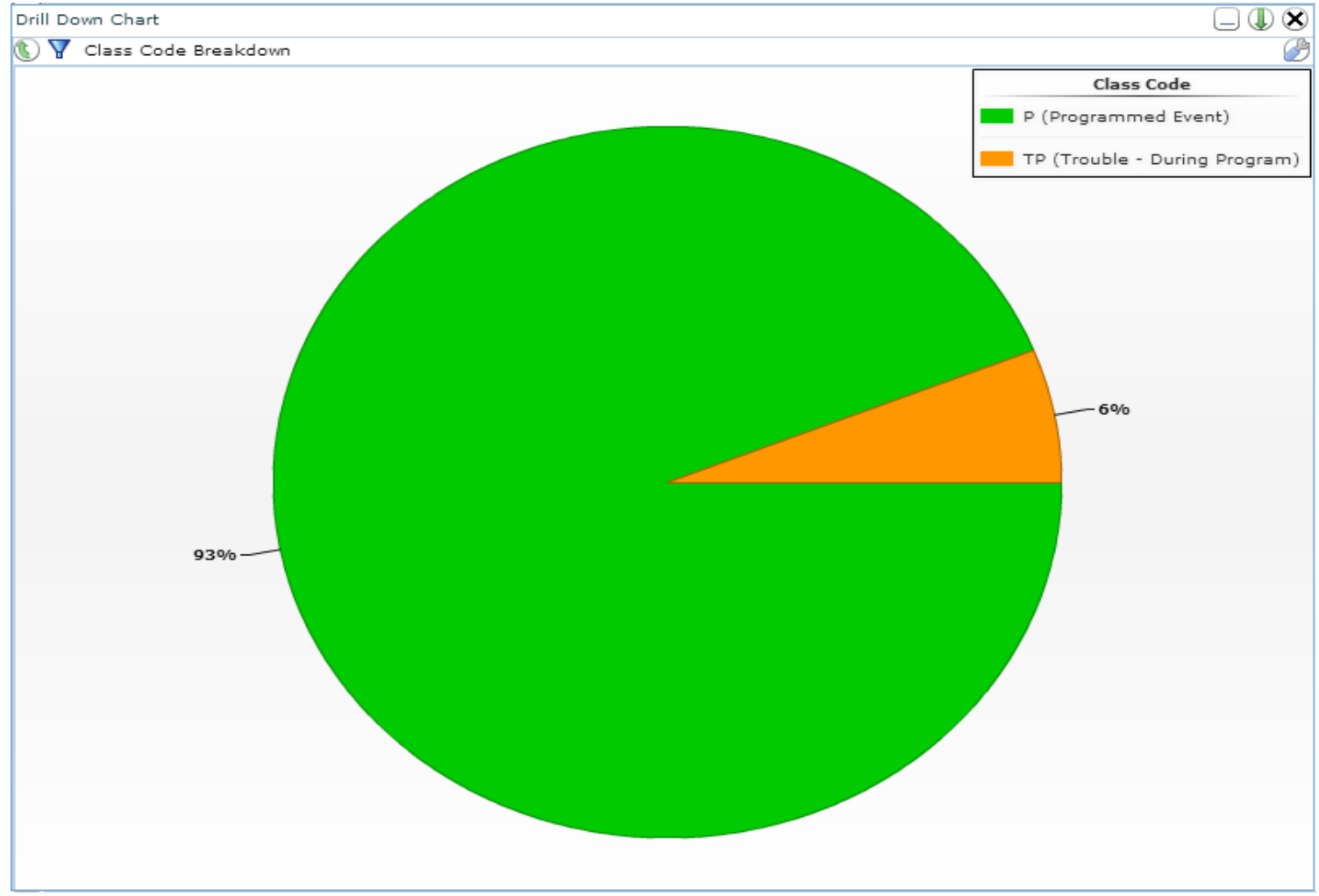

Figure 2. Petroleum drilling operations nonproductive time (orange) 


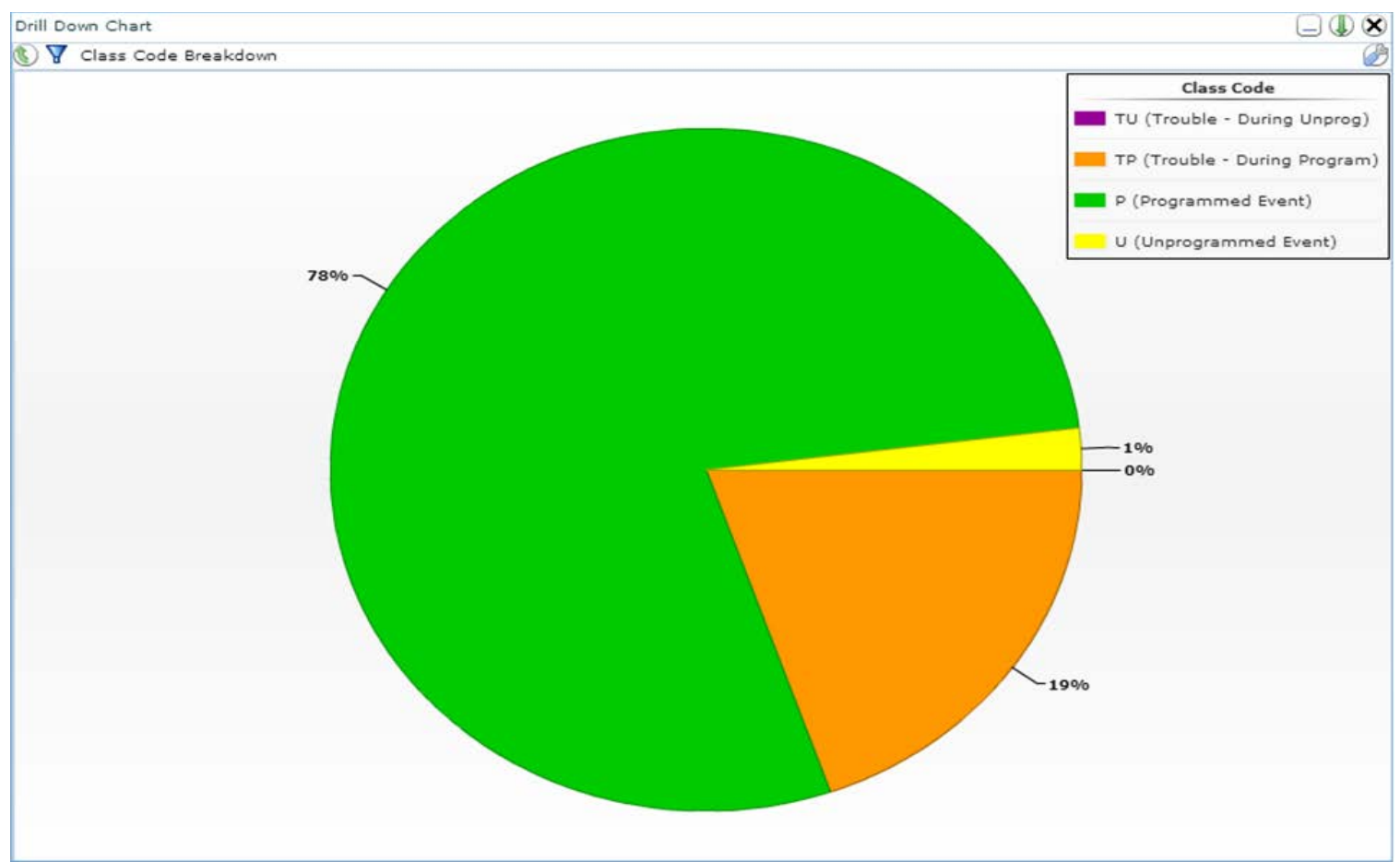

Figure 3. Geothermal drilling operations nonproductive time (orange and yellow)

\subsection{Geothermal Technologies Office Hydrothermal Goals}

Reducing wellbore construction costs and increasing drilling and completion success rates will make more geothermal prospects viable and will directly lead to faster capacity expansion in the United States. The project will allow exploration geologists, operators, rig contractors, and drilling and completion engineers to leverage the greater level of investment and experimentation that has taken place in the petroleum drilling and completion sector.

The project supports the following goals of the Geothermal Technologies Office (GTO):

- Accelerate near-term hydrothermal growth.

- Lower risks and costs of development and exploration.

- Lower levelized cost of electricity (LCOE) to 6 cents/kWh by 2020.

- Accelerate development of $30 \mathrm{GWe}$ of undiscovered hydrothermal resources.

This project also aims to quantify opportunities for technology transfer from geothermal to the petroleum sector, to build on successful application of geothermal drilling innovations (such as polycrystalline diamond compact [PDC] bits) to petroleum drilling. The project will also facilitate transfer of technologies and practices across all subsurface energy fields, supporting the U.S. Department of Energy's (DOE's) crosscutting Subsurface Technology and Engineering Research, Development, and Demonstration (SubTER) initiative.

The project's overarching goals are to:

- Expand the amount of technology transfer between petroleum and geothermal drilling and vice versa. 
- Formalize and strengthen collaboration between NREL and CSM.

- Establish laboratory partnerships with the petroleum and geothermal industries to explore, test, and demonstrate technology transfer opportunities.

- Educate a generation of new drilling engineers in the challenges of drilling in the geothermal environment.

- Demonstrate the value of increased investment in enhanced geothermal drilling technology and practices.

- Leverage the results to benefit drilling capabilities across the subsurface energy sectors.

\subsection{Specific Project Objectives}

The Colorado SURGE team objectives were to:

- Develop a plan and acquire additional geothermal well data.

- Define drilling data analysis protocols.

- Investigate mechanical specific energy (MSE)/rate of penetration (ROP) relationships in geothermal wells.

- Investigate productive versus non-productive time.

- Continue to evaluate petroleum technology and practices.

- Develop workflows.

- Identify technology/practice demonstration opportunities in future geothermal wells.

- Recommend a base data suite for future DOE-supported geothermal wells.

- Investigate equipment, data streams, and sample format and rates.

- If opportunity arises, assist and monitor field operations in data acquisition.

- Cooperate with other laboratories' drilling research.

The activities for the project were:

1. Develop, implement, monitor, and analyze detailed drilling records to determine key drilling performance indicators in non-productive time (NPT - time spent on lost time in operations not needed for well completion, i.e., lost circulation), productive time (including ROP issues), and invisible lost time (ILT - time lost due to inefficiencies in operations).

2. Investigate specific problem areas in geothermal drilling that were defined by interviewing geothermal drilling experts as well as the previous analysis process. The problem areas identified as the primary components of the high NPT include: lost circulation, rig/equipment selection, ROP, efficient and consistent drilling program, effective time management, and cementing. Select two problem areas for deep focus.

3. Investigate the performance challenges in geothermal drilling that stem from the small numbers of wells, the one-off nature of many of the wells, and the lack of continuity among teams drilling these wells. By leveraging the partnership with industry, the project will test drilling management practices adapted from the advanced manufacturing approaches being employed by petroleum operators. These advanced approaches focus on drilling team cohesion, continuous improvement based on feedback, and reducing many small components of NPT. 
4. Develop an ROP analysis to determine if drilling energy is being applied effectively. By determining MSE as related to the rock properties (e.g., compressive strength), the efficiency of applying drilling parameters to penetrating rocks can be determined, as well as what drilling dysfunctions (e.g., whirling, stick-slip, balling) are occurring. Correlate drilling data to various geological parameters. Investigate whether detailed drilling data can help identify fracture intersections from the surface drilling parameters, and whether more detailed drilling data can help detect lithology changes and geomechanical properties.

5. Set a standard for drilling sensors and analysis for all DOE co-funded geothermal wells in the future. Sensors alone are of little potential value without real-time analysis to optimize drilling decisions. The project will investigate how successful petroleum drilling programs are using these data to increase ROP, decrease NPT, and reduce costs. 


\section{Introduction}

\subsection{Outcomes from the FY14 Activities}

A recap of the FY14 project is as follows:

- Interview industry experts in geothermal and petroleum.

- Collect and input well data.

- Conduct "perfect-well analysis."

- Determine geothermal and petroleum drilling divergence.

- Determine potential solutions or mitigation techniques.

Outcomes for the FY14 report indicated six potential areas for improving geothermal drilling, listed in no particular order:

- Drilling program

- ROP

- Rig management of time and crew

- Lost-circulation issues

- Rig and equipment selection

- Cementing issues.

The team presented two papers based on our FY14 report, with all of the students and principal investigators contributing to the papers. The first paper was presented by Mitch Tilley at the Stanford Geothermal Workshop in Stanford, CA, on January 28, 2015.

SGP-TR-204 Optimizing Geothermal Drilling: Oil and Gas Technology Transfer; M. Tilley, A. Eustes, C. Visser, W. Baker, D. Bolton, J. Bell, U. Nagandran, R. Quick

The second paper was presented by Kate Denninger, an undergraduate Petroleum Engineering (PE) student, at the Geothermal Resources Council (GRC) meeting in Reno, NV, on September 23, 2015. This paper was selected as the "best in session" for the GRC conference.

Optimizing Geothermal Drilling with Petroleum Technology; K. Denninger, A. Eustes, C. Visser, W. Baker, D. Bolton, J. Bell, S. Bell, A. Jacobs, U. Nagandran, M. Tilley, R. Quick

The team had the following students involved in the project:

- Ralph Quick - undergraduate student (B.S. PE, 2016)

- Sean Bell-undergraduate student (B.S. PE, 2017)

- Kate Denninger - undergraduate student (B.S. PE, 2015; now with Devon Energy)

- Mitch Tilley_-graduated student (B.S. PE, 2014; now with Oxy)

- Ami Jacobs - graduated student (B.S. PE, 2015; now with Vertex)

- Walt Baker-graduated student (M.S. PE 2017)

- Jason Bell — graduated student (B.S. PE 2015; formerly with Halliburton)

- Dan Bolton - graduated student (B.S. PE 2015; now with Halliburton)

- Uneshddarann Nagandran_-graduated student (B.S. PE 2015; now in Malaysia). 


\subsection{Report for FY15}

Given the list identified in FY14, the team decided to pursue two of the more quickly and economically achievable goals: better rig management and ROP improvements.

In the fall semester of 2014, the team continued cleaning up and organizing the data and writing the Stanford Geothermal Conference paper. In a fortuitous development, a geothermal operator headquartered in Denver (with operations in Idaho's Raft River area) granted the team access to their drilling data from their last three wells. The team immediately uploaded the operator's data into IDS Datanet, which the team had done with the previous 42 wells in FY14, and output that data similar to the previous work. The team also had access to the electric and mud logs, fracture ID logs, the geological descriptions, and drilling end-of-well summary reports. This trove provided the team with a new set of data. In addition, the operator gave the team access to their data spreadsheets, which had the real-time drilling surface-data outputs from 1-minute to 1second increments (depending on the data stream). The data spreadsheets included the following data:

- Depth (feet)

- Block height (feet)

- Bit depth (feet)

- ROP (1-foot increments)

- ROP (1-minute increments)

- Hook load (lbf)

- Weight on bit (WOB) (lbf)

- Pump pressures (psi)

- Rotary amperage (amps)

- Surface torque (lb-ft)

- Bit speed (rpm)

- Rotary speed (rpm)

- Pump rates (spm)

- Pit volume (bbls)

- Flow in and out (gal/min)

- Temperature out $\left({ }^{\circ} \mathrm{F}\right)$.

These new data had some advantages and disadvantages. The team had the surface output data for all of the drilling operational sensors on the rig. The team was able to analyze the drilling operations as well as determine the NPT more precisely and directly. The disadvantage was that the dataset was huge - the data were in 1-second increments - and this large dataset was difficult to manage. Secondly, the team did not have access to the metadata, and some of the data were suspected to be measured incorrectly.

\subsubsection{Real-Time Operational Data}

The team incorporated the AC drilling operational data and e-logs in Techlog, a Schlumberger software product used for showing and manipulating electric log output and other depth-related data such as drilling operations data. Techlog enables tracks to be built to manipulate the data and to create charts for analysis. CSM has a free license to use the software. 
Many challenges were encountered. The drilling data are time-based, requiring the team to convert to depth-based data. The team was only interested in the data when rock penetration was actually taking place, so a tedious hand-search was required to identify only the time intervals during which there was active drilling. The team was unable to use Techlog to determine NPT using the electronic drilling data recording; instead, the team used the daily drilling reports and the IDS Datanet software to analyze NPT.

At the September 2014 Society of Petroleum Engineers (SPE) Advanced Technology Workshop, From Sensors to Solutions, many presentations and discussions centered around the various drilling operational sensors and their use not only for information, but also, for input into drilling automation. The consensus was that although some sensors for automation are available, there is much left to do to build autonomous drilling rigs; participants even wondered if that was something desired. Contact was made with many different groups, which has given the team a lead on autonomously taking the data and pulling out the desired information.

\subsubsection{Drilling Energetics}

One of the questions brought to the forefront in our discussions with DOE and NREL was the issue of lithological contrasts between petroleum and geothermal drilling operations. Could the difference in lithology account for the $13 \mathrm{x}$ difference in the same time-to-depth ratio we saw in the two historical "perfect wells"?

Based on recent Sandia National Laboratories work with a major geothermal operator, the team was able to show a significant increase in ROP by applying MSE concepts to its operational parameter selection, mainly WOB and RPM. The team continued that process with the geothermal operator, in coordination with Sandia. The data from the geothermal operator's four wells were analyzed to determine the lithology and corresponding MSE. This allowed the team to compare and contrast the drilling energy against the lithology. The industry consensus is that efficient drilling is when the energy input equals the rock's compressive strength. The reality is that efficient drilling is when the energy input is two to three times this value. Anything greater than this value indicates some drilling dysfunction that is taking energy that should have gone into ROP.

\subsubsection{Drilling-Rig Sensor Data}

One goal was to develop a set of detailed requirements for any future proposed DOE-supported drilling-rig operations. Previously supported drilling operations did not have any specifications on the collection and recording of drilling information, which limited the scientific value of the wells.

Operational drilling surface sensors are an essential requirement. These sensors can be split into direct measurements (e.g., block height, hook load, pump pressure) and derived data (e.g., ROP from block height and time, WOB from hook load). This would be a minimum set of sensors. We also determined what other sensors could be useful for a "sweet suite" for potential studies not only with drilling parameters but perhaps for trend analysis for NPT and unscheduled events (i.e., can lost circulation precursor events be determined?), drilling dysfunctions (e.g., whirling, stick-slip, balling), interfacial reservoir characterization (e.g., rock strength from drilling energy output), and fracture identification. 
However, even in the petroleum sector, sensor data quality can be suspect. The SPE's Drilling Systems Automation Technical Section (DSATS) has a sub-committee working on codifying drilling-rig sensor data-quality assurance. Dr. Eustes is on the DSATS board and is in contact with this sub-committee. In discussions, we agreed to cooperate with the sub-committee's team members, and using their outcomes, to develop requirements that can be ported to geothermal operations. The team anticipated that those required raw drilling sensors, the derived data specifications for accuracy, precision, timing, and calibration would be the basis for any requirement for future DOE drilling support. 


\section{Geology of the Raft River Site}

The Raft River Geothermal Field (Figure 4 and Figure 5) was discovered and delineated by the Energy Research and Development Administration (ERDA) and the DOE between 1974 and 1983. The Raft River project was the first demonstration of binary-cycle geothermal technology, and it proved its technical feasibility in 1979, using isobutene as the binary fluid. It produced heat from a resource with $135^{\circ} \mathrm{C}$ to $146^{\circ} \mathrm{C}\left(275^{\circ} \mathrm{F}\right.$ to $\left.300^{\circ} \mathrm{F}\right)$ fluid flowing about $400 \mathrm{~kg} / \mathrm{s}$ (about $220,000 \mathrm{bbl} /$ day) from fractured Precambrian basement rocks and immediately overlying fractured Tertiary sediments at depths of 1,500 to 2,000 m (4,900 to 6,600 ft). The Raft River Power Plant has an 11-MW capacity.

The Raft River geothermal system is near the boundary between the Basin and Range province and the Snake River Plain, the path of the Yellowstone Hotspot. The geology in the valley is complex, reflecting the combined influences of the Basin and Range and Snake River geologic terranes (Jones et al. 2011).

The stratigraphy of the Raft River Field relevant to geothermal drilling is described next.

\subsection{Raft River Formation}

Non-indurated Pleistocene deposits consists of conglomerates, sandstones, and siltstones composed of angular, poorly sorted lithic clasts. Lithic clasts include quartzites, granites, lava flows, ash-flow tuffs, and fragments of calcite. The Raft River Formation overlies the Salt Lake Formation and reaches thicknesses of up to $300 \mathrm{~m}$ (Dolence et al. 1981). The Raft Formation/Salt Lake Formation contact is gradational and difficult to distinguish.

\subsection{Salt Lake Formation}

Mid-Tertiary rocks of the Salt Lake Formation comprise a thick (up to 1,600 m) sequence of tuffaceous sedimentary rocks of largely fluviatile and possibly lacustrine origin. Fine-grained tuffaceous lithologies predominate in the section with conglomerate as a minor rock type. Siltstone and sandstone of the Salt Lake Formation have been deformed by numerous high-angle microfaults and bedding convolutions. Bedding is commonly inclined 10 to 30 degrees. The Salt Lake Formation has been subdivided into three members: an Upper Tuffaceous Member, the Jim Sage Volcanic Member, and the Lower Tuffaceous Member.

\subsection{Precambrian Rocks}

Precambrian rocks penetrated by deep test wells in the Raft River Known Geothermal Resource Area (KGRA) comprise quartz monzonite basement overlain by a series of schists and quartzites. The quartz monzonite is overlain locally by the Older Schist, a discontinuous biotite-chloritemuscovite-rich quartz schist. The Elba Quartzite, a muscovite-bearing quartzite, rests locally on the Older Schist; where the Older Schist is absent, the Elba rests directly on quartz monzonite. The Upper Narrows Schist, a biotite-muscovite-quartz schist, and the discontinuous Yost Quartzite overlie the Elba Quartzite. 


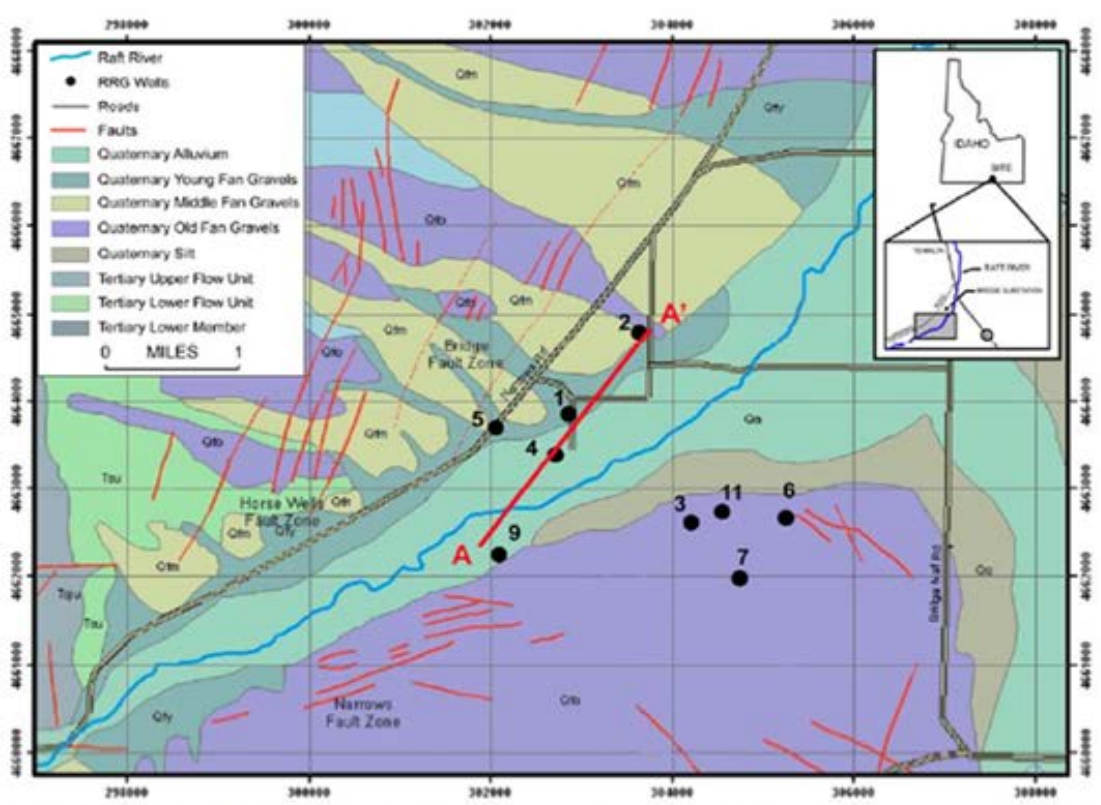

Figure 4. Raft River Geothermal Field

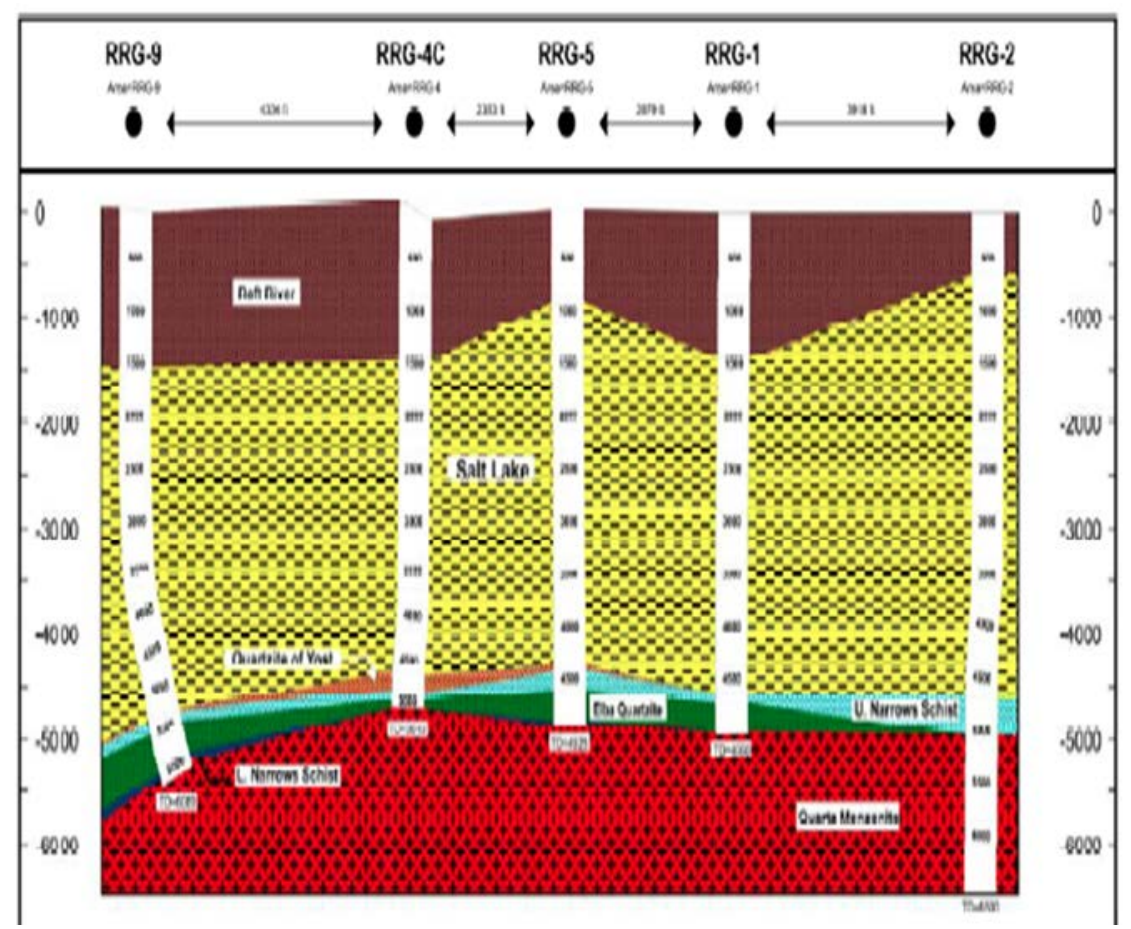

Figure 5. Cross section of Raft River Geothermal Field 


\subsection{Reservoir Characteristics}

The Raft River geothermal reservoir consists of fractured Precambrian schist, quartzite, and monzonite cut by younger diabase intrusions. High fluid flow rates of more than $400 \mathrm{~kg} / \mathrm{s}$ from these basement rocks suggest an open fracture system. Open fractures have been identified on borehole televiewer logs and core samples taken from drilling. The listric fault and fracture conduits are believed to increase in frequency with depth.

Some researchers have postulated a significant contribution — and perhaps principal contribution - to hydrothermal flow from fractures in the Salt Lake Formation sedimentary strata overlying the basement rocks, with the most intense fracturing at the base of the Salt Lake Formation at the listric detachment between the Cenozoic rocks and the underlying Paleozoic and Precambian rocks (Blackett et al.). 


\section{Rig Time Analysis}

The purpose of this component of the research is to identify causes of NPT that occurred in geothermal wells (Geo Wells) 22 through 25, which are numbered so as to continue the location anonymity from the previous work. NPT can be defined as an unplanned event during the drilling program that causes a loss of time and results in economic losses. Events of NPT are based on three categories: mechanical, human, or natural/geological. The mechanical aspect includes equipment failures or waiting on repairs on such equipment; mechanical failures are to be anticipated and replacement of or maintenance on equipment is expected. The human aspect includes occurrences such as waiting on personnel or waiting on secondary contractors; human occurrences of NPT can be handled through proper management practices. The natural / geological aspect includes waiting on weather, lost circulation, or well-control problems; natural occurrences of NPT are often unavoidable but can be managed through safety, technological innovation, and knowledge.

Our team chose Independent Data Services (IDS) as the platform to organize and analyze the copious amounts of drilling data required to report the operational performance of the drilling projects (see Figure 6 for an example of an input page). This allowed detailed daily drilling reports to be entered and analyzed so that the knowledge to enhance drilling performance would ultimately be available. The database allows for events of the rig's activities to be entered in detail on an hourly basis; moreover, it classifies events as either programmed or unprogrammed, which, in turn, focuses on what went awry during the drilling program. With this information broken down by the hour, a series of plots were generated that showed all of the causes of NPT for each well. IDS also produced a cost analysis of how much each NPT event cost in relation to the entire project. IDS was very helpful in uncovering the inefficiency of drilling practices or the duration of the drilling projects, and it has given direction to steps that can be taken to mitigate any future inefficiency. Examples of NPT are shown in Table 1.

Table 1. Examples of Non-Productive Time

\begin{tabular}{|l|l|}
\hline Lost circulation & $\begin{array}{l}\text { Waiting on repairs } \\
\text { - rig equipment } \\
\text { Well control }\end{array}$ \\
\hline Wellbore fluids \\
\hline Mud pump failure & Directional drilling \\
\hline $\begin{array}{l}\text { Waiting on operator / } \\
\text { contractor equipment } \\
\text { / people }\end{array}$ & $\begin{array}{l}\text { Service company } \\
\text { equipment, } \\
\text { people, } \\
\text { procedures }\end{array}$ \\
\hline Waiting on weather & Stuck pipe \\
\hline
\end{tabular}




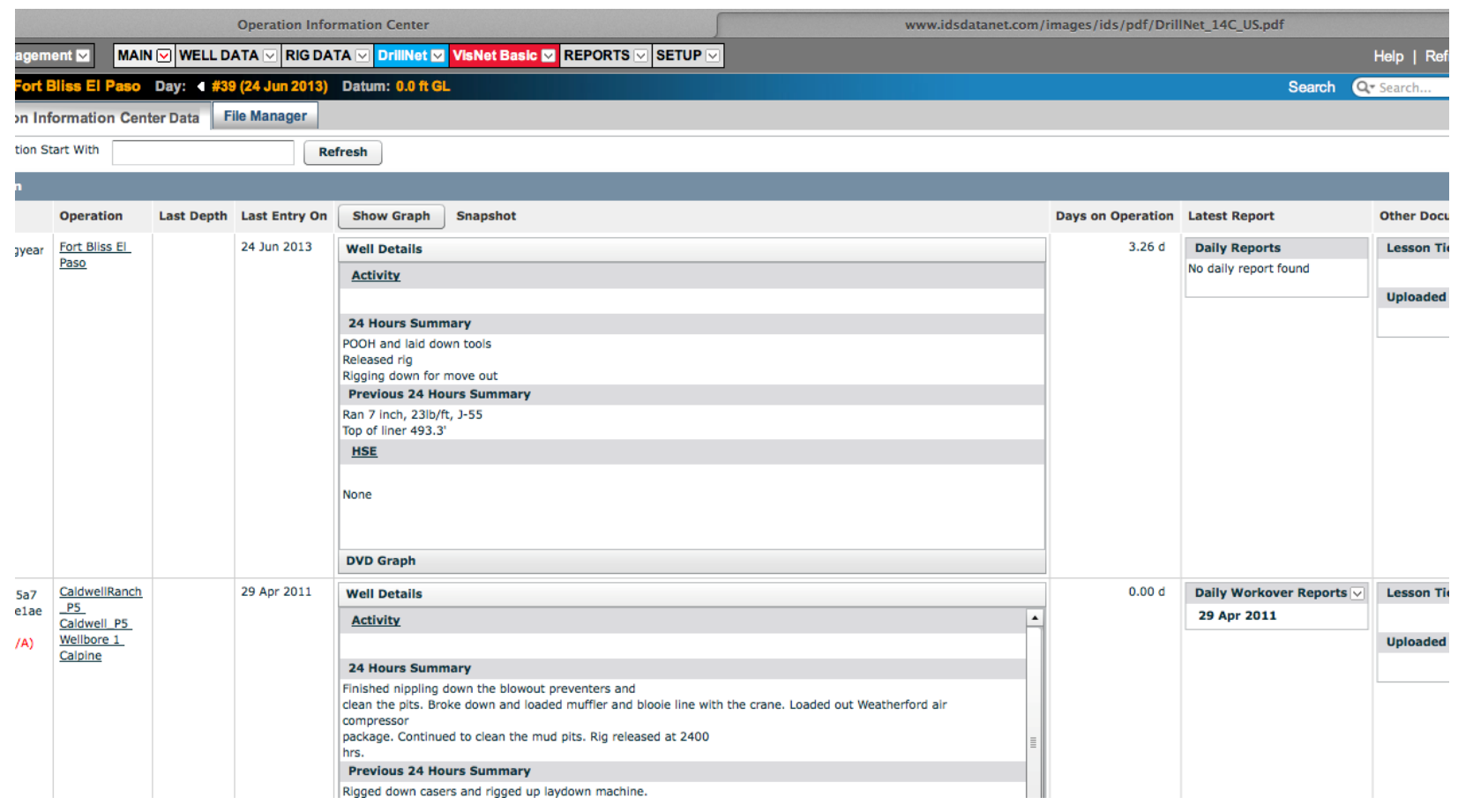

Figure 6. Example of IDS data input

\subsection{Geo Well 22}

Geo Well 22 was the most recent well drilled and took 73 days to complete. It experienced a series of issues while being drilled - specifically, a very costly lost-circulation event that lasted several days. Figure 7 shows the days vs depth chart for the well and as can be seen, it required several days and just over a fifth of the total well cost to remedy the lost circulation in the well. The horizontal sections of the plot represent NPT events; the ramping sections indicate the crew making hole. The actual depth/day line represents the actual project depth and the time it took to bring to completion. The productive depth/day line represents the progress of the well if there were no instances of NPT experienced. The cost line shows the increase of expenses as the project progressed. 


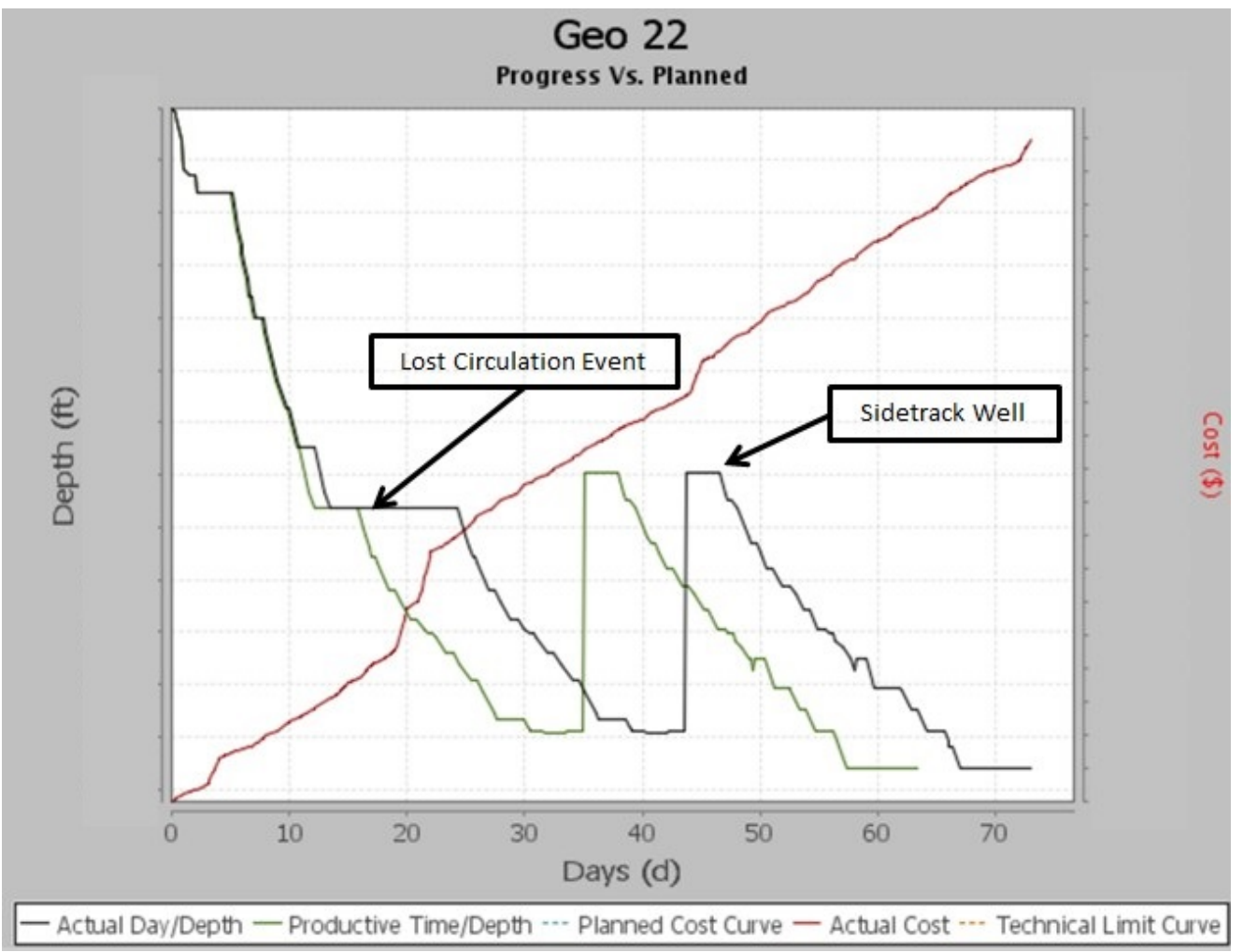

Figure 7. Days vs depth for Geothermal Well 22

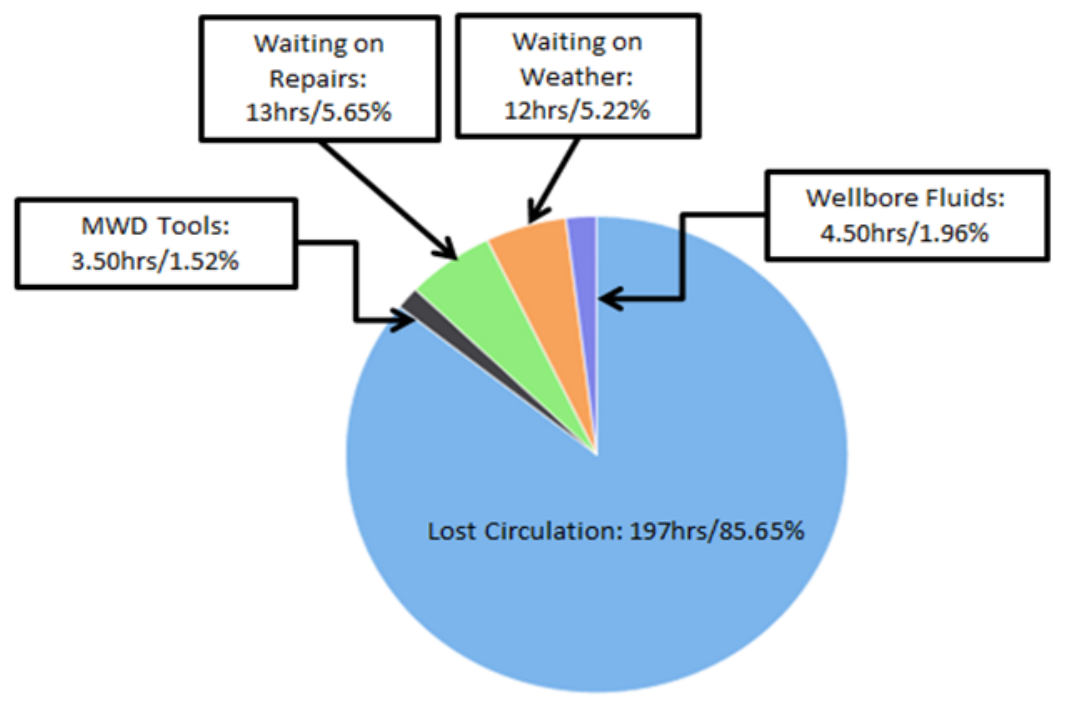

Lost Circulation (DiO Wollbore Fluids (DFP)

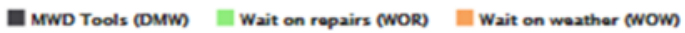

Figure 8. Root cause of NPT identified for Geothermal Well 22

In Figure 8, a large lost-circulation event can be identified. A sidetrack, identified in Figure 7, was required when it was determined that drilling was aimed off the target source rock. The IDS program identified 230 hours of NPT that occurred during the development of Well 22; 
furthermore, the root causes of NPT events can be seen in Figure 8. It is clear that lost circulation is the costliest of all events for this well. This lost circulation took 197 hours or roughly eleven days to remedy before continuing to drill. Lost circulation becomes a great financial burden for an operator if the situation is not managed quickly and with the proper materials.

Figure 9 shows the cost, by cause, of each NPT event in relation to the overall cost of the project. The figure shows that lost circulation accounted for $21 \%$ of the overall cost of the project. This is a large financial burden for the operator. An idea for mitigating lost circulation is to develop a substance to expand sufficiently to fill fractures and vugs that cause lost circulation and that can be relied on to have the integrity of cement so that it can be drilled through shortly after its down-hole application.

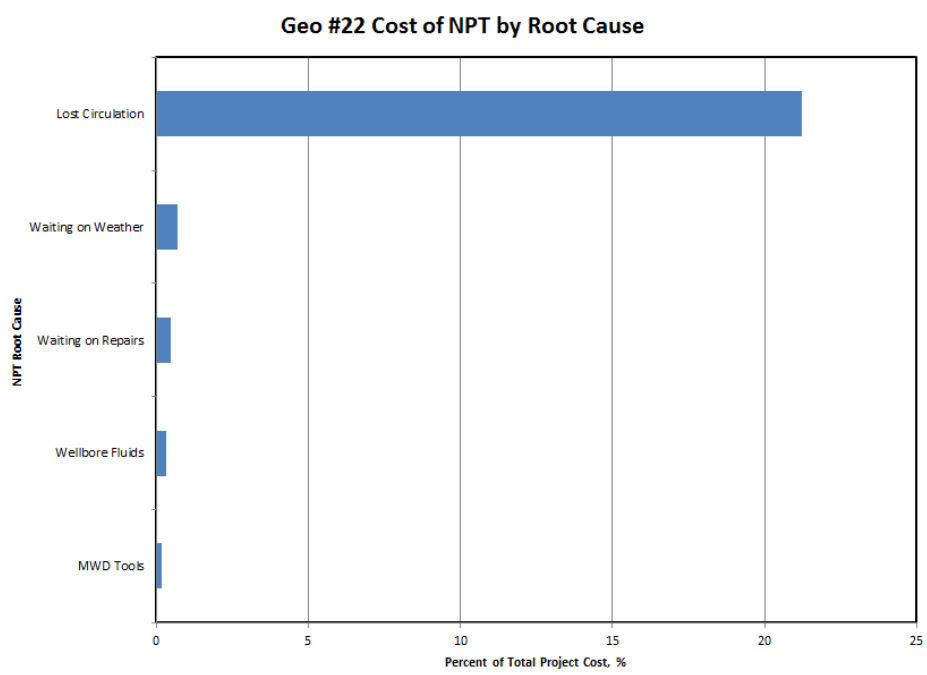

Figure 9. Cost analysis of NPT for Geothermal Well 22

\subsection{Geo Well 23}

Geo Well 23 required 52 days to well complete. This well experienced very minor instances of NPT, but the small events added up over time. This well endured a large variety of NPT as the plot in Figure 10 shows. However, for the most part, the project ran according to plan.

Unfortunately, no information was given on cost for Geo 23 , so no correlations can be analyzed with cost.

Figure 11 displays the root causes of NPT that were experienced in Geo Well 23. The figure shows that the greatest issue the crew dealt with was platform delays, which include activities such as cleaning the rig floor, rig maintenance, and setting up tools. This crew often stopped operation to accomplish these tasks. This well experienced 65 hours of NPT, with human NPT accounting for 34 hours and mechanical NPT accounting for 31 hours. Figure 11 displays the breakdown of human-caused NPT as well as the percentage of time each cause accounted for in the 34 hours of human-caused NPT experienced. Figure 12 displays all of the NPT encountered by the crew on Geo Well 23, as well as the percentage of time for the various NPT. This figure also shows that the crew had a few hours of weather-related NPT - namely, the lines on the rig began to freeze; therefore, they had issues with their mud pumps and associated systems. 
The NPT analysis of Geo Well 23 showed that there were opportunities to improve the personnel management of the rig.

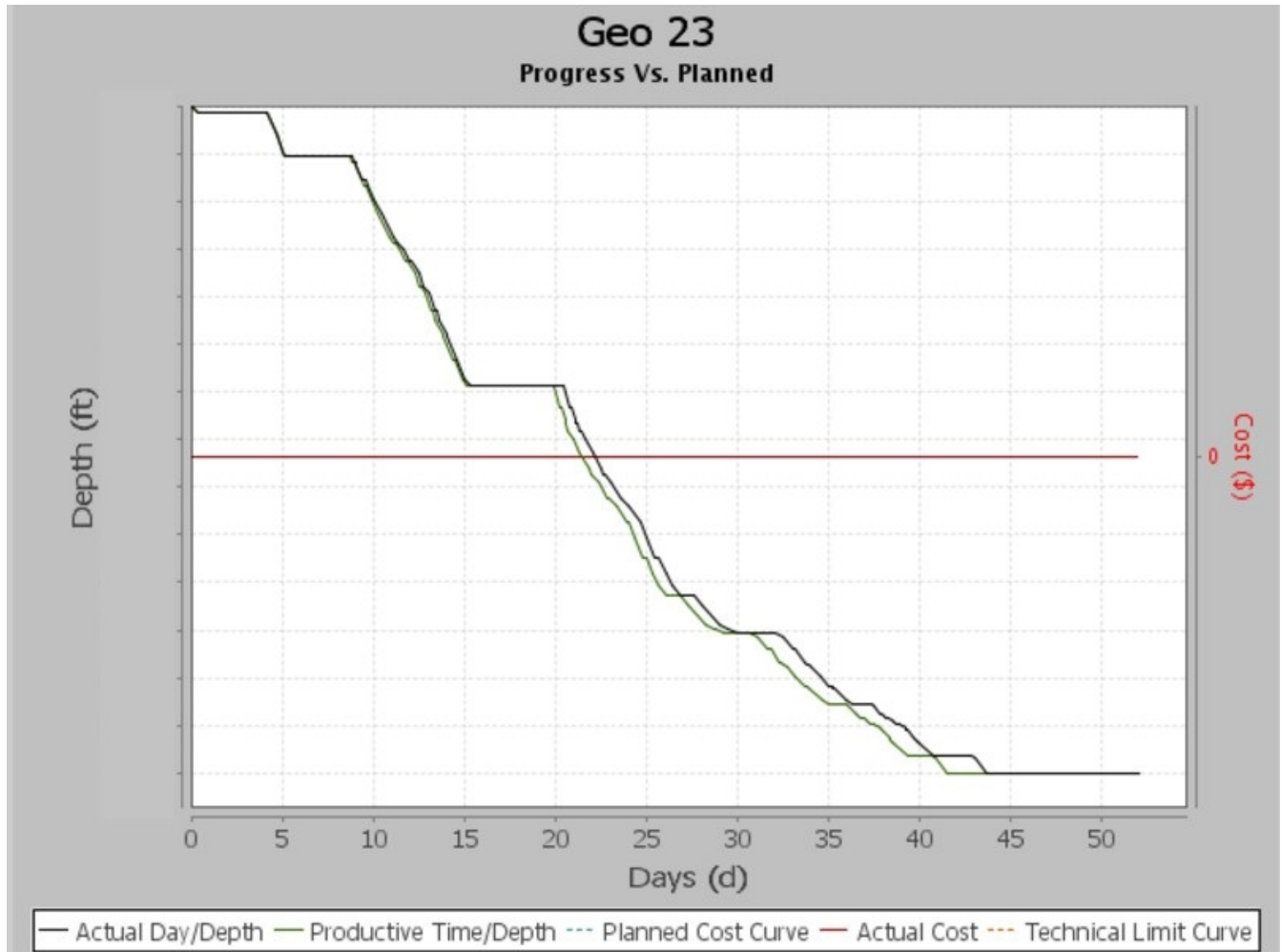

Figure 10. Days vs depth of Geothermal Well 23

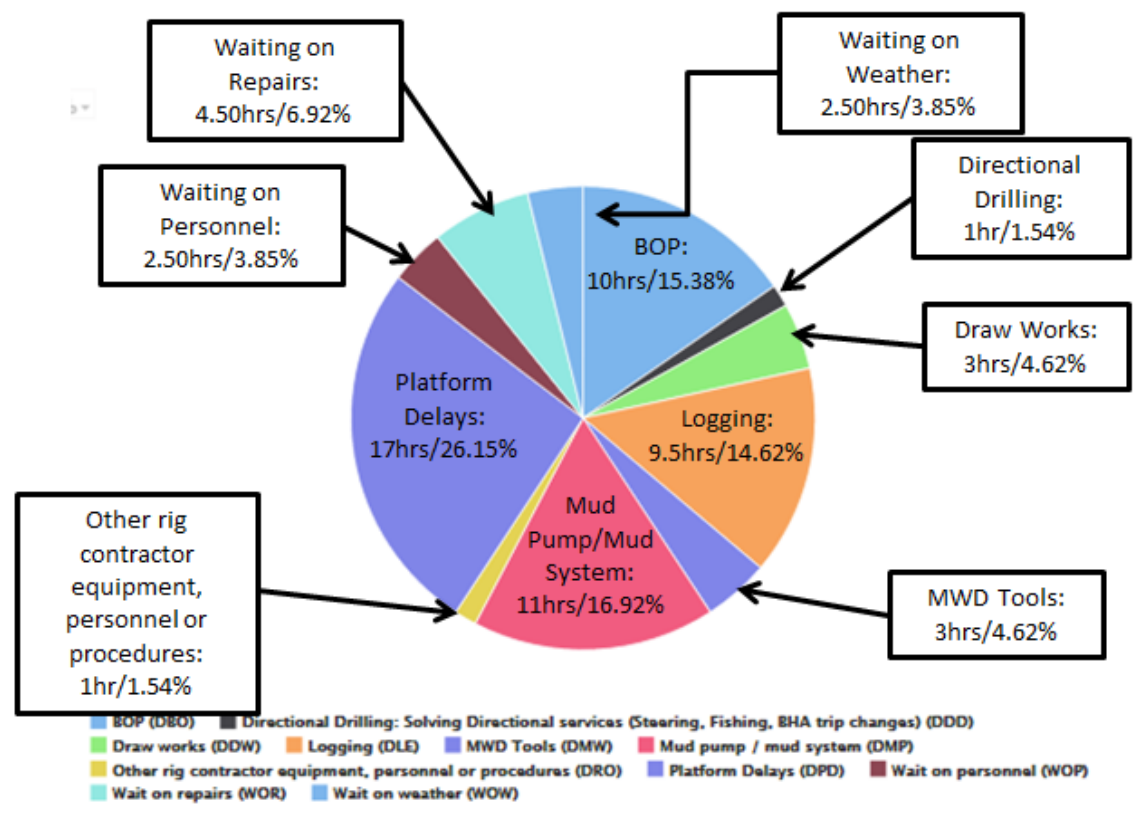

Figure 11. Root cause of NPT identified for Geothermal Well 23 


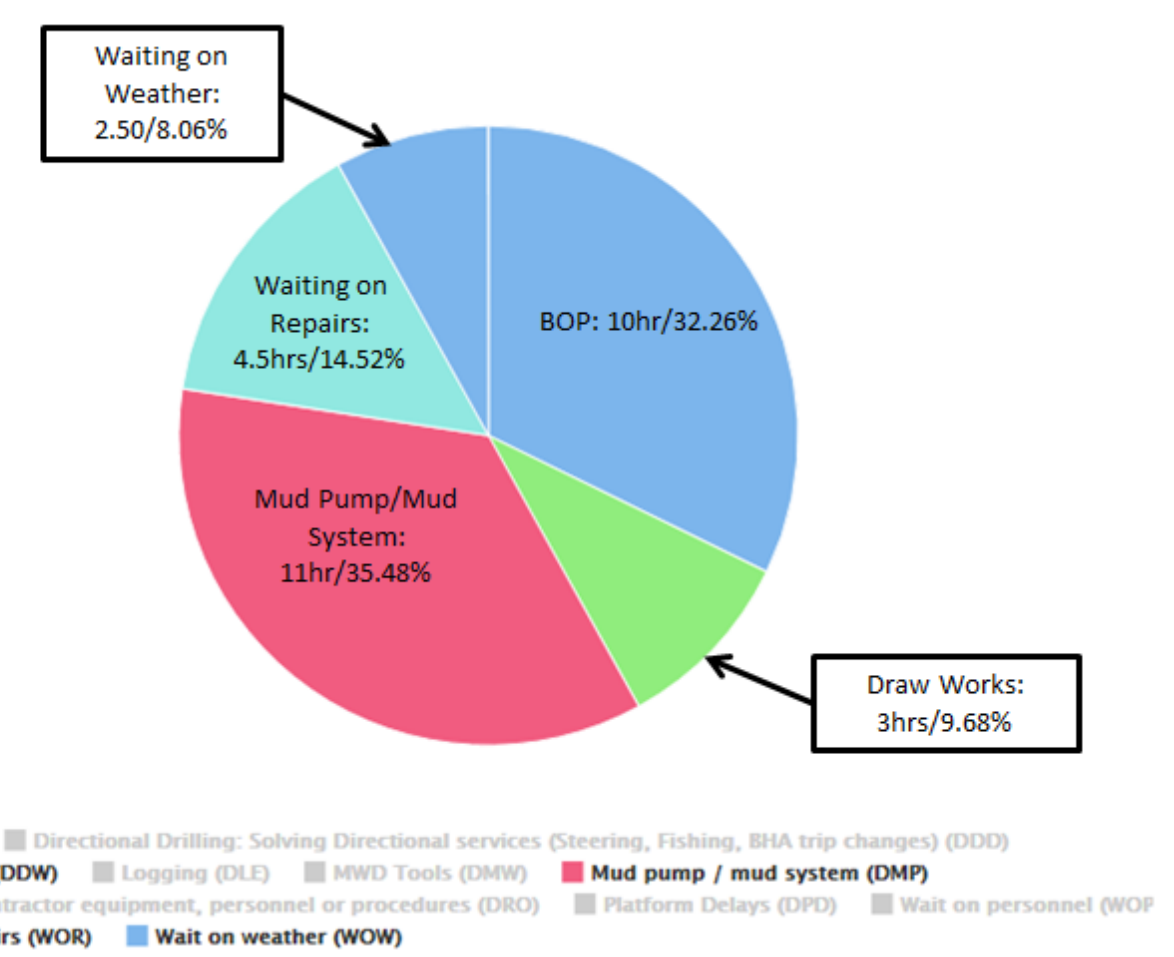

Figure 12. Mechanical-caused NPT experienced by Geothermal Well 23

\subsection{Geo Well 24}

Geothermal Well 24 required 55 days to well complete. This well experienced very minor instances of NPT, but the small events added up over time, as well. The Figure 13 plot shows that that mechanical issues with the rotary table were a significant issue of NPT. Figure 14 displays the root cause of NPT in Geo Well 24. There were 82 total hours of NPT experienced during the development of Well 24: mechanical NPT accounted for 74 hours and human and geological NPT accounted for 8 hours. Figure 15 shows the human and geological NPT events, along with the percentage of time each cause accounted for in the 8 hours of human-caused NPT. The figure shows that lost circulation accounted for more than half of the NPT experienced by human and geological influence, but the lost circulation event was minor and was dealt with quickly and efficiently. Personnel management and geological issues were not a significant problem while drilling this well. Figure 14 shows the mechanical NPT events, along with the percentage of time each cause accounted for in the 74 hours of mechanical NPT. "Waiting on repairs" is overwhelmingly the leading cause of NPT experienced due to issues experienced with the rotary table on the rig. The rotary table broke down and took nearly two days to fix. Mechanical failures are expected and should be planned for; but often, due to relatively remote locations of geothermal projects, it takes longer than anticipated to resolve mechanical issues. For future projects, it would be beneficial to have spare parts for equipment on the rig site, and ideally, an on-site mechanic. 


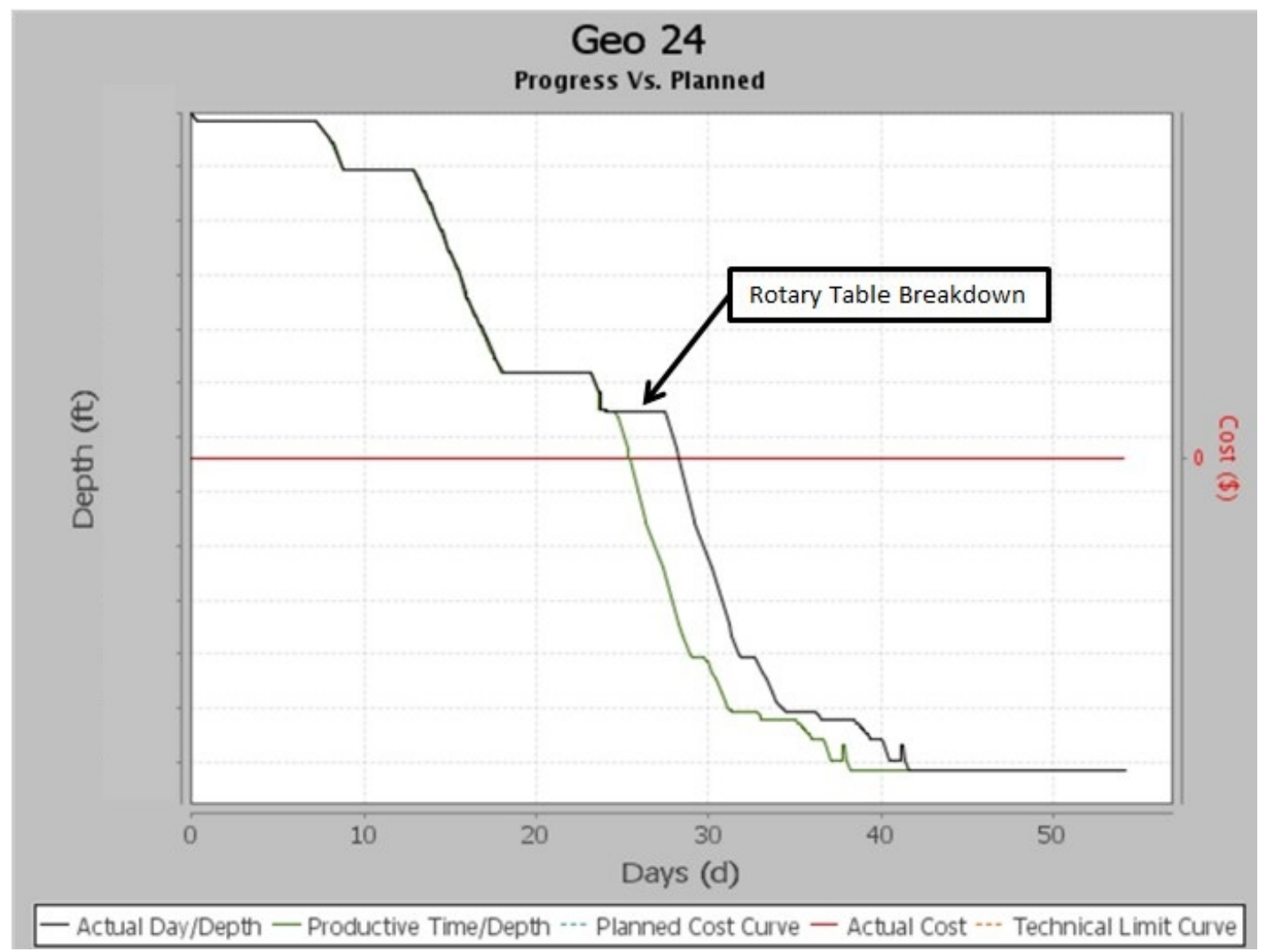

Figure 13. Days vs depth for Geothermal Well 24

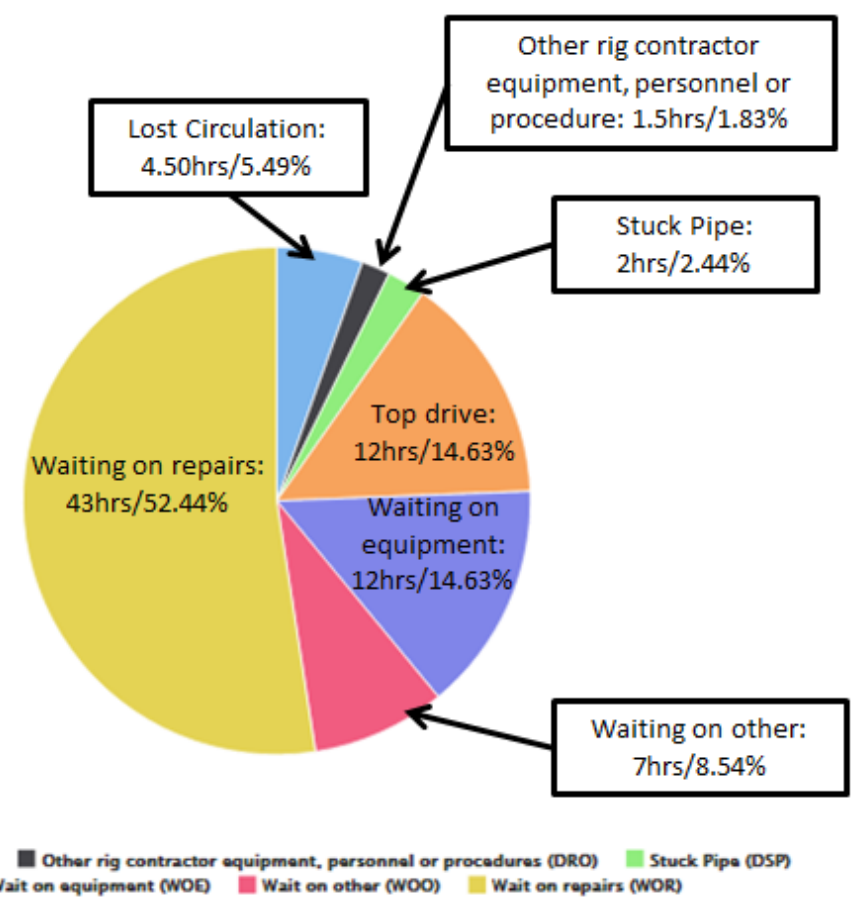

Figure 14. Root cause of NPT identified for Geothermal Well 24 


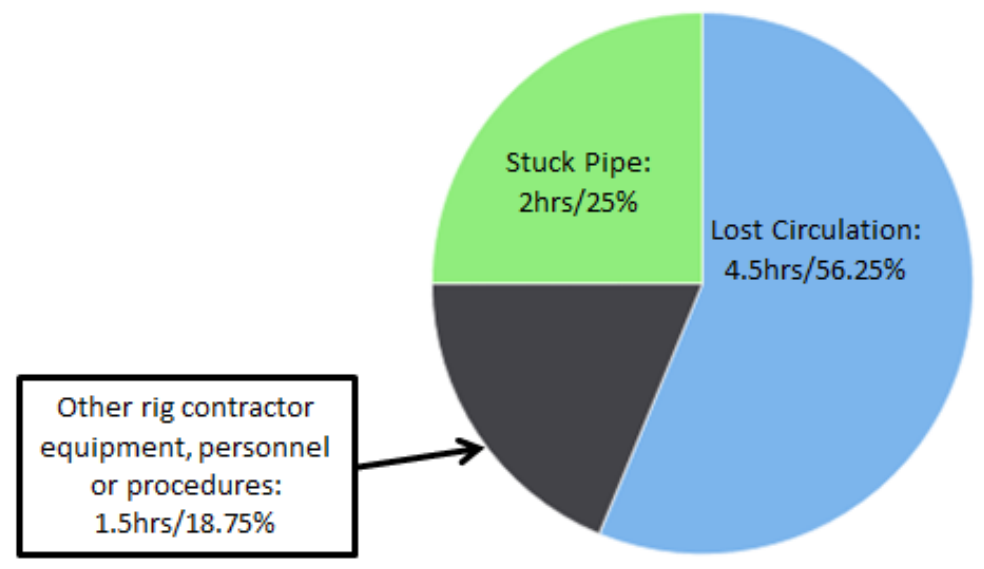

Elest Circulation (DLC) Other rig contractor equipment, personnel or procedures (DRO) II Stuck Pipe (DSP)

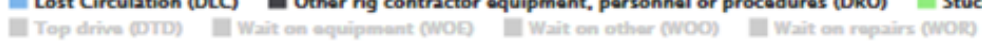

Figure 15. Human- and geological-caused NPT experienced by Geothermal Well 24

\subsection{Geo Well 25}

Geo Well 25 took 58 days to complete and had a major mechanical failure event that caused the crew to experience a large amount of NPT. Figure 16 identifies the major mechanical issue that was experienced by the crew while developing this well. Figure 17 shows the root causes of 100.75 hours of NPT while developing the well. The figure shows that mechanical issues with the pumps were by far the leading cause of NPT. The crew experienced the extremely rare event of having their main mud pump and their backup mud pump both break down. Figure 18 excludes all of the mechanical NPT that was experienced in the well, which gives an idea of the geological issues experienced; geological NPT accounted for 12 hours of the total NPT.

Figure 18 shows that this project also had issues with lost circulation; however, this is very minor compared to the mechanical issues. The event of lost circulation was more of a financial burden than it was an issue with the NPT. Figure 19 shows the cost associated with each cause of NPT: the mud pumps were the largest cost, but excluding the mechanical costs, lost circulation is the largest financial burden of the sources of NPT. 


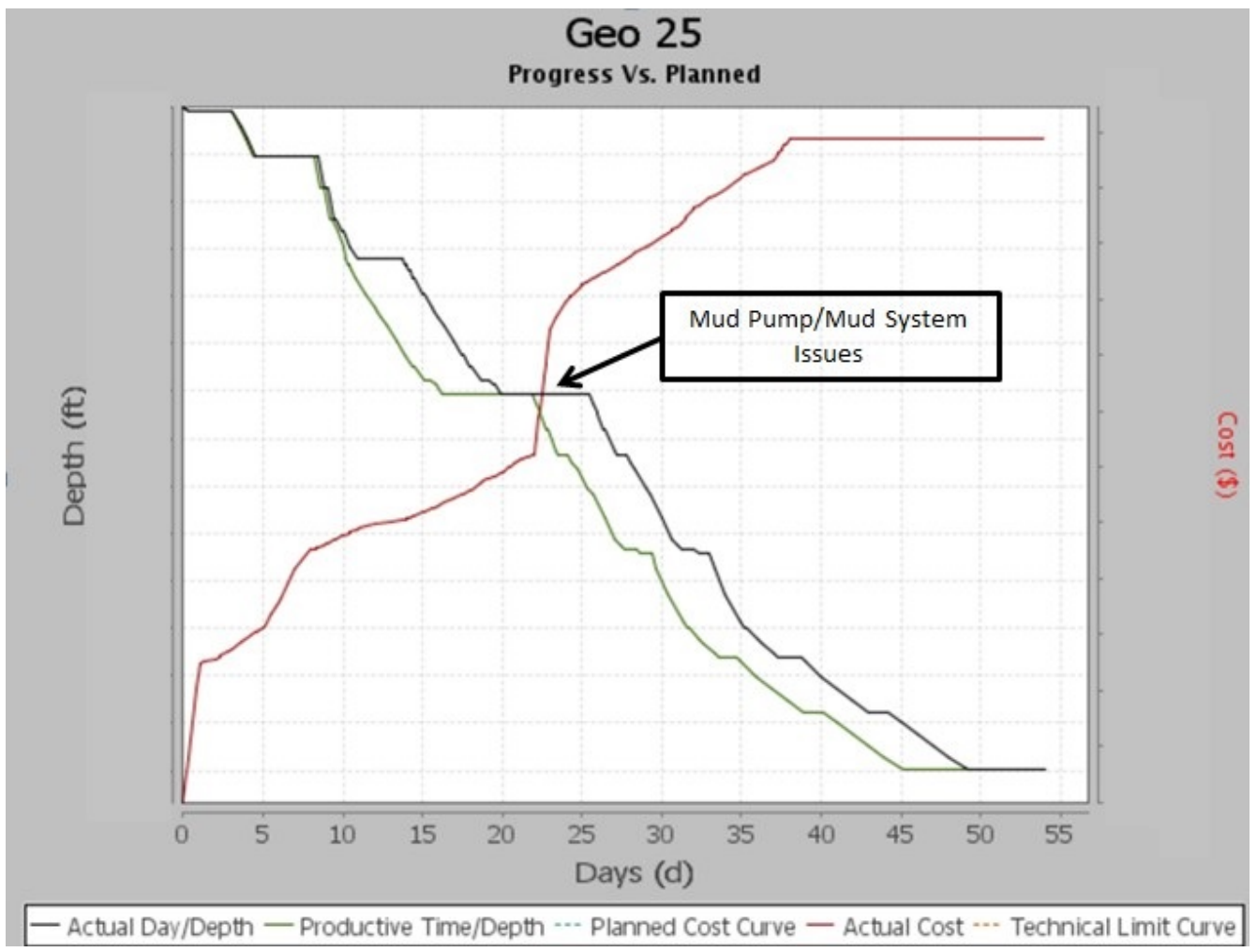

Figure 16. Days vs depth for Geothermal Well 25

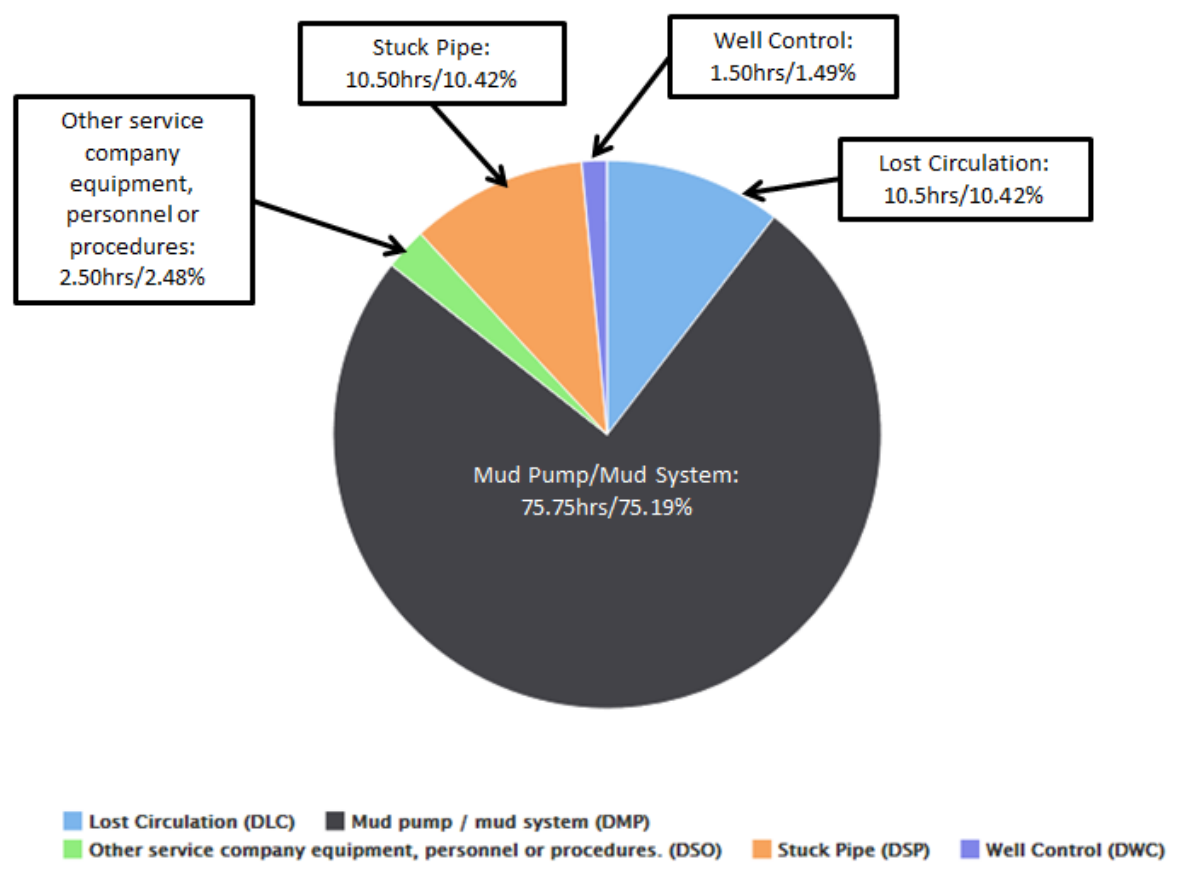

Figure 17. Root causes of NPT experienced in Geothermal Well 25 


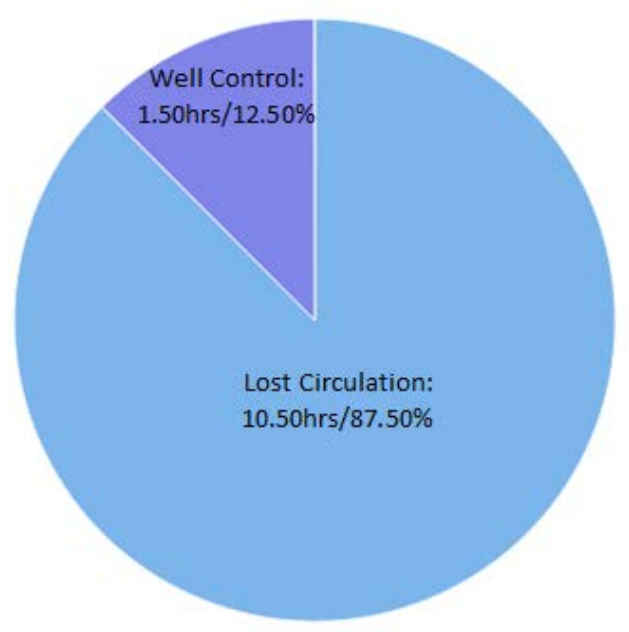

Lost Circulation (DLC) 미 Mud pump / mud system (DMP)

[1. Other service company equipment, personnel or procedures. (DSO) II Stuck Fipe (DSP) Dell Control (DWC)

Figure 18. Geothermal causes of NPT experienced by Geothermal Well 25

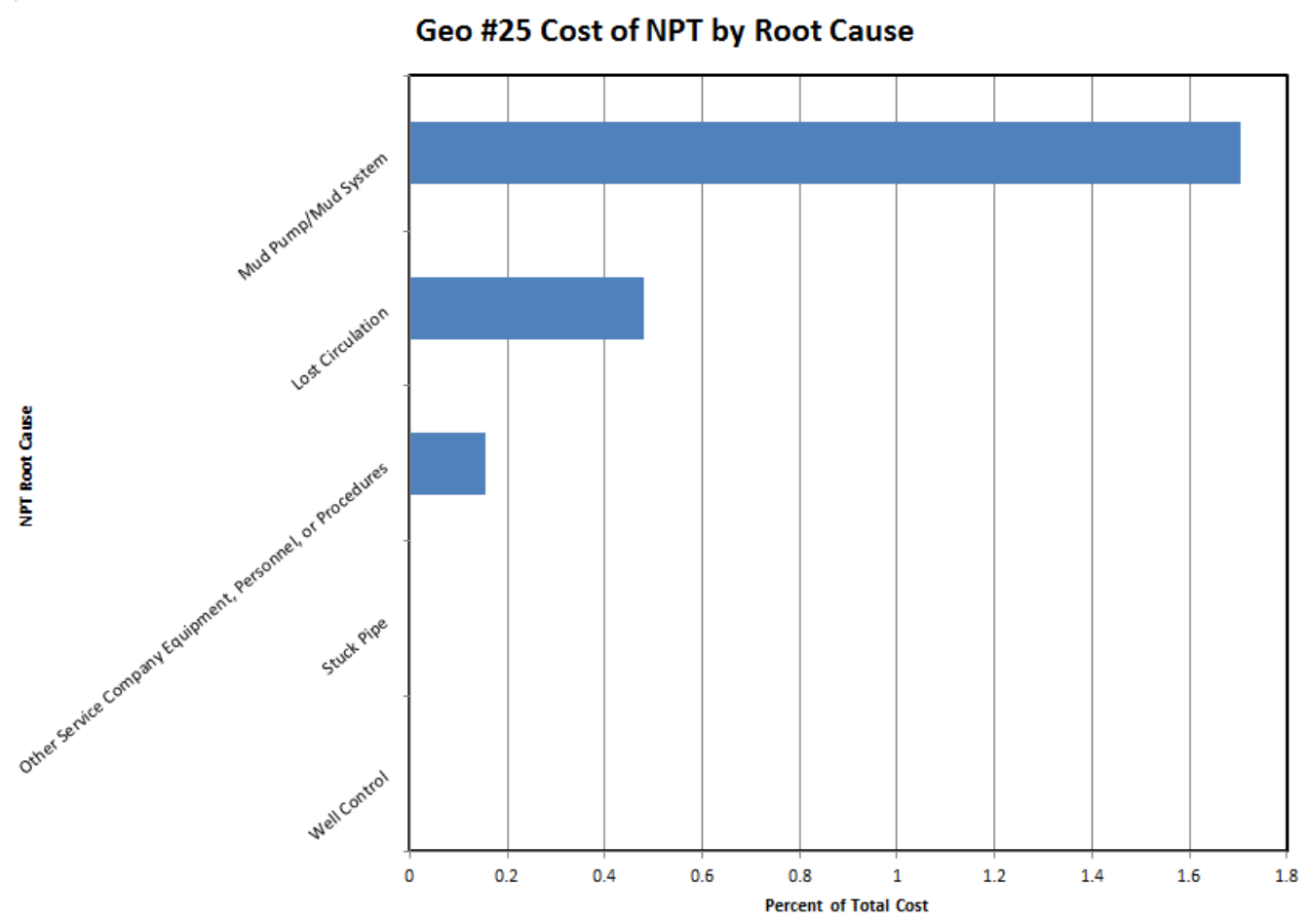

Figure 19. Cost analysis of NPT for Geothermal Well 25 


\subsection{Nonproductive Time in General}

The NPT analysis of Geothermal Wells 22 to 25 shows that some improvements can be made in drilling efficiencies.

- Mechanical Failures. The majority of issues seen in all of the wells were due to mechanical failures. These failures can be prevented by maintaining and updating equipment regularly. It is also suggested to have replacement parts to avoid long wait times on equipment; this will speed up the repair process and get crews back to drilling quicker.

- Personnel Management. There were several instances of issues with the personnel management. This is a cultural issue in the geothermal industry that is easily remedied; moreover, it highlights the cultural difference between the petroleum industry and the geothermal industry.

- Lost Circulation. Ostensibly, the geothermal industry can benefit by the advances of lost-circulation materials to mitigate the inherent lithological challenges that currently cost the geothermal industry millions.

- Drilling Rigs and Equipment. A slow oil and gas market is an opportunity for the geothermal industry to acquire adequate drilling rigs and equipment to augment drilling efficiency.

Developing proper personnel management, cutting-edge equipment, and downhole lostcirculation technology will be the future for obtaining affordable geothermal energy. 


\section{Rate of Penetration Analysis}

Mechanical specific energy (MSE) is defined as the mechanical energy needed to excavate a unit volume of rock. This mechanical energy consists of the weight needed to penetrate rock (a force over a penetration distance) and the torque needed to rotate the bit (torque being a force times a lever arm and the rotation a distance traveled). In both cases, it is a force times the distance, which is the definition of energy. In Imperial units, this is $\mathrm{ft}-\mathrm{lbf} / \mathrm{ft}^{3}$, which is equivalent to psi (with an appropriate conversion factor of $1 \mathrm{psi}=144 \mathrm{ft}-\mathrm{lbf} / \mathrm{ft}^{3}$ ).

The minimum MSE needed to remove a unit volume of rock from a borehole is a function of the rock properties - predominately its compressive strength - and is called the specific energy. If one knows the specific energy of a rock and the mechanical specific energy, the ratio of the two gives a measure of drilling efficiency (see Equation 1):

$$
M S E / S E_{\text {rock }} \geq 1
$$

A value of 1 would be perfect; but, in reality, the energy needed is on a factor of 2 to 3 times due to inefficiencies in energy application at the bit (friction). Surface measurements also have other issues that involve the fact that there is energy used along the drill string (torque and drag) and losses in the surface equipment. In addition, drilling dysfunctions (e.g., whirling, stick-slip, balling) can take enormous an amount of energy out of a system. Finally, the surface sensors have inherent limitations in accuracy, precision, and calibration.

Many parameters affect the efficient drilling operation of petroleum and - to an even greater extent - geothermal drilling. Problems can arise such as lost circulation (loss of drilling fluid to formation), bit balling (floundering downhole without efficient rates of penetration), and in-situ conditions affecting the rock itself. High temperature affects the rock being drilled in many different ways, and we will look into this in more detail in the rest of this report.

\subsection{High-Temperature Rock Properties}

Based on the team's previous work, geothermal drilling takes roughly 13 times longer than petroleum wells of equivalent depth. One of the responsible factors may be the higher geothermal gradient and "hotter" rocks found in the geothermally active systems. Three studies were researched to develop an understanding of the drillability of high-temperature rocks and their associated properties: 1) "Experimental Study on Mechanical Properties of Rocks at High Temperature," by L.Y. Zhang et al.; 2) "High-Temperature Mechanical, Physical and Thermal Properties of Granitic Rocks. A Review," by F.E. Heuze; and 3) "Drilling Mechanisms at Elevated Rock Temperatures," by M.G. Karfikas.

\subsubsection{Zhang Study}

The first study researched was by Zhang et al. and provided valuable information on the mechanical properties of marble, limestone, and sandstone. These three rock types are a good comparison for this study because of the reservoir-quality rocks seen in the petroleum industry (limestone and sandstone for comparison to geothermal) and the equivalent hardness of granite to the study using marble. Limestone, sandstone, and marble samples were elevated to $800^{\circ} \mathrm{C}$ and stress-strain curves, peak strength and strain, and elastic modulus were studied using a 
MTS810 Rock Mechanics Servo-controlled Testing System; again, these rocks were tested from room temperature to $800^{\circ} \mathrm{C}$.

The study results showed limestone to have a downward trend for peak strength and elastic modulus for temperatures below $200^{\circ} \mathrm{C}$, inferring a weaker and more elastic rock. As the temperature was further increased from $200^{\circ} \mathrm{C}$ to $600^{\circ} \mathrm{C}$, there was little change in the rock's mechanical properties. However, above $600^{\circ} \mathrm{C}$, there was a sharp decrease in the elastic modulus and peak strength of the rock. Decreasing the strength of the limestone would intuitively increase the ability to drill through it; however, with a more elastic sample, the limestone will resist penetration by the drill bit.

As with the limestone, sandstone also had a decreased peak strength and little change in elastic modulus up to $200^{\circ} \mathrm{C}$. From $200^{\circ} \mathrm{C}$ to $600^{\circ} \mathrm{C}$, however, the peak strength actually increased with little change in elastic modulus. Finally, above $600^{\circ} \mathrm{C}$, peak strength and elastic modulus drop rapidly. Peak strain was also found to decrease up to $200^{\circ} \mathrm{C}$ and increase rapidly above $200^{\circ} \mathrm{C}$.

Marble, the last sample tested, is most similar to rock found in geothermal reservoirs. This metamorphic rock has with a similar hardness to igneous rocks encountered in geothermal drilling. This sample has a fluctuating peak strength and elastic modulus up to $400^{\circ} \mathrm{C}$, whereas above this threshold, these properties decreased gradually. Peak strain decreased up to $200^{\circ} \mathrm{C}$ then increased rapidly above $200^{\circ} \mathrm{C}$.

This experiment was effective in testing samples that are readily seen or are comparable to rocks in the field. It was also effective in testing these rocks to extremely high temperatures $\left(800^{\circ} \mathrm{C}\right)$. No direct correlations were made to drillability, but it would seem that the decreasing elastic modulus of many of the samples would greatly hinder the rate of penetration.

\subsubsection{Heuze Study}

This study measured the following properties of granitic rocks: modulus, Poisson's ratio, tensile strength, compressive strength, thermal expansion, density, permeability, melting temperature, heat of fusion, specific heat, thermal conductivity, and thermal diffusivity. Some of these properties - such as melting temperature, heat of fusion, specific heat, and thermal conductivity/diffusivity - are not included in the analysis of this report because they do not readily apply to aiding geothermal field practices.

Many study figures for the relationships listed above are included in this report and will be addressed in the order of relevancy. Figure 20 shows the relationship between normalized modulus and temperature, without the effects of pressure. This graph shows a downward trend in elastic modulus for all granites tested. Figure 22 shows the same variables, but now including the effects of pressure. This is a more real-world example of what is seen in the field. This graph shows a similar decreasing modulus as temperature increases, but the slopes of the different granitic rocks vary greatly. The third figure shows the relationship between tensile strength and temperature. Tensile strength is less important when considering drillability because the rock is being put under compression; however, the tensile strength decreases as temperature increases, as expected. 


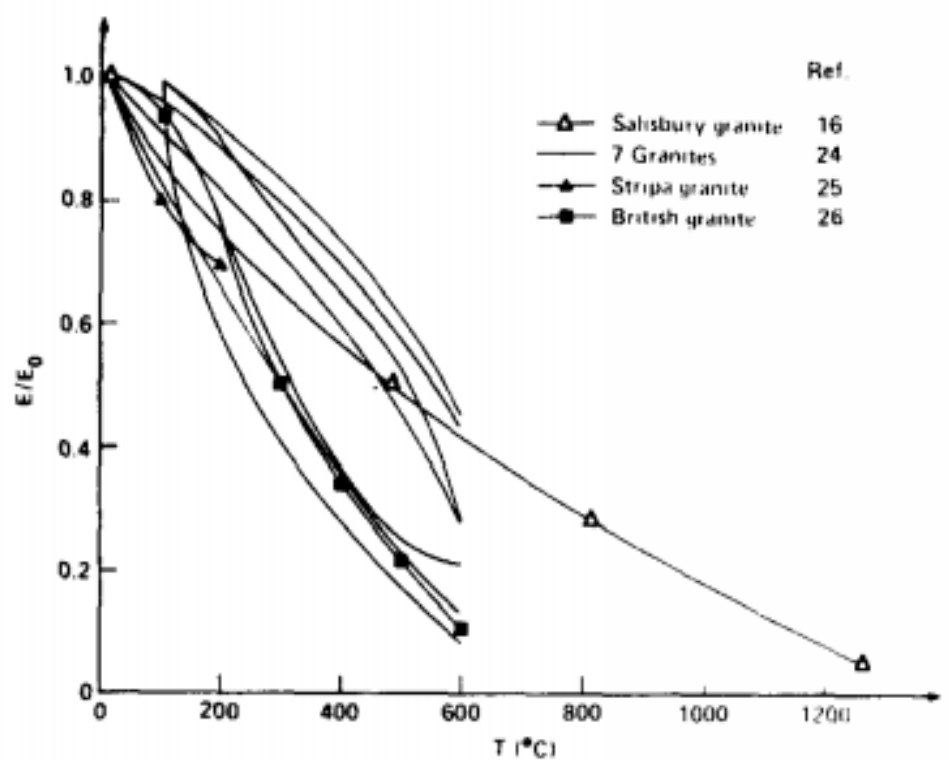

Figure 20. Granite modulus vs temperature (Heuze 1983)

Figure 21 shows the dependence of ultimate strength as a function of temperature. This was a comprehensive triaxial compression test with Westerly Granite up to a temperature of $900^{\circ} \mathrm{C}$. The compressive strength in this test was reduced by more than 1,750 $\mathrm{MPa}$ when the rock was increased from 300 to $900^{\circ} \mathrm{C}$. This test also found wet rock to be slightly stronger than its dry counterpart. Following this test, the Poisson's ratio (ratio of length contraction to width elongation) was tested for three different granites at 25 and $200^{\circ} \mathrm{C}$ as well as under two variable stress conditions of 50 and $500 \mathrm{MPa}$. These results are summarized in Table 1 . The experiment found there is little change in the Poisson's ratio for the Woodybury and Pink Llano granites under a pressure of $50 \mathrm{MPa}$ when heated from 25 to $200^{\circ} \mathrm{C}$. However, when the pressure is greater $(500 \mathrm{MPa})$ and the sample is heated, the Poisson's ratio decreases in all three of the samples. 


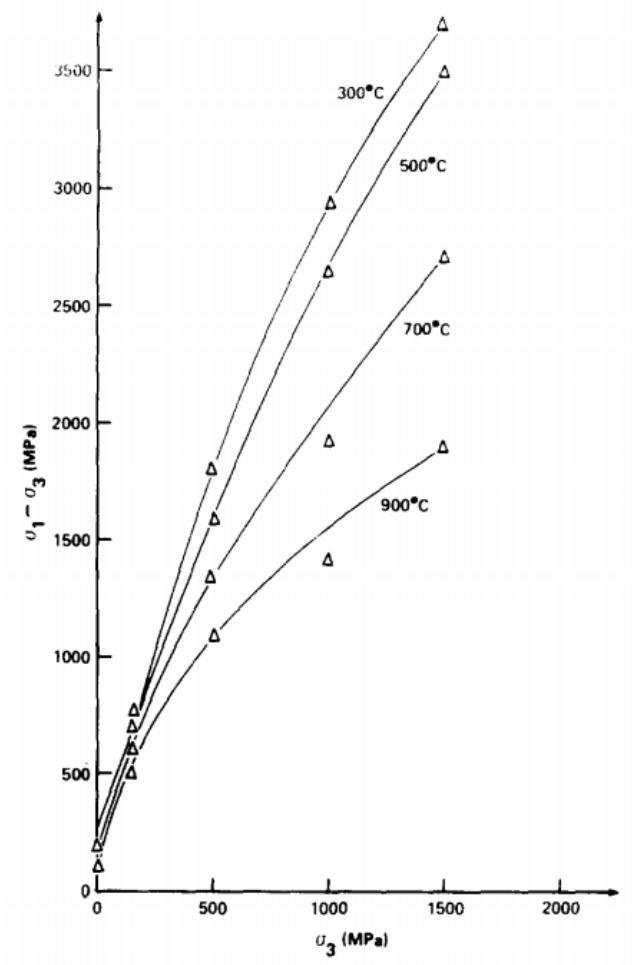

Figure 21. Granite ultimate strength vs temperature (Heuze 1983)

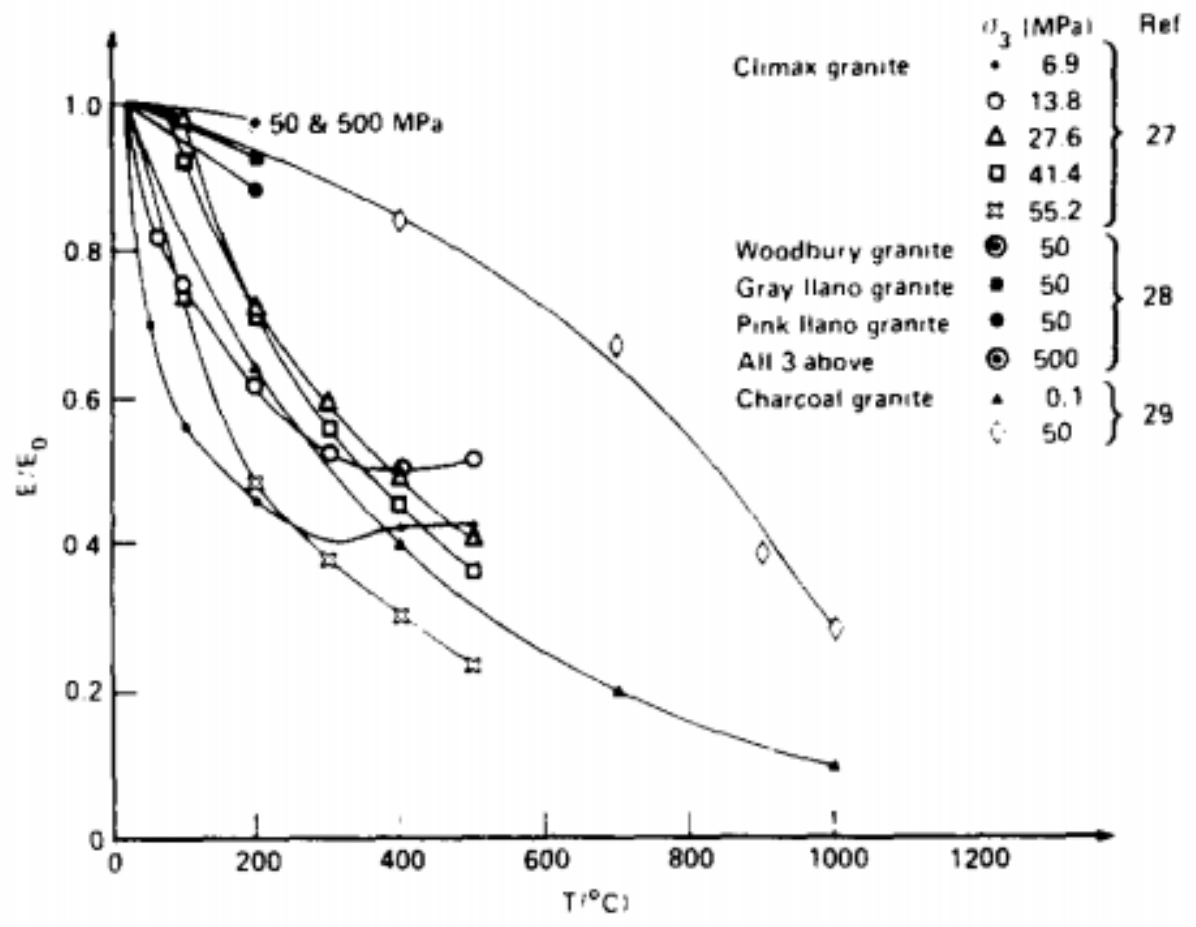

Figure 22. Granite normalized modulus vs temperature and pressure (Heuze 1983) 
Later in the study, various different granites were tested as a function of pressure and temperature. These results are synopsized in Figure 23 and are as follows: all four samples show decreasing strength trends with increasing temperature. This would infer that as temperature increases, the mechanical specific energy required to break the rock should decrease proportionally to the strength. This assumption has not been tested, but it also brings up questions associated with the increased plasticity of the rock. This increase in "gumminess" could cause problems such as bit balling and foundering, decreased rate of penetration, and finally, complications with what type of bit to use (roller cone vs polycrystalline diamond cutter).

This study comprehensively tested the relationship between different granites, temperature, and pressure, which is crucial to developing an effective drilling operation for geothermal energy. However, the next study will introduce a more applicable drilling application of hightemperature rock mechanics.

\subsubsection{Karfikas Study}

This laboratory study aimed to determine the effects of elevated temperature on drilling rates of penetration and how they are associated with changes in the mechanical properties of the rock as the rock is heated. Samples were, "Drilling tests...performed on Indiana limestone with air as the drilling fluid." In summary, multiple tests showed the following: "Rocks subject to elevated temperatures are microfractured and drill more slowly than rocks that are intact. Nevertheless, the magnitude of the temperature (at least in the range typically encountered in geothermal drilling, 177 to $316^{\circ} \mathrm{C}$ ) has no significant effect on drilling penetration rates." However, note that limestone was used in this study, which is not a typical geothermal reservoir rock. Nevertheless, these results are still likely to aid in the effectiveness of geothermal drilling.

In agreement of the other studies, rock strength is reduced dramatically as temperature of the rock is increased. The study noted that the decrease in strength is largely due to the microcracks found in the heated samples. This is typical in geothermal systems. The vast majority of target reservoirs are highly fractured igneous formations. The study also related the failure mechanism under high temperature and high pressure (HTHP) for geothermal drilling to be fracture failure (Karfikas). Another similarity found between this study and the previous experiments was a decreasing Young's Modulus as temperature increases.

The direct application of rock drillability was addressed by this study. The drillability of rock depends on the interaction between the bit and rock. This interaction also depends on variables such as rock strength, rock ductility, weight on bit, and rotary speed. The two properties addressed directly in this experiment were rock strength and ductility, and the results found for any given rock type are that the following factors decrease strength and increase ductility:

- Increase in temperature

- Increase in porosity

- Decrease in strain rate

- Pressure of fractures and/or other planes of mechanical discontinuity.

These findings directly apply to geothermal drilling, which is also examined in the study. High penetration rates were achieved in the lab in which air was used as a drilling fluid. 


\subsection{Observations}

Many analytical results of the three studies are the same. At elevated temperatures, the mechanics of reservoir rocks are altered in different ways. Typically, there is a decrease in Poisson's ratio, Young's modulus, as well as ultimate strength of the rock. Due to these changes in mechanical properties, one could assume two scenarios: 1) ROP would be increased due to the decrease in strength of the rock at higher temperatures. The lower strength of the rock would require less mechanical specific energy to chip and higher drillability is achieved. 2) ROP would decrease due to increased ductility (decreased Young's modulus) at higher temperatures. This increase in ductility would increase the resiliency of the rock and make chipping away at the rock with the bit more difficult.

It is unknown at this point which scenario is occurring; however, it is expected that both are occurring while drilling at elevated temperatures in geothermal applications. The dominant scenario is assumed to be the latter because all observed field data suggest drilling for geothermal resources takes significantly longer than the petroleum counterpart.

More studies are needed on mechanical specific energy models of geothermal wells, and a more accurate final conclusion can then be made as to whether or not geothermal wells are more difficult to drill due to the rock properties and temperatures. However, it is known that because geothermal resources are found in granitic rocks, the increase in drilling time is not solely due to the change in lithological formations.

More detailed observations on the results of the three studies are contained in the following subsections.

\subsubsection{Experimental Study on Mechanical Properties of Rocks at High Temperature}

Mechanical properties of marble, limestone, and sandstone, and stress-strain curve, peak strength/strain, and elastic modulus were studied using an MTS810 Rock Mechanics Servocontrolled Testing System from room temperature to $800^{\circ} \mathrm{C}$.

Results include the following:

- Marble: Peak strength and elastic modulus fluctuate up to $400^{\circ} \mathrm{C}$ and decrease gradually over $400^{\circ} \mathrm{C}$. Peak strain decreases up to $200^{\circ} \mathrm{C}$ and increases rapidly above $200^{\circ} \mathrm{C}$.

- Limestone: With increasing temperature, the peak strength and elastic modulus show a downward trend up to $200^{\circ} \mathrm{C}$, have little change from $200^{\circ} \mathrm{C}$ to $600^{\circ} \mathrm{C}$, and decrease sharply above $600^{\circ} \mathrm{C}$. Peak strain shows little change up to $600^{\circ} \mathrm{C}$ and increases rapidly above $600^{\circ} \mathrm{C}$.

- Sandstone: Peak strength shows a downward trend, with only slight change in elastic modulus up to $200^{\circ} \mathrm{C}$; from $200^{\circ} \mathrm{C}$ to $600^{\circ} \mathrm{C}$, peak strength increases with little change for elastic modulus. Peak strength and elastic modulus drop rapidly above $600^{\circ} \mathrm{C}$. Peak strain decreases up to $200^{\circ} \mathrm{C}$ and increases rapidly above $200^{\circ} \mathrm{C}$. 


\subsubsection{Granite High-Temperature Mechanical, Physical, and Thermal Properties}

Testing was done on modulus, Poisson's ratio, tensile strength, compressive strength, viscosity, thermal expansion, density, permeability, melting temperature, heat of fusion, specific heat, thermal conductivity and thermal diffusivity. Experiments found that wet rock is slightly stronger than the dry counterpart, which is "contrary to the notion of stress corrosion cracking of rock."

Table 2 shows a moderate disparity in Poisson's ratio with an increase in temperature from $25^{\circ} \mathrm{C}$ to $200^{\circ} \mathrm{C}$. Figure 23 shows the ultimate strength of different types of granites as temperature increases. All four types of granite shown in the figure display decreasing strength with an increase in temperature. This is interesting and raises several questions: as temperature increases, should MSE decrease? What about plasticity effects? Young's Modulus decreases as well (i.e., the rock becomes more plastic/less stiff), bringing up questions such as:

- Increased bit balling?

- Decreased ROP?

- MSE complications?

- Bad for roller cones? Bad for PDC? (Cannot crush or grind rock?)

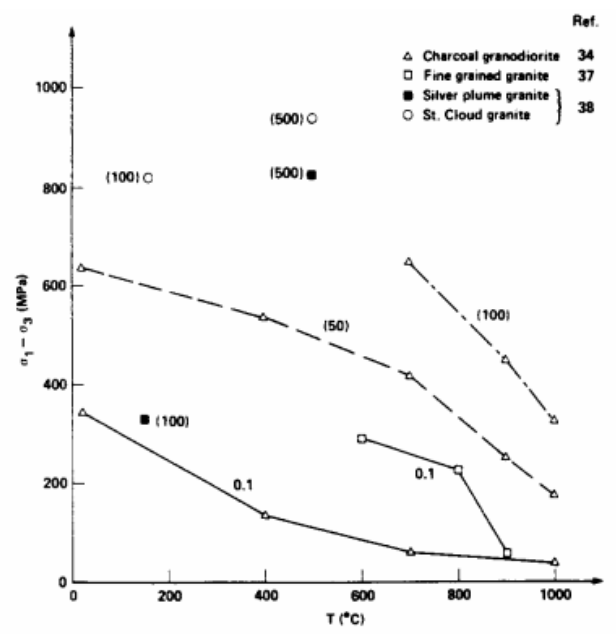

Figure 23. Granite ultimate strength vs temperature and pressures (Heuze 1983)

\subsubsection{Drilling Mechanism at Elevated Rock Temperatures}

Laboratory study was conducted to determine the effects of elevated temperatures on drilling penetration rates and how these penetration rates correlate with changes in the mechanical properties of rock due to heating. Drilling tests were performed on Indiana limestone with air as the drilling fluid. These tests determined that rocks subjected to elevated temperatures are microfractured and drill more slowly than do intact rocks. Nevertheless, the magnitude of the temperature (at least in the range typically encountered in geothermal drilling, $177^{\circ} \mathrm{C}$ to $316^{\circ} \mathrm{C}$ ) has no significant effect on drilling penetration rates.

The strength of rock is dramatically reduced with an increase in temperature. This decrease is due to thermally induced microcracks. 
- The failure mechanisms under the pressure and temperature regimes of geothermal drilling are fracture, grain-boundary slip, and intergranular gliding.

- Closmann and Bradley found that the tensile and compressive strength of shale decreased and that there was a decrease in Young's modulus as temperature increased.

- In their studies on the effects of heat on the mechanical properties of igneous rocks, Barbish, Johnson, Handin, Friedman, and Higgs [3-6] have also demonstrated that these thermally induced microcracks decreased the elastic moduli $[11,12]$, decreased the tensile and compressive strengths, and increased the porosity and permeability of the rock.

Table 2. Poisson's Ratio (Heuze 1983)

\begin{tabular}{|l|l|l|l|l|}
\hline & \multicolumn{2}{c|}{$\mathbf{T}=\mathbf{2 5}^{\circ} \mathbf{C}$} & \multicolumn{2}{c|}{$\mathbf{T}=\mathbf{2 0 0}^{\circ} \mathbf{C}$} \\
\hline Rock Type & $\mathrm{P}=50 \mathrm{Mpa}$ & $\mathrm{P}=500 \mathrm{Mpa}$ & $\mathrm{P}=50 \mathrm{Mpa}$ & $\mathrm{P}=500 \mathrm{Mpa}$ \\
\hline Woodbury Granite & 0.257 & 0.242 & 0.26 & 0.237 \\
\hline Pink Llano Granite & 0.306 & 0.317 & 0.302 & 0.312 \\
\hline Gray Llano Granite & 0.225 & 0.253 & 0.236 & 0.24 \\
\hline
\end{tabular}




\section{Drilling Data}

The SURGE team was given access to drilling data from four geothermal wells drilled in the western United States. In this section, we discuss the given data and data cleanup processes. The data given for Geothermal Wells 23, 24, and 25 were similar, so these datasets are discussed together. Geothermal Well 22 had a different set of data associated with it, and it will be discussed separately because the additional data created additional data-processing steps.

\subsection{Available Data for Geothermal Wells 23, 24, and 25}

Table 3 summaries data for the following three wells. The data package given for these wells is the industry standard. The resolution of one data point per foot for the drilling parameters allowed us to evaluate fundamental drilling efficiency indicators. For example, we used flow in, flow out, temperature in, and temperature out to evaluate the fluid losses and gains during drilling. Understanding fluid flow in the well and surrounding formations during drilling allowed the team to determine which formations were at a high risk of loss circulation during drilling. Identifying these so-called thief zones before the zones are encountered will allow drillers to more effectively and efficiently solve lost-circulation issues in this field. The team also had access to the mud-log data for these wells. The main parameter taken from the mud logs was the lithology determined by the mud logger. This lithology was accessed on a 1 data point per 10 feet measured-depth basis. The pairing of the mud-log data with drilling data allowed for more complex conclusions than if the two datasets were analyzed separately. By pairing the mud-log and lithology data with the drilling data, the team was able to determine what caused drilling issues and inefficiencies. In some cases, inefficiencies were caused by lithology, whereas other issues stemmed from the actual drilling process. Overall, the data allowed for basic evaluations of the efficiencies of these wells.

\subsection{Data Clean-Up and Issues for Geothermal Wells 23, 24, and 25}

The data were presented in a very usable 1 data point per foot format, so little data clean-up was necessary to begin analyzing the data. However, a couple issues in the data made it difficult for the team to draw concrete conclusions. To begin, the data were presented in measured depth, so true vertical depth had to be calculated. This is common practice in both oil and gas and geothermal drilling. The true vertical depth was calculated using the measured depth, azimuth, and inclination of the well. The azimuth and inclination were taken from the numerous surveys run during the drilling of the wells. The true vertical depth is important when correlating data across wells or developing field-wide models. Using true vertical depth, a complete geological model can be built so that geology encountered while drilling future wells can be predicted accurately.

The data clean-up was a straight-forward process, but a couple measurement errors or collection issues occurred that made it difficult to draw concrete conclusions. For Geothermal Well 23, the rotary-speed indicator malfunctioned during the majority of the time spent drilling. The lack of trustworthy rotary-speed data made it difficult to evaluate many basic key performance indicators (KPIs). The flow-in meter for this well was not calibrated, which made it difficult to understand the fluid gains and losses during drilling. 


\begin{tabular}{|l|l|l|}
\hline \multicolumn{2}{|c|}{ Table 3. Available Drilling and Well Data for Geothermal Wells 23, 24, and 25 } \\
\hline Parameter & Unit & $\begin{array}{l}\text { Sampling Rate } \\
\text { (points/ distance) }\end{array}$ \\
\hline Measured Depth & $\mathrm{ft}$ & $1 / \mathrm{ft}$ \\
\hline Block Height & $\mathrm{ft}$ & $1 / \mathrm{ft}$ \\
\hline Bit Depth & $\mathrm{ft}$ & $1 / \mathrm{ft}$ \\
\hline Rate of Penetration (1 ft) & $\mathrm{ft} / \mathrm{h}$ & $1 / \mathrm{ft}$ \\
\hline Rate of Penetration (1 min) & $\mathrm{ft} / \mathrm{h}$ & $1 / \mathrm{ft}$ \\
\hline Hook Load & $\mathrm{klbf}$ & $1 / \mathrm{ft}$ \\
\hline Weight on Bit (WOB) & $\mathrm{klbf}$ & $1 / \mathrm{ft}$ \\
\hline Rotary Speed & rev/min & $1 / \mathrm{ft}$ \\
\hline Pump Pressure & $\mathrm{psi}$ & $1 / \mathrm{ft}$ \\
\hline Rotary Amps & amps & $1 / \mathrm{ft}$ \\
\hline Surface Torque & $\mathrm{psi}$ & $1 / \mathrm{ft}$ \\
\hline Pump 1 Rate & strokes/min & $1 / \mathrm{ft}$ \\
\hline Pump 2 Rate & strokes/min & $1 / \mathrm{ft}$ \\
\hline Pump 3 Rate & strokes/min & $1 / \mathrm{ft}$ \\
\hline Total Pit Volume & bbls & $1 / \mathrm{ft}$ \\
\hline Flow In & gal/min & $1 / \mathrm{ft}$ \\
\hline Flow Out & $\%$ of flow in & $1 / \mathrm{ft}$ \\
\hline Well-Head Pressure & $\mathrm{psi}$ & $1 / \mathrm{ft}$ \\
\hline Temperature In & ${ }^{\circ} \mathrm{F}$ & $1 / \mathrm{ft}$ \\
\hline Temperature Out & degF & $1 / \mathrm{ft}$ \\
\hline Lithology from Mud Logs & $\%$ & $1 / 10 \mathrm{ft}$ \\
\hline
\end{tabular}

For Geothermal Well 24, the flow-in meter and rotary-speed indicator functioned properly, but the torque indicator malfunctioned during drilling. (Torque is also a fundamental parameter for determining KPIs.) So, torque had to be calculated using a correlation of rotary speed, WOB, and ROP.

Geothermal Well 25 was very similar to Geothermal Well 24. Most data were reliable except for the torque data. Similar assumptions from Geothermal Well 24 also were made for Geothermal Well 22. Again, these torque assumptions greatly lower the team's confidence in any conclusions from the data.

\subsection{Available Data for Geothermal Well 22}

Table 4 summarizes the data given to the team for Geothermal Well 22. These data were much more extensive than data from the other three geothermal wells discussed here. Geothermal Well 22 data included the same fundamental drilling parameters as the other geothermal wells, but 
with much greater resolution - a rate of 1 data point per second. This means that Geothermal Well 22 had more data points than the other three wells combined. However, this treasure trove of data also needed to be manipulated so it could be presented in a more usable format - to be discussed in detail in the next section. The mud-log data were similar to the other wells discussed, with the lithology data taken at 1 data point per 10 feet drilled. The mud-log data and drilling parameter data were evaluated together to help draw the most accurate conclusions.

\subsection{Data Clean-Up and Issues for Geothermal Well 22}

The main goal of the data clean-up process for this well was to manipulate the data so that they could be presented in a more user-friendly manner. This was done by creating a depth plot of the data from the time data, which allowed the team to identify issues on the depth plot and then use the time data to "zoom-in" and take a second-by-second look at the problem area.

To convert the time data into a depth plot, the team assumed that the first incidence of a certain depth was during drilling. The team wanted to evaluate the data during drilling and not tripping, so the first occurrence of each depth was used in the depth plot. We assumed that all occurrences of this depth after the first were during tripping or other operations. The "remove duplicates" function was used in Excel to remove every occurrence of depth except the first occurrence. Below is the step-by-step processes used.

1. Start with the single-day data and sort so that the data are in chronological order, with the beginning of the day at the top and end of day at the bottom of the spreadsheet.

2. We used the "remove duplicates" function in Excel. Because the data are in chronological order, only the first occurrence of a given depth will remain.

3. Once the data from each day have been cleaned, we combined the daily data into one master spreadsheet and sorted the data chronologically — again, the oldest data were on top.

4. Again, we used the "remove duplicates" function in Excel to remove all occurrences except the first.

5. At this point, the team had the data in a depth and time format similar to that in Geothermal Wells 23, 24, and 25. This allowed the team to identify areas of interest on the depth plot and then analyze the data at a 1-second sample rate. The data for Geothermal Well 22 also had the same quality issues as in Geothermal Wells 23, 24, and 25.

The torque indicator for this well was also malfunctioning during drilling, which forced the team to use the same correlation used for Geothermal Wells 23 and 24 to calculate torque values for Geothermal Well 22. The flow-in and flow-out meters were also malfunctioning on this well, thus making it difficult for the team to evaluate fluid-flow patterns during drilling. Instead, the team used temperature-in and temperature-out data to try to identify formations with lostcirculation issues, which is less accurate than using a combination of flow and temperature. Even though the data for Geothermal Well 22 required an extensive data manipulation process, the second-by-second data allowed for complex in-depth analysis on the well. 


\section{Drilling-Bit Observations and Recommendations}

Drill-bit selection is critical for any drilling process, no matter if the well is an oil and gas, water, or geothermal well. The team evaluated the efficiency of the bits using KPIs, including average ROP, length of bit run, and the cost per foot of drilling with the bit. The bit records for Geothermal Well 22 were the most detailed records the team had access to, so efforts focused on evaluating the bit selection of this well. It was also a good candidate for bit evaluation because the operator experimented with a PDC bit. Most geothermal operators use tricone bits in their operations. The test run using the PDC bit was heavily evaluated by the team to determine which bit type performed better. Geothermal Well 22 was drilled in three different sections: the surfacecasing section, intermediate-casing section, and the final production section. The one PDC bit was run as part of the production section. 


\begin{tabular}{|c|c|c|}
\hline Parameter & Unit & $\begin{array}{l}\text { Sampling Rate } \\
\text { (point / distance) }\end{array}$ \\
\hline Measured Depth (MD) & $\mathrm{ft}$ & $1 / \mathrm{s}$ \\
\hline Block Height & $\mathrm{ft}$ & $1 / \mathrm{s}$ \\
\hline Bit Depth & $\mathrm{ft}$ & $1 / \mathrm{s}$ \\
\hline Rate of Penetration per Foot Drilled (ROP 1-ft) & $\mathrm{ft} / \mathrm{h}$ & $1 / \mathrm{s}$ \\
\hline Rate of Penetration per Minute Drilled (ROP 1-min) & $\mathrm{ft} / \mathrm{h}$ & $1 / s$ \\
\hline Hook Load & klbf & $1 / s$ \\
\hline Weight on Bit (WOB) & klbf & $1 / s$ \\
\hline Pump Pressure & psi & $1 / s$ \\
\hline Rotary Amps & amps & $1 / \mathrm{s}$ \\
\hline Bit Speed & $\mathrm{rev} / \mathrm{min}$ & $1 / \mathrm{s}$ \\
\hline Rotary Speed & $\mathrm{rev} / \mathrm{min}$ & $1 / s$ \\
\hline Pump 1 Rate & strokes/min & $1 / \mathrm{s}$ \\
\hline Pump 2 Rate & strokes/min & $1 / s$ \\
\hline Pump 1 Stroke Counter & strokes & $1 / s$ \\
\hline Pump 2 Stroke Counter & strokes & $1 / s$ \\
\hline Pit Total & bbls & $1 / s$ \\
\hline Pit Gain/Loss & gals & $1 / s$ \\
\hline Flow In & $\mathrm{gal} / \mathrm{min}$ & $1 / s$ \\
\hline Flow Out & $\mathrm{gal} / \mathrm{min}$ & $1 / s$ \\
\hline Vent Pressure & psi & $1 / s$ \\
\hline Well-Head Pressure & psi & $1 / s$ \\
\hline Temperature In & ${ }^{\circ} \mathrm{F}$ & $1 / s$ \\
\hline Temperature Out & ${ }^{\circ} \mathrm{F}$ & $1 / \mathrm{s}$ \\
\hline Vent Temperature & ${ }^{\circ} \mathrm{F}$ & $1 / s$ \\
\hline $\mathrm{H}_{2} \mathrm{~S}$ Floor & ppm & $1 / s$ \\
\hline $\mathrm{H}_{2} \mathrm{~S}$ Cellar & $\mathrm{ppm}$ & $1 / \mathrm{s}$ \\
\hline $\mathrm{H}_{2} \mathrm{~S}$ Pits & ppm & $1 / \mathrm{s}$ \\
\hline Pit Levels & bbls & $1 / \mathrm{s}$ \\
\hline Bit Coefficient & unitless & $1 / \mathrm{s}$ \\
\hline Bit Diameter & in & $1 / \mathrm{s}$ \\
\hline Bit Area & $\mathrm{in}^{2}$ & $1 / \mathrm{s}$ \\
\hline Lithology from Mud Logs & $\%$ & $1 / 10 \mathrm{ft}$ \\
\hline
\end{tabular}




\subsection{International Association of Drilling Contractors Dull Grading}

The Dull grading system, developed by the International Association of Drilling Contractors (IADC), is the main system used in all drilling industries to evaluate the condition of bits when they are pulled. The Dull grading for Geothermal Well 22 is shown in Table 5. The cutter grade is assessed on a linear scale from 0 to 8 -with 8 being total loss of tooth height and 0 being no loss of tooth height. The left number is for the inner rows and the right number is for the outer rows. The Dull characterization describes any special dulling seen in the bit—again, with the inner rows on the left and outer-row characteristics on the right. The bits in this well include dulling characteristics such as: NO — no dull characteristics; FC — flat crested wear; BT — broken teeth; WT—worn teeth; LT — lost teeth; and SD—shirttail damage. The Wear column describes the location of the wear pattern: A-all rows; $\mathrm{G}$ - gauge row; $\mathrm{M}$-middle row; and $\mathrm{N}$-nose row. The Bearings column describes the condition of the bearings: E-seals effective; F-seals failed; and X-not applicable. The Gauge column measures if the gauge is still true or has changed. Typically, it is $1 / 16$ inch or $1 / 32$ inch; however, the records on this well are not consistent.

\begin{tabular}{|l|l|l|l|l|l|l|}
\hline \multicolumn{7}{|c|}{ Table 5. Bit Grades for Geothermal Well 22 } \\
\hline $\begin{array}{l}\text { Bit } \\
\text { Number }\end{array}$ & $\begin{array}{l}\text { Cutter } \\
\text { Grade }\end{array}$ & Dull & Wear & Bearings & Gauge & Pull Reason \\
\hline 1 & $8 / 8$ & NO/NO & A & E & 10 & Casing Depth Reached \\
\hline 2 & $6 / 4$ & FC/NO & M & E & 0 & Formation Change \\
\hline 3 & $2 / 2$ & BT/NO & M & E & 0.625 & Casing Depth Reached \\
\hline 4 & $3 / 6$ & BT/NO & S & E & 0 & BHA Change \\
\hline 5 & $5 / 5$ & WT/NO & A & E & 1 & Penetration Rate \\
\hline 6 & $5 / 8$ & LT/SD & S & E & 8 & Penetration Rate \\
\hline 7 & $4 / 4$ & BT/SD & A & E & 0.0625 & Penetration Rate \\
\hline 8 & $4 / 4$ & WT/SD & A & E & 0.0625 & Downhole Tool Failure \\
\hline 9 & $4 / 4$ & WT/BT & A & E & 0.0625 & Hours on Bit \\
\hline 10 & $3 / 6$ & BT/WT & G & X & 0 & BHA Change \\
\hline 11 & $2 / 2$ & WT/NO & A & E & 0 & Hole Problems \\
\hline
\end{tabular}

\subsection{Analysis Completed in Spotfire}

Spotfire was used for detailed data-driven analytics of bit performance for the example Geothermal Well. Spotfire is an advanced analytics and data visualization software developed by TIBCO software. TIBCO provided free academic licenses to allow for the data-driven analytics presented here. Spotfire can sync data with any Excel or database file, and if the data file is updated, the data in Spotfire will update, as well. The data pre-processing necessary before syncing the data was limited. The most important process was to assign a bit number, bit type, and section number to each data point so that data could be sorted accordingly. To sort data by 
any other category, each data point must be assigned an indicator for that category. The spreadsheet must also contain only a one-line header and the units should be included in that header to avoid confusion. Once formatted, the Excel spreadsheet can be linked to a Spotfire project.

\subsection{Power at the Bit}

The bits used in Geothermal Well 22 were evaluated using a method developed by Pessier, Wallace, and Oueslati of Baker Hughes. Their findings and methods are presented in detail in IADC/SPE 151389. The methods are used to calculate the horsepower used by the bit, which helps to evaluate the amount of rig power that actually reaches the bit. Power that does not reach the bit is lost due to friction and vibrations. Little power reaching the bit indicates drilling inefficiencies. Tricone bits are limited in how much bit power can be applied to the formation because the ability of the roller cones to rotate freely limits the amount of horsepower that can be applied downhole. On the other hand, PDC bits have no bit horsepower limit because of the fixed nature of the cutters. The horsepower of the bits can continue to be increased on a fixed cutter bit until the cutters physically break. Figure 24 shows the amount of horsepower for each drilling data point during the drilling of the production section of Geothermal Well 22. Every bit in this section is a roller-cone-style bit except for bit number 10, shown in orange in the figure. The relationship between ROP and MSE shows a very definitive trend in this figure. In general, as MSE increases, ROP will decrease, with the two reasons for this trend being formation strength and drilling inefficiencies. As rock strength increases, MSE will also increase because it takes more energy per unit volume to drill through a stronger formation. MSE will also increase with increasing drilling inefficiencies because more energy will be needed to make up for the energy lost by inefficiencies. 


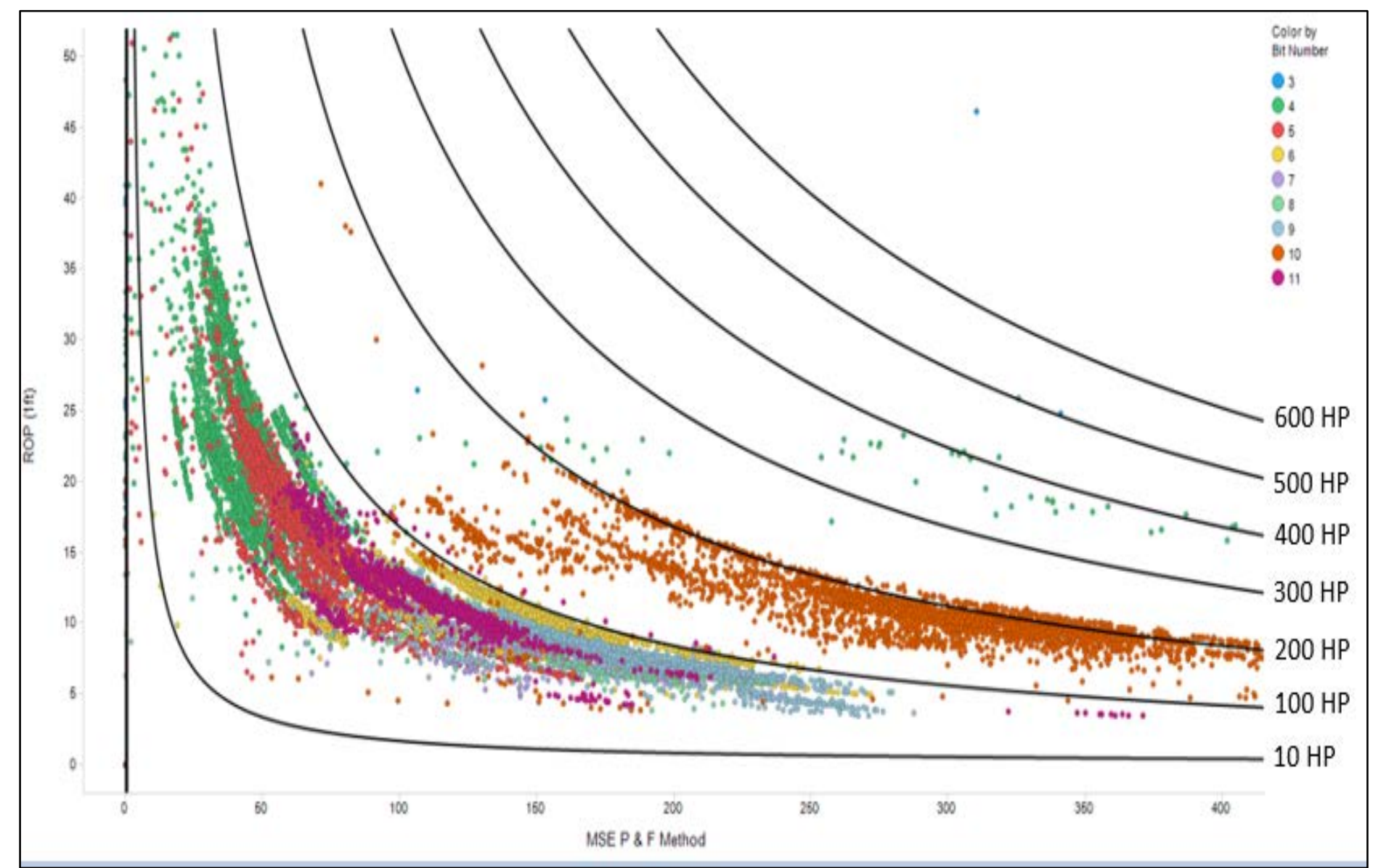

Figure 24. Bit horsepower in the production section of Geothermal Well 22 


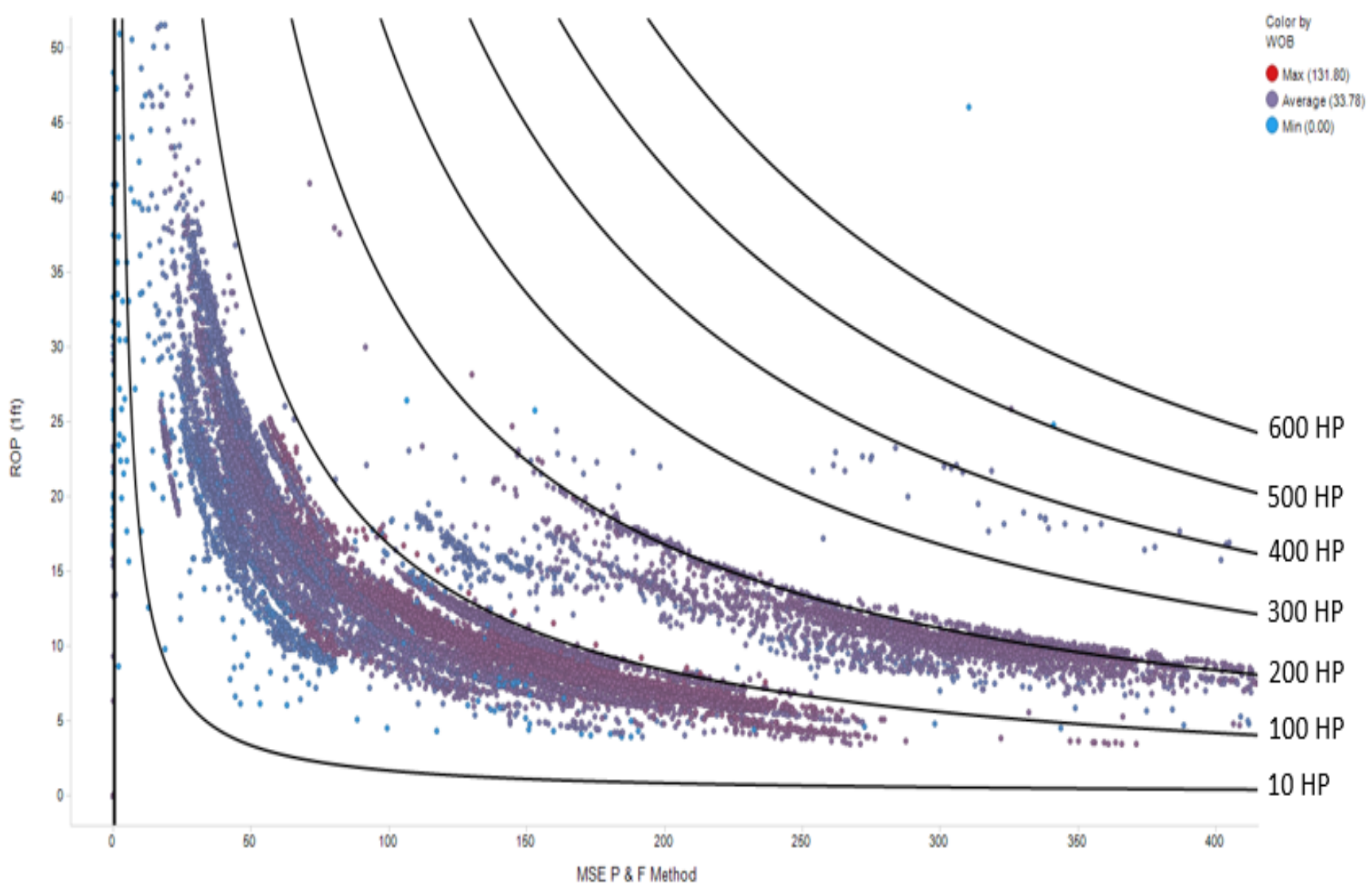

Figure 25. The effects of WOB on bit horsepower 


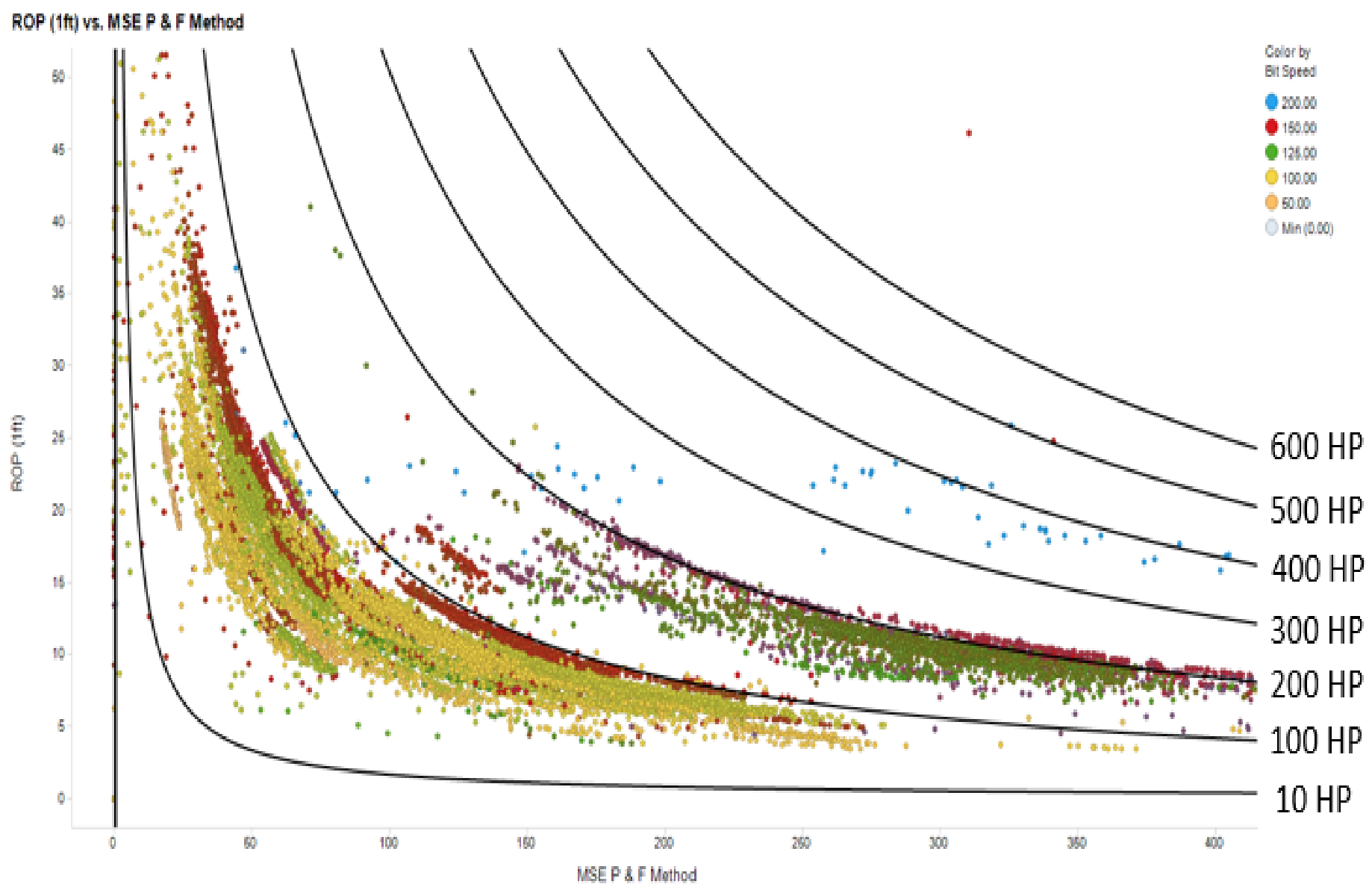

Figure 26. The effects of rotary speed on bit horsepower 
Figure 25 and Figure 26 present the bit horsepower data with an overlay of the WOB and RPM, respectively. Figure 25 illustrates that horsepower at the bit will increase with increasing WOB, and Figure 26 illustrates that horsepower at the bit will increase with increasing RPM.

\subsection{Rate of Penetration Evaluation}

In almost all drilling operations, the rig cost is assessed under a daywork drilling contract. This means that the faster the well is drilled, the lower the cost of the well will be. For this reason, rate of penetration is an important KPI in bit selection.

The surface and intermediate sections were drilled using only tricone bits. These sections were drilled with minimal bit runs and overall were drilled very efficiently. This is mainly because the formations in the surface and intermediate sections were softer and easier to drill than the underlying formations in the production section. The harder formations in the production section were difficult to drill, which resulted in much lower rates of penetration. The main item the team wanted to explore was the difference in performance between the tricone and PDC bits. One PDC bit was experimented within the production section whereas the rest of the section was drilled with tricone bits. The average ROP for the tricone bits was $6.1 \%$ higher than the PDC bit over the entire production section. The formations at the top of this section are softer than the hard formations encountered by the PDC bit. A more accurate evaluation is to compare the ROP of the tricone bit that was run above and below the PDC bit. The tricone bit run above the PDC bit had an average ROP 15.9\% lower than the PDC bit and the tricone bit run below the PDC bit had an average ROP 5.9\% higher than the PDC bit. This further analysis demonstrates that the PDC bit performance was as good if not slightly better than the tricone bits through the lower production section of the well.

\subsection{Length of Bit Run Evaluation}

The length of the bit run is important because the longer the life of a bit, the fewer number of bits are needed to drill a well. Also, tripping out and then tripping back into the well to replace a bit takes up valuable time that could be spent drilling. Because the cost of tripping is fixed, the cost per foot associated with a drill bit depends on three parameters: the cost of the bit, length of the bit run, and ROP of the bit. For this reason, it is important to maximize the length of the bit run for each bit.

The surface and intermediate sections were drilled using only tricone bits and with a minimum number of bit runs. The production interval required numerous bit runs because the bit life was limited in the hard and difficult formations. Comparing the PDC and tricone bits, we found that the average length of a tricone bit run was $30.42 \%$ lower than the PDC bit run. This increased PDC bit run can offset the extra cost associated with most PDC bits and can also decrease the overall drilling time by reducing the time spent tripping for bits. The increased length of bit run shown by the PDC bit could make the more expensive PDC bits cheaper on a cost-per-foot basis, which is discussed in the next section.

\subsection{Cost-per-Foot Evaluation}

The cost-per-foot evaluation of a bit is the most important KPI for any bit. This KPI demonstrates the true cost of a bit by accounting for the cost of replacing the bit as well as the retail cost of the bit. As already discussed, a longer bit run can drive down the cost per foot of a 
bit even if the bit is expensive. For these reasons, the economics of a bit should always be evaluated on a cost-per-foot basis instead of a blanket cost. In many cases, a more expensive bit is cheaper on a cost-per-foot basis because the bit has a longer run life. The formula used for cost per foot (CPF) is shown in Equation Error! Reference source not found.:

$$
C P F=\frac{\$_{\text {rigdayrate }}\left(\text { time }_{\text {rotating }}+\text { time }_{\text {tripping }}\right)+\$_{\text {bit }}}{\text { length }_{\text {bitrun }}}
$$

For Geothermal Well 22, the tricone bits used in the surface and intermediate section had the lowest associated CPF because these bits had a long run life through the soft formations in the shallow sections of the well. As previously discussed, the bits used in the production section had much shorter bit runs because of the exposure to harder, less drillable formations.

\subsection{Evaluation of Bits Using Bit Index}

Bit index (BI) is a commonly used KPI in the petroleum drilling industry. The version of BI used to evaluate the bits in Geothermal Well 22 was developed by ENI E\&P and the University of Bologna (Macini, et al. 2005, SPE/IADC 107536). The bit index takes into account the WOB (in $1,000 \mathrm{lbf}$ ), rotary speed (RPM), hydraulic horsepower (HHP in hp), ROP (in $\mathrm{ft} / \mathrm{h}$ ), torque (T in foot-pound force), bit footage ( $\mathrm{L}$ in feet), and dull bit condition (DG). These parameters were used to calculate a BI at each interval where the data were available. The equation is presented below where $\mathrm{b}$ is the measurement at that data point:

$$
B I=\frac{1}{3}\left[\left(\frac{W O B}{35}\right)+\left(\frac{R P M}{60}\right)+\left(\frac{H H P}{600}\right)\right]\left[\left(\frac{50}{R O P}\right)+\left(\frac{\mathrm{T}}{1000}\right)+\left(\frac{500}{L}\right)\right] .
$$

Once the BI was calculated for each interval, the specific energy (SE) at each interval was calculated using the equation below:

$$
B I_{r u n}=\log \left[4\left(\frac{W O B}{\pi D_{b i t}}\right)\left(\frac{T V D \cdot R P M}{R O P}\right)\right] .
$$

Once the SE was calculated, the BI for each bit was summarized using the following equation:

$$
B I_{\text {runs }}=\frac{S E_{M_{i}} \sum_{i=1}^{n} B I_{1}}{\sum_{i=1}^{n} S E_{M_{i}}} .
$$

The BI is designed to complement the cost-per-foot KPI. The higher the BI, the better the mechanical performance of the bit. The BI does not take into account the economics of a bit, so the cost-per-foot KPI must be used with BI to make strong conclusions about bit performance.

When comparing BI between bits, we found that the bits in the production section of the well performed much better than the bits used in the surface and intermediate sections. This shows 
that even though the bits in the top sections drilled faster and longer, the bits in the lower sections were closer to reaching their maximum performance. When comparing the tricone and PDC bits in the production section, we found that the PDC bit had a BI that was $6.9 \%$ higher than the average of the tricone bits used in this section.

\subsection{Advanced Cost-per-Foot Data Analytics}

The two main goals for running the advanced cost-per-foot metrics are to: 1) determine the main drivers of cost per foot, and 2) compare a trial PDC bit to tricone bits run in the example well.

Figure 27 shows the cost per foot of the bit versus the time of the bit run. As a bit is run, the cost per foot will quickly decrease because the denominator of the CPF equation is increasing faster than the numerator. At a certain time, the cost per foot of the bit will begin to increase again because of decreasing ROP caused by bit wear. The goal of any drilling contractor is to pull the bit at the lowest value of cost per foot. This graph allows us to examine the success of minimizing cost per foot. The dark blue line (labeled as empty) is an example line to show how a bit's cost per foot will slowly increase after a certain time. None of the bits run in this well reached the point of increasing cost per foot, which means that it would have been economic to run each bit for a longer depth interval.

Figure 28 shows the effect of bit run length on cost per foot. This figure validates the intuitive idea that a longer bit run will lower the cost per foot of the well. If the life of each bit can be increased, then the number of bits needed and the time spent tripping for bits will be decreased. This will result in cost savings for the operator. 


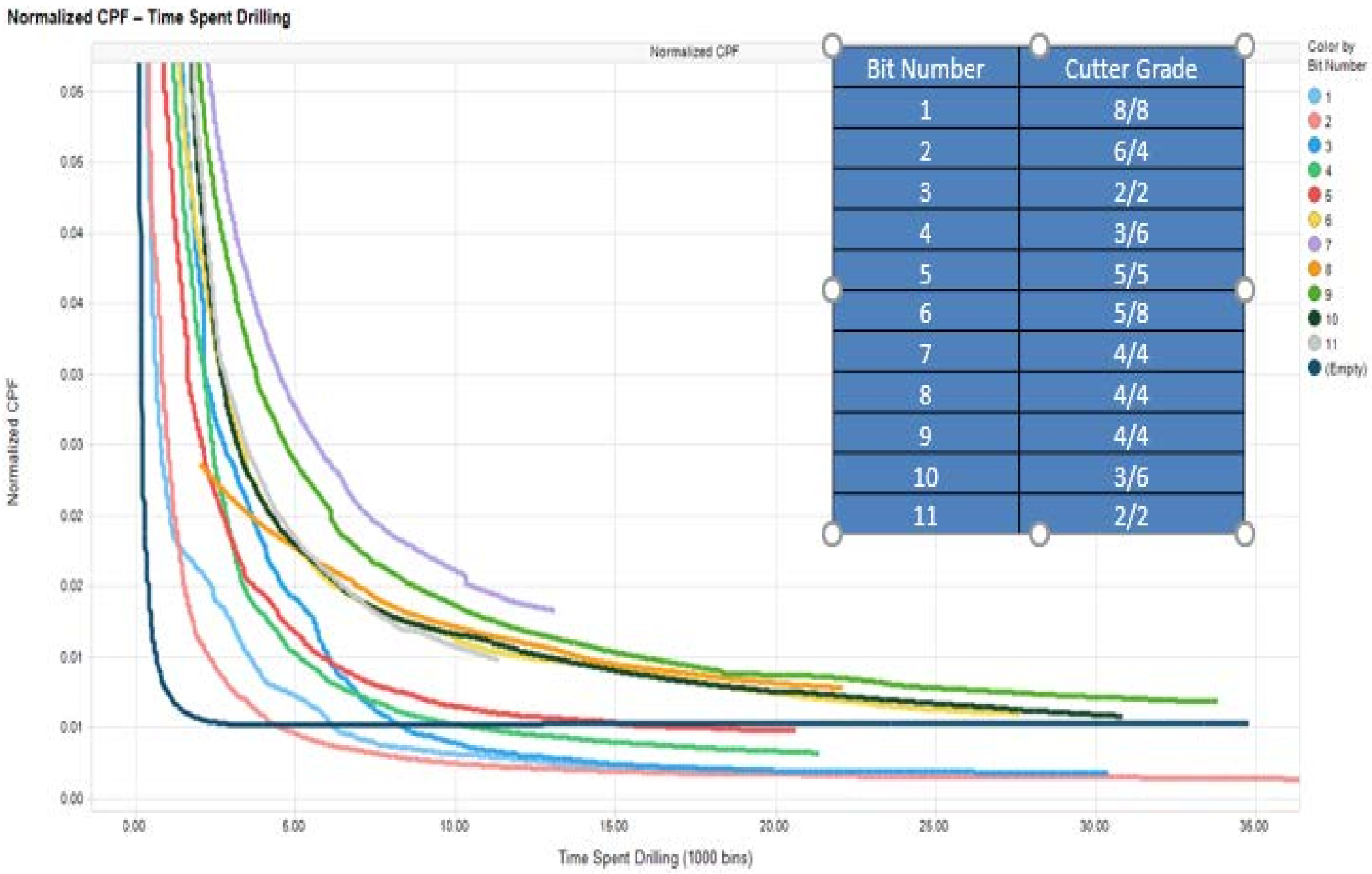

Figure 27. Drilling time effect on cost per foot 


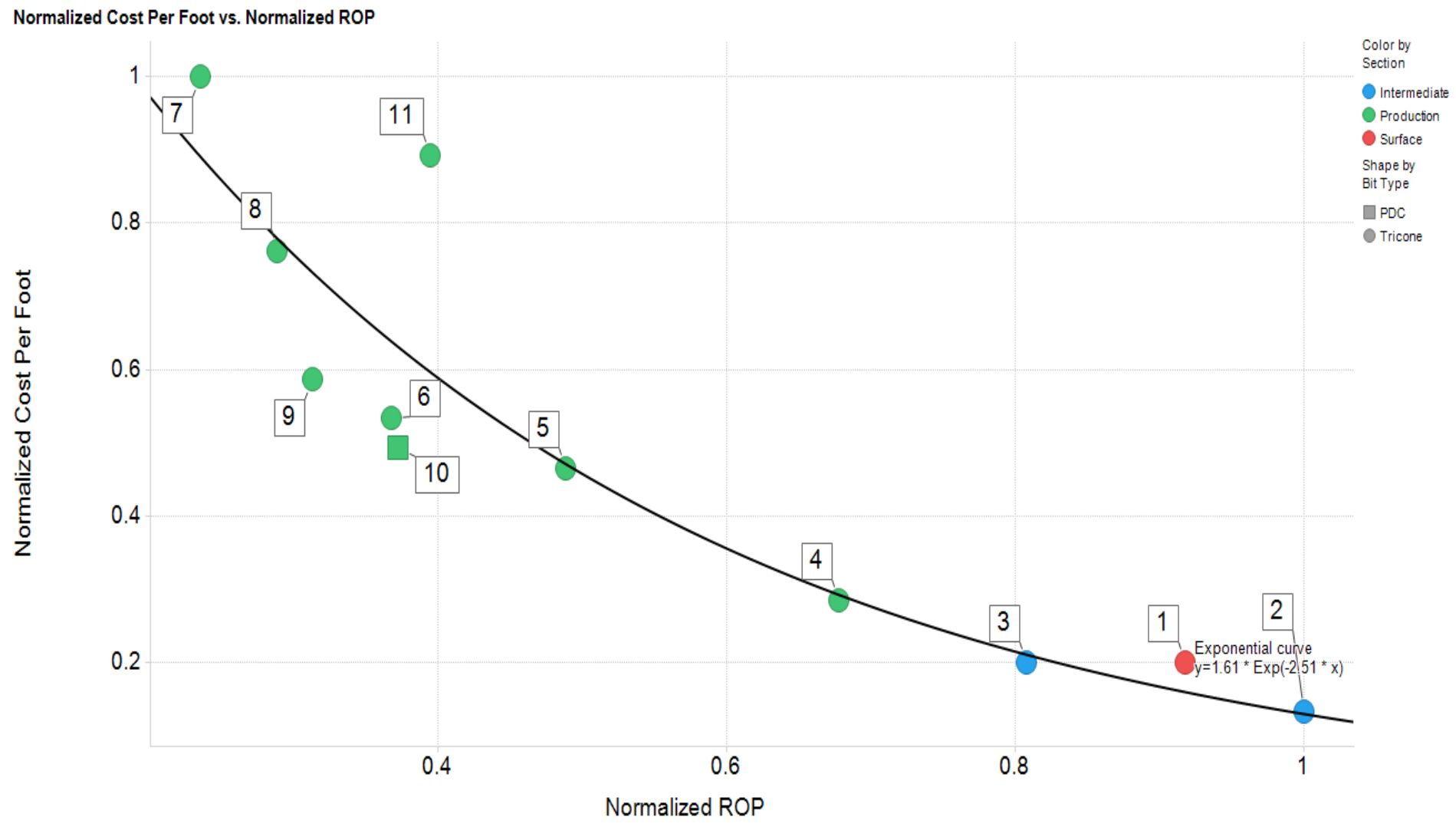

Figure 28. Bit run length effects on cost per foot 


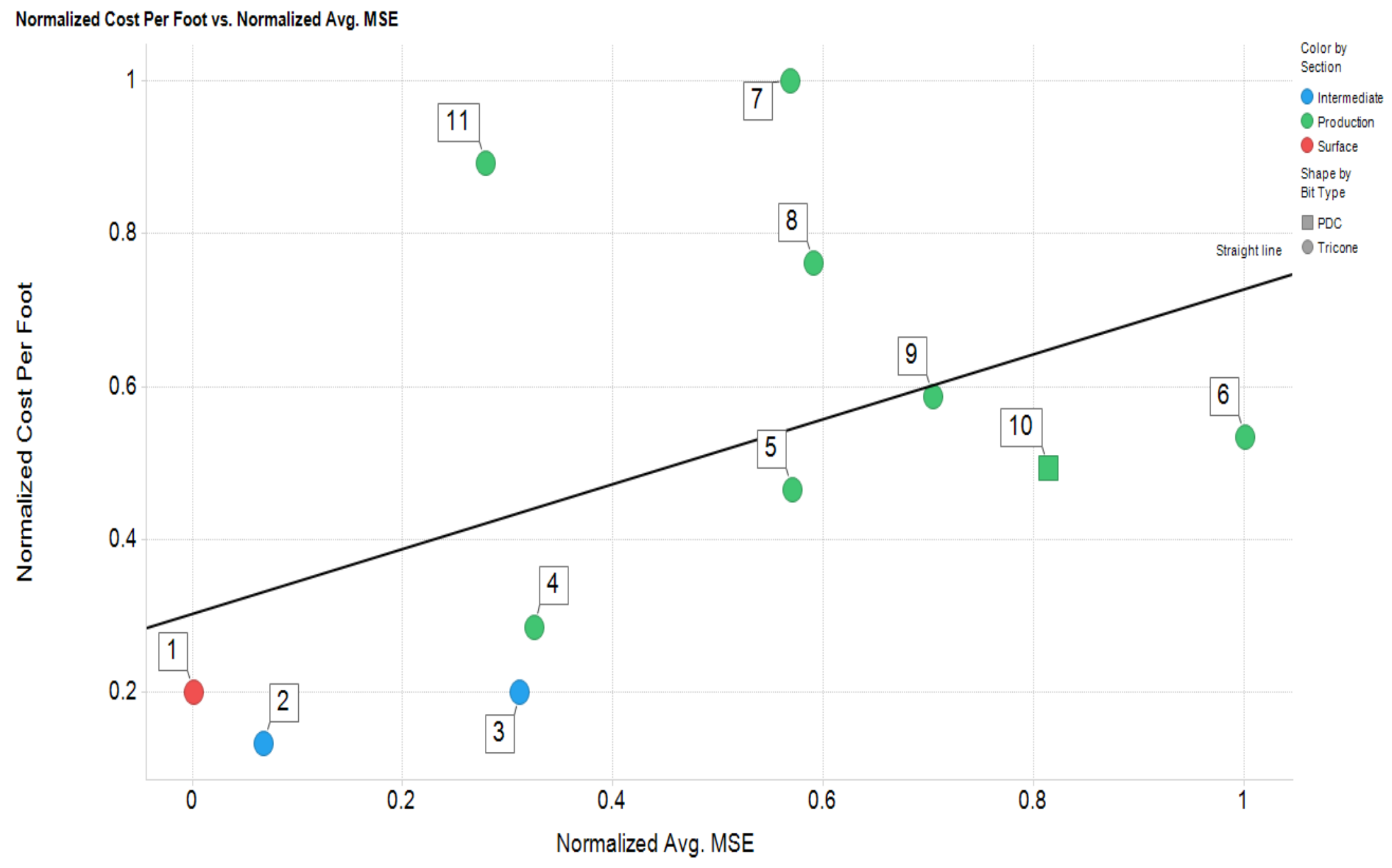

Figure 29. Average MSE effects on cost per foot 


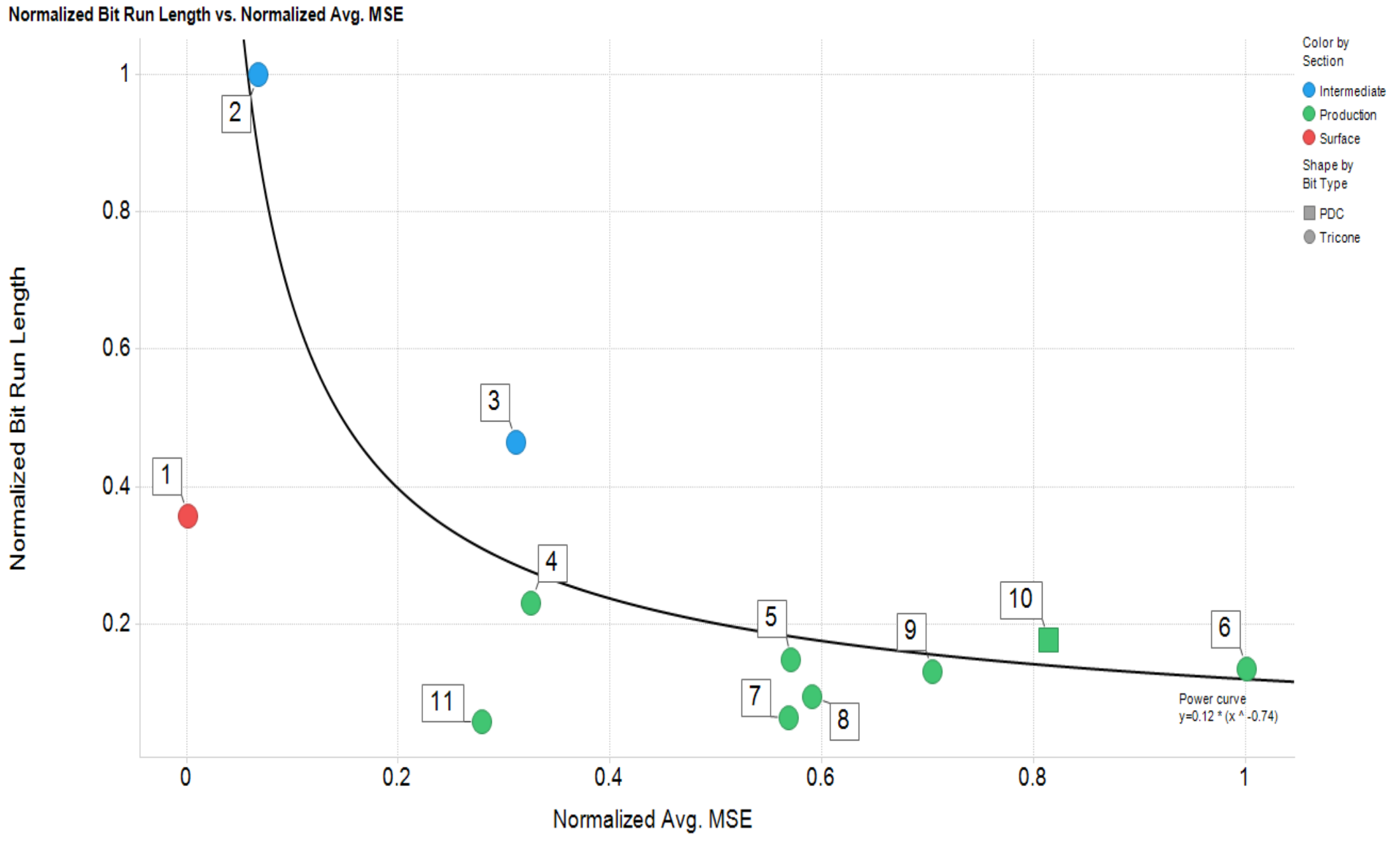

Figure 30. Average MSE effect on bit life 


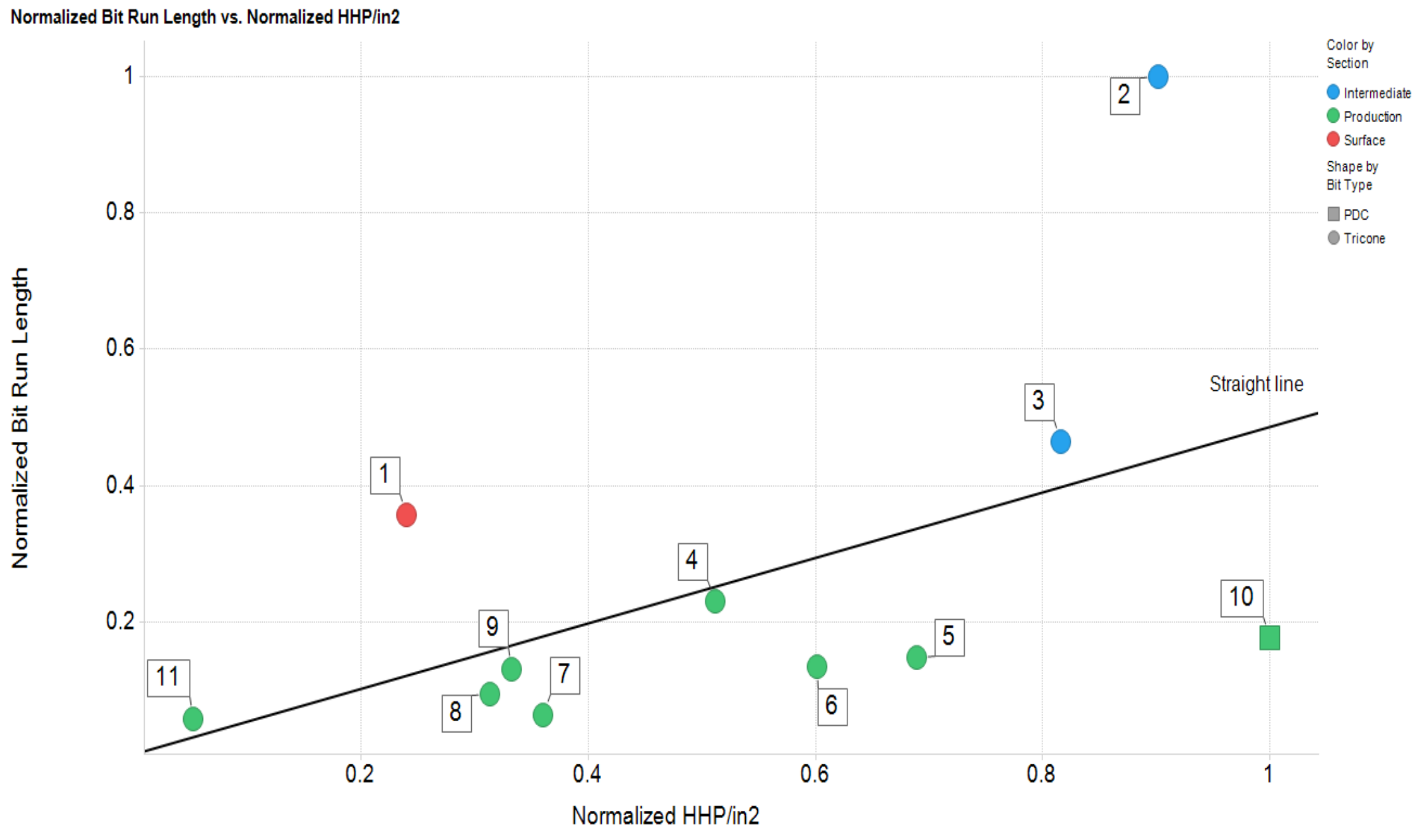

Figure 31. Hydraulic effects on bit life 
Figure 29 shows the correlation of cost per foot and MSE. This correlation is a positive trend, which means that as average MSE increases, the cost per foot will increase, as well. MSE is a measure of both drilling efficiency and rock strength. If a drilling operator is perfectly efficient, then MSE will be driven by the strength of the formation. A stronger formation will be drilled slower and wear out bits at a faster rate, thus driving up the cost per foot of the bit being used. MSE will also increase if a drilling operation is inefficient because more energy must be input into the system to make up for the energy lost due to inefficiencies. For these two reasons, increasing MSE will increase the cost per foot of the drilling operation.

The next figures illustrate the key drivers of bit life.

- Bit Run length. Increasing the bit run length has already been demonstrated to decrease the cost per foot of each bit and the overall cost of the well. Figure 29 and Figure 30 demonstrate these relationships.

- Mechanical Specific Energy. Figure 30 illustrates the relationship between MSE and bit life, demonstrating that minimizing MSE will maximize the life of a bit.

- Drilling Efficiency. Because MSE is a measure of drilling efficiency, this figure demonstrates that an inefficient drilling process will decrease bit life.

o Formation Strength. MSE also increases in stronger formations, which will decrease the life of a bit.

For this reasoning, minimizing MSE using real-time MSE monitoring will help to maximize both the efficiency of the drilling operation and the economics of the well. 


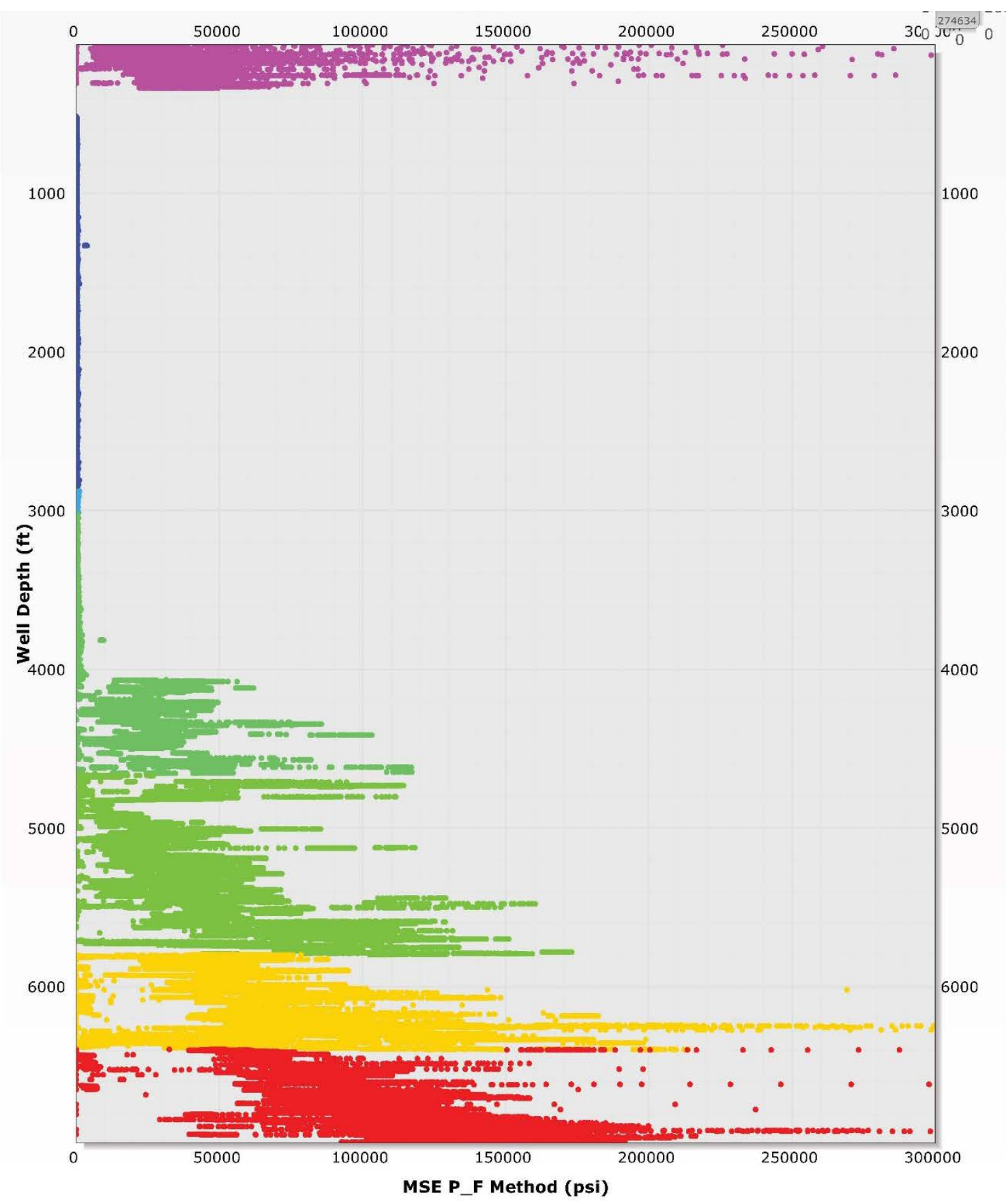

Figure 32. MSE versus depth

Figure 31 shows the downhole hydraulics of the bit. Increasing hydraulic horsepower per in ${ }^{2}$ will increase the effectiveness of hole cleaning. The cleaner the bottom hole is kept, the less debris that is in place to damage and wear out the bit. This explains why increasing HHP/in ${ }^{2}$ can increase the life of the bit.

In Figure 32, the MSE from another local well is compared to drilling depth. This well was drilled with all tricone-type bits. In this chart, one can see that the surface bit required significant energy (pink) whereas the next three bits (dark, light blue, and dark green) require relatively low 
energy inputs. These wells were drilled in sedimentary rocks. However, the last section of the dark green bit shows a significant increase in drilling energy, which is a result of encountering metamorphic rocks. The light green, yellow, and red bits are in the metamorphic rocks, and the energy to drill is much higher than in the sedimentary sections. Notice the general trend that as a particular bit drills deeper (and hence, longer), the energy needed to drill increases - in some cases, by a factor of three. Although lithology has not been correlated to this chart, the energy trend does show an interesting result of what could be considered wear action on the bit. It takes more energy to drill as the bit wears, so MSE could be a potential indicator for when to pull a bit.

\subsection{Comparison of Polycrystalline Diamond Compact and Tricone Bits}

For the example geothermal well, the tricone bits used in the surface and intermediate section had the lowest associated cost per foot because these bits had a long run life through the soft formations. The bits used in the production section had much shorter bit runs because of the exposure to harder, less drillable formations.

When comparing the average of the tricone bits to the PDC bit used in the production interval, the cost of the PDC bit was $13.3 \%$ more than the average cost of the tricone bits; but the CPF of the PDC bit was $23.8 \%$ lower than the CPF of the tricone bits. It is important to note that the operator was able to get a discounted price on the PDC bit because it was a trial run. To account for this, the breakeven price for the PDC bit was calculated to determine the maximum premium the operator should be willing to pay for the PDC bit compared to the tricone. For the specifics of the example geothermal well, the PDC bit cost could be $118 \%$ higher than the tricone bits and still have a lower CPF. Based on the one isolated field trial, a PDC bit is much more costeffective under the well conditions of the example well. Many more trials will need to be conducted before any concrete conclusions can be reached.

Figure 33 shows the average performance of each bit type in the production section. Based on KPIs, the PDC bit outperformed the tricone bits. As discussed previously, the key drivers of bit economics are ROP, bit run length, MSE, and hydraulics. The PDC bit outperformed the tricone bits in ROP, bit run length, and hydraulics. The PDC bit does exhibit a higher MSE than the tricone bits, but this is associated with the style of bit. As illustrated in Figure 24, the horsepower at the bit seen in a PDC is higher than in a tricone bit because the tricone bit is limited in the amount of horsepower that can be applied at the bit. This increased bit horsepower will increase the ROP that can be achieved by the PDC bit, but it will also increase the MSE seen during drilling. It is important to note that even though the average MSE seen by the PDC bit was higher, the bit life of the PDC still outperformed the tricone bits. This was an isolated trial run of the PDC, but the bit's performance was impressive enough that more PDC trials should be conducted in geothermal wells.

\subsection{Final Bit Recommendations}

After evaluating the performance of the various bits used to drill Geothermal Well 22, the team recommends further trials using PDC bits. The data are limited, but the PDC bit used in Geothermal Well 22 outperformed the tricone bits typically used in geothermal wells. More trials 
are necessary before a concrete conclusion can be reached, but PDC bits have the potential to lower the cost of geothermal wells.

The team also suggests more research and development into bits specifically designed for geothermal wells, rather than for oil and gas drilling. Although these bits get the job done, there is room for improvement, especially in the run life of bits. If bit designers could develop bits that could better withstand the environment found in geothermal wells and increase run life of these bits, then operators would see a large amount of cost savings associated with bit use and time spent changing out bits.

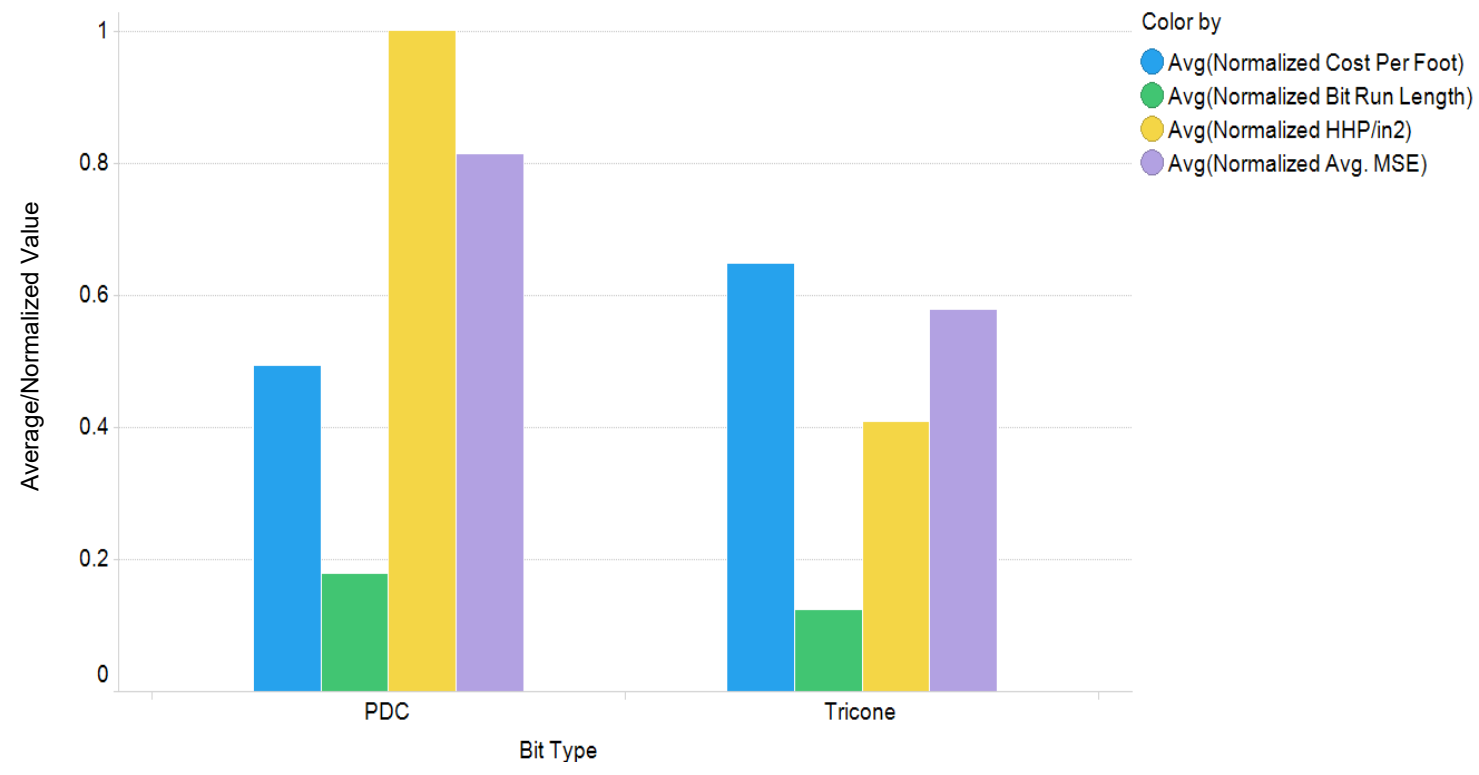

Figure 33. Bit performance summary by bit type 


\section{Drilling Data Sensors}

The team reviewed drilling-rig data sensors from two companies, Pason and National Oilwell Varco (NOV).

\subsection{Primary Pason Sensors}

Pason has the Electronic Drilling Recorder (EDR). This system has a doghouse touchscreen station, but can also have workstations able to see the same information with more customization around the rig and offsite. The system as a whole has a sampling rate of every 10 seconds. However, every sensor has a sampling rate of every second or sub-seconds. The sampling rates can be customized to the specific need. The EDR comes with the standard sensors for depth, pump strokes, hook load, mud pressure, and rotary RPM. A semi-accurate torque can also be determined.

\subsubsection{Depth}

This is a crown sensor that attaches to the fast sheave and as primary data, it records revolutions of the fast sheave. From this, depth can be determined because, based on the size of the fast sheave, the number of feet of depth is equal to a given number of revolutions. On average, 10 revolutions equals 1 foot of depth. Knowing the depth, one can find the ROP.

\subsubsection{Pump Strokes}

This is a counter-style sensor. A lever clicks every time one mud-pump piston is fully extended. The primary data are the number of strokes from one mud-pump piston. One can determine volume of mud pumped by knowing the pump factor and multiplying the number of strokes. And knowing how many strokes per minute times the pump factor determines the flowrate.

\subsubsection{Hook Load}

This is a clamp-style sensor attached to the hoisting system deadline. It measures changes in tension applied to this portion of deadline. From changes in tension, the string weight can be determined. Based on the block and tackle, wire rope, and total drill string weight, one can find the WOB. This measurement can have deviations in accuracy due to friction from the draw works, sheaves, and wire rope.

\subsubsection{Mud Pressure}

This sensor, which reads fluid pressure from the standpipe, is a pressure transducer that can read up to 10,000 psi circulation pressure. This sensor has the highest sampling rate of all standard sensors.

\subsubsection{Rotary Rotations per Minute}

This sensor is a proximity sensor. For a kelly-drive rig, it attaches to the rotary table. For a topdrive rig, the sensor attaches to the rotational component of the top drive. It measures the number of rotations per given amount of time.

\subsubsection{Standard Torque}

There is no sensor for direct-drilling torque measurement; however, drilling torque can be derived from changes in either electrical or hydraulic resistance on the motor. The torque is 
calculated - albeit inaccurately - by backward computation. The starting torque is known, and the resistance put back onto the motor is measured. The additional power needed to make up for this resistance is added to the starting torque to roughly calculate the applied torque.

\subsection{Add-On Pason Sensors}

\subsubsection{Torque and Tension Sub}

This sub is attached near the top of the pipe system, replacing the hookload sensor and giving a very accurate hook-load and torque reading. It uses piezoelectrics and a 32-strain-gauge sensor with $\mathrm{x}, \mathrm{y}, \mathrm{z}$ components. The deformations on the strain gauge can accurately measure the weight and torque applied on it. It has a 50-hertz data rate and an accuracy of $\pm 0.01 \%$. Many users in the petroleum drilling industry have reported doubled ROP rates after installing this equipment. The reason is that the driller can much more closely manage the limitation line for the drill string and bit. This allows much more effective use of equipment, and due to high accuracy, the system is not likely to be over or under torqued; however, the system is expensive.

\subsubsection{Pit Volume Totalizer}

This totalizer is a set of sensors for the mud-tank system. A flow rate sensor and mud probes determine the volume of the mud tanks.

\subsubsection{Flow Rate Sensor}

This sensor is a tube with a paddle in the middle, and the paddle ranges from all the way up ( $100 \%$ flow rate) to all the way down ( $0 \%$ flow rate). The sensor indicates flow rate coming back to the mud tanks in a percentage; but it cannot provide an accurate volume measurement because mud can have gas, rock, or other debris in it. However, it can provide information about kicks or lost circulation from quick, unexpected changes in return flow-rate percentage. The sensor is usually attached in the flowline from the bell nipple.

\subsubsection{Mud Probes}

These probes reside in the mud tanks. A steel float is attached around cables, and the float has magnets and electrical resistors, as does the cable. As the float moves up and down, the magnets and resistors measure changes in elevation. When compared to the known volume of the tank, the total volume can be determined.

\subsection{National Oilwell Varco}

National Oilwell Varco (NOV) drilling rig sensors are very similar to Pason's sensors.

\subsubsection{Rotary Encoder}

Sensors employ three rotary encoders in the drawworks that provide the primary data of elevation of the elevator. ROP can then be obtained by comparing the height of the elevator against the time.

\subsubsection{Hook Load}

Sensors employ three Wheatstone bridge load cells that use strain-gauge technology. This means that the load cells deform when stress is applied to them in different ways, such as when weight 
is applied; these deformations are then interpreted to determine weight. From these data, WOB is calculated by subtracting present hook load from the total weight of piping.

\subsubsection{Fluid Pressure}

Similar Wheatstone bridge load cells are used inside the standpipe to determine fluid pressure. 


\section{Recommendation for Future U.S. Department of Energy Wells}

We recommend the following for any future DOE-sponsored drilling project such as research at the Frontier Observatory for Research in Geothermal Energy (FORGE):

\subsection{Minimum Drilling Data Suite}

- Primary
○ Hook load
○ Block position
- Rotary speed
- Rotary torque
- Pump flow rate
○ Pump pressure

- Derived
o Measured depth
- Bit depth
○ ROP
O WOB.

\subsection{Requirements}

- Require a drilling data suite.

- Acquire and record at a rate of one sample per second (and recommended to be a faster sample rate).

- Store data in a secure location.

- Collect metadata.

- Require and record all sensor calibrations.

- Collect all specifications for sensor accuracy and precision.

- Be aware of the large storage issues and have methods for onsite storage.

- Determine and implement secure data transfers and storage off location.

- Require a method to determine lithology using a mud log or wireline/measurementwhile-drilling (MWD) log.

- Require operators to use an electronic form (such as IDS style of data entry) for IADC reports. 


\section{Conclusions and Future Directions}

\subsection{Conclusions}

- The team accomplished two primary geothermal drilling challenges based on the FY14 analysis of rig operations (NPT analysis) and ROP (MSE study):

- A detailed rig-time study yielded more focused analysis and economic impact of geothermal drilling NPT.

$\circ$ The detailed real-time surface-data analysis gave a way forward to more-efficient drilling operations and bit analysis.

- A change in lithology (from Gamma Ray [natural radiation], Photoelectric Adsorption [density], and/or Spontaneous Potential [electric potential] logs) led to a decline in drilling efficiency. A drill-off test should be required to accommodate the change in formation properties and to optimize the drilling parameters at the surface.

- Absolute conclusions due to inaccurate and missing data are misleading; hence, no specific absolute conclusions can be made in this study due to the following:

- Well data were occasionally missing and inconsistent. In some cases, the data stated physically impossible situations.

○ The drilling data had problems with reliability, accuracy, and precision. For example, areas in the data stream were simply non-existent for hours.

- Drilling data had calibration issues in that they were unknown; this was especially true of torque data.

- Not enough emphasis is given to sensor data-quality, and this is an issue across all drilling operations, whether petroleum or geothermal. This study emphasizes this issue. A sub-committee of the Drilling Systems Automation Technology Section of the SPE is developing requirements for drilling-sensor data. More will be forthcoming.

- Overall, however, post-analysis of drilling surface data was useful in determining trends and general behaviors.

- We recommend the following for any future DOE-sponsored drilling project such as research at FORGE:

- Require a drilling data suite for all future DOE-sponsored drilling operations.

- Require a method to determine lithology.

- Require operators to use an electronic (IDS style) of data entry for IADC/daily drilling reports.

\subsection{Future Directions}

- Continue detailed analysis of drilling information:

○ Add a better electronic data-collection system. 
- Continue to review NPT issues and add Invisible Lost Time ${ }^{1}$ (ILT) to future analysis.

- Develop a more detailed analysis of lost-circulation events over time and depth.

- Review detailed surface data streams for precursor events for NPT.

- Review more surface data output for:

○ Other DOE/national laboratory drilling operations

- Various geothermal operators in other areas including international locations

- Various petroleum operators

- Other drilling operations.

- Develop drilling data analytics work flows, results, and methodology.

\subsection{Technology Transfer Opportunities}

- Stanford Geothermal Workshop Palo Alto, CA; Jan 26-28, 2015

- SGP-TR-204, Optimizing Geothermal Drilling: Oil and Gas Technology Transfer, M. Tilley, A. Eustes, C. Visser, W. Baker, D. Bolton, J. Bell, U. Nagandran, R. Quick

- GRC 2015; Reno, NV; Sept 21-23, 2015

○ Optimizing Geothermal Drilling with Petroleum Technology, K. Denninger, A. Eustes, C. Visser, W. Baker, D. Bolton, J. Bell, S. Bell, A. Jacobs, U. Nagandran, M. Tilley, R. Quick

\subsection{Students Supported}

One of the outcomes of this project and the previous FY14 project was the inclusion of undergraduate and graduate student support. Table 6 shows the list of supported students. Their enthusiasm, hard work, and seriousness was greatly appreciated. They learned much about drilling, geothermal energy, project management, and working in industry and government. These students now have a greater appreciation for the challenges of geothermal energy in general and drilling in particular.

\footnotetext{
${ }^{1}$ Time lost to operational inefficiencies, not related to NPT (e.g., connection times taking much longer due to a poor elevator design).
} 
Table 6. List of Students Supported in the Project

\begin{tabular}{|c|c|c|c|}
\hline \multicolumn{2}{|c|}{ Name } & Graduation & Degree \\
\hline Walt & Baker & Dec-16 & BSPE \\
\hline Jason & Bell & May-15 & BSPE \\
\hline Sean & Bell & May-18 & BSME \\
\hline Daniel & Bolton & May-15 & BSPE \\
\hline Kate & Denninger & Dec-15 & BSPE \\
\hline Amelia & Jacobs & May-15 & BSPE \\
\hline Uneshddarann & Nagandran & May-15 & BSPE \\
\hline Taylor & Nagle & Dec-16 & BSPE \\
\hline Ralph & Quick & May-15 & BSPE \\
\hline Mitch & Tilley & Dec-15 & BSPE \\
\hline Jordan & Tucker & May-15 & BSPE \\
\hline
\end{tabular}




\section{References}

Ayling, B., P. Molling, R. Nye, and J. Moore. 2011. "2011 Geothermal Technologies Peer Review Summary: EGS Development at Raft River, Idaho.” U.S. Department of Energy. University of Utah. Raft River, Idaho. Jan. 31-Feb. 2.

Blackett, R.E. and P.T. Kolesar. "Geology and Alteration of the Raft River Geothermal System, Idaho.” Earth Science Laboratory/University of Utah Research Institute. Utah State University. Logan, Utah.

Blankenship, D. and G. Bettin. 2013. Geothermal Technologies Office Peer Review Presentation. Topic: "Evaluation of Emerging Technology for Geothermal Drilling and Logging Applications." U.S. Department of Energy. Sandia Laboratories. Albuquerque, New Mexico.

Bloomfield, K.K. and P.T. Laney. 2005. "Estimating Well Costs for Enhanced Geothermal System Applications.” Idaho National Laboratories: Battelle Energy Alliance. Idaho Falls, Idaho. INL/EXT-05-00660. August.

Culver, G. 1998. "Geothermal Direct Use Engineering and Design Guidebook.” Geo-Heat Center. Oregon Institute of Technology. Klamath Falls, Oregon. Third Edition, Chapter Six.

Eaton, B.A. 1969. "Fracture Gradient Prediction and Its Application in Oilfield Operations." Society of Petroleum Engineers. doi:10.2118/2163-PA. October 1.

Finger, J. and D. Blankenship. 2010. "Handbook of Best Practices for Geothermal Drilling." Sandia National Laboratories. Albuquerque, New Mexico. Tech. Report. SAND2010-6048. December.

Finger, J., R. Jacobson, C. Hickox, J. Combs, G. Polk, and C. Goranson. 1999. "Slimhole Handbook: Procedures and Recommendations for Slimhole Drilling and Testing in Geothermal Exploration." Sandia National Laboratories. Albuquerque, New Mexico. Nov. 2.

Fleckenstein, W.W. "Shale Completion Applications to Geothermal.” Colorado School of Mines. Golden, Colorado.

Glowka, D.A. 1997. "Recommendations of the Workshop on Advanced Geothermal Drilling Systems." Sandia National Laboratories. Albuquerque, New Mexico. Sandia Report: SAND972903. December.

Heuze, F.E. 1983. "High-Temperature Mechanical, Physical and Thermal Properties of Granitic Rocks-A Review." International Journal of Rock Mechanics and Mining Sciences \& Geomechanics Abstracts 20.1. 1983: 3-10. Sciencedirect.com. Web. March 6, 2015.

Jones, C., J. Moore, W. Teplow, and S. Craig. 2011. "Geology and Hydrothermal Alteration of the Raft River Geothermal System, Idaho.” Proceedings, Thirty-Sixth Workshop on Geothermal Reservoir Engineering. Stanford University. 
Karfakis, M.G. 1985. "Drilling Mechanisms at Elevated Rock Temperatures.” International Journal of Rock Mechanics and Mining Sciences \& Geomechanics Abstracts 22.6. 1985: 40717. Science Direct. Web. March 17, 2015.

Macini, P., M. Magagni, and P. Valente. 2005. "Drill-Bit Catalog and Bit Index: A New Method for Bit Performance Evaluation." Society of Petroleum Engineers. doi:10.2118/94798-MS. January 1.

Pessier, R., S. Wallace, and H. Oueslati. 2012. "Drilling Performance Is a Function of Power at the Bit and Drilling Efficiency." Society of Petroleum Engineers. doi:10.2118/0412-0074-JPT. April 1.

Petrowiki. 2015. "Rock Acoustic Velocities and Temperature.” Petrowiki, n.d. Web. Feb. 17. http://petrowiki.org/Rock_acoustic_velocities_and temperature.

Polsky, Y., L. Capuano Jr., J. Finger, M. Huh, S. Knudsen, A.J. Mansure, D. Raymond, and R. Swanson. 2006. "Enhanced Geothermal Systems (EGS) Well Construction Technology Evaluation Report." Sandia National Laboratories. Albuquerque, New Mexico. Sandia Report SAND2008-7866. December.

Sandia National Laboratories. 2012. "Enhanced Geothermal Systems Directional Well Cost." Bakerhughes.com. Dec. 20.

Sanyal, S.K., J.W. Morrow, S.J. Butler, and A. Robertson-Tait. 2007. "Is EGS Commercially Feasible?” GeothermEx, Inc. Richmond, California. GRC Transactions, Vol. 31.

Sveinbjornsson, B.M. and S. Thorhallsson. 2015. "Drilling Performance, Injectivity and Productivity of Geothermal Wells.” Geothermics 50 (2014): 76-84. Web. March 6, 2015.

U.S. Department of Energy. 2011. "2011 Geothermal Technologies Peer Review Summary: Newberry Volcano EGS Demonstration.” AltaRock Energy Inc. Seattle, Washington.

U.S. Department of Energy. 2011. "2011 Geothermal Technologies Peer Review Summary: New York Canyon Stimulation.” Terra-Gen Power Development Company, LLC.

U.S. Department of Energy. "Geothermal Technologies Program: The Basics of Enhanced Geothermal Systems."

Walters, M. 2011. "2011 Geothermal Technologies Peer Review Demonstration of an Enhanced Geothermal System at The Geysers, CA Summary." U.S. Department of Energy. Lawrence Berkeley National Laboratory. Middletown, California.

Williams, C.F., M.J. Reed, R.H. Mariner, J. DeAngelo, and S.P. Galanis. 2008. “Assessment of Moderate- and High-Temperature Geothermal Resources of the United States." United States Geological Survey. Fact Sheet 2008-3082. U.S. Geological Survey. Menlo Park, California. 
Zhang, L., M. XianBiao, and L. AiHong. 2015. "Experimental Study on Mechanical Properties of Rock at High Temperature." Springer Link. Science in China Press. 2009. Web. Feb. 17, 2015. http $\% 3 \mathrm{~A} \% 2 \mathrm{~F} \% 2 \mathrm{Flink}$.springer.com $\% 2$ Farticle $\% 2 \mathrm{~F} 10.1007 \% 252 \mathrm{Fs} 11431-009-0063-$ y\%23page- 2 .

Ziagos, J., B.R. Phillips, A. Boyde, G. Jelacic, G. Stillman, and E. Hass. 2013. “A Technology Roadmap for Strategic Development of Enhanced Geothermal Systems.” Stanford University. Stanford, California. SGP-TR-198, Feb. 11-13. 